\title{
QUEEN'S
UNIVERSITY
BELFAST
}

\section{Non-pharmacological interventions for cognitive impairment due to systemic cancer treatment (Review)}

Treanor, C. J., McMenamin, U. C., O'Neill, R. F., Cardwell, C. R., Clarke, M. J., Cantwell, M., \& Donnelly, M. (2016). Non-pharmacological interventions for cognitive impairment due to systemic cancer treatment (Review). Cochrane database of systematic reviews (Online). https://doi.org/10.1002/14651858.CD011325.pub2

Published in:

Cochrane database of systematic reviews (Online)

Document Version:

Publisher's PDF, also known as Version of record

Queen's University Belfast - Research Portal:

Link to publication record in Queen's University Belfast Research Portal

Publisher rights

(C) 2016 The Cochrane Collaboration Cochrane

\section{General rights}

Copyright for the publications made accessible via the Queen's University Belfast Research Portal is retained by the author(s) and / or other copyright owners and it is a condition of accessing these publications that users recognise and abide by the legal requirements associated with these rights.

Take down policy

The Research Portal is Queen's institutional repository that provides access to Queen's research output. Every effort has been made to ensure that content in the Research Portal does not infringe any person's rights, or applicable UK laws. If you discover content in the Research Portal that you believe breaches copyright or violates any law, please contact openaccess@qub.ac.uk. 


\section{(E) Cochrane Library}

Cochrane Database of Systematic Reviews

\section{Non-pharmacological interventions for cognitive impairment due to systemic cancer treatment (Review)}

Treanor CJ, McMenamin UC, O’Neill RF, Cardwell CR, Clarke MJ, Cantwell M, Donnelly M

Treanor CJ, McMenamin UC, O’Neill RF, Cardwell CR, Clarke MJ, Cantwell M, Donnelly M.

Non-pharmacological interventions for cognitive impairment due to systemic cancer treatment.

Cochrane Database of Systematic Reviews 2016, Issue 8. Art. No.: CD011325.

DOI: 10.1002/14651858.CD011325.pub2.

www.cochranelibrary.com

Non-pharmacological interventions for cognitive impairment due to systemic cancer treatment (Review) Copyright $\odot 2016$ The Cochrane Collaboration. Published by John Wiley \& Sons, Ltd. 
TABLE OF CONTENTS

HEADER . . . . . . . . . . . . . . . . . . . . . . . . . . . . . . . . . . 1

ABSTRACT . . . . . . . . . . . . . . . . . . . . . . . . . . . . . . . . . . . . . . . 1

PLAIN LANGUAGE SUMMARY . . . . . . . . . . . . . . . . . . . . . . . . . . . . . . . . . . . .

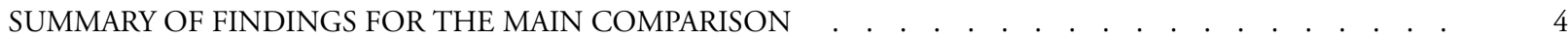

BACKGROUND . . . . . . . . . . . . . . . . . . . . . . . . . . . . . . . . . . . . . . . . . 6

OBJECTIVES . . . . . . . . . . . . . . . . . . . . . . . . . . . . . . . . . . . . . . . . . . . . . . .

METHODS . . . . . . . . . . . . . . . . . . . . . . . . . . . . . . . . . . . . . . . . .

RESULTS . . . . . . . . . . . . . . . . . . . . . . . . . . . . . . . . . . . . . . . 11

Figure 1. . . . . . . . . . . . . . . . . . . . . . . . . . . . . . . . . . . . 12

Figure 2. . . . . . . . . . . . . . . . . . . . . . . . . . . . . . . . . . . . . . 17

Figure 3. . . . . . . . . . . . . . . . . . . . . . . . . . . . . . . . . . . 20

Figure $4 . \quad$. . . . . . . . . . . . . . . . . . . . . . . . . . . . . . . . . . . . . 20

Figure 5. . . . . . . . . . . . . . . . . . . . . . . . . . . . . . . . . . . . . . $\quad . \quad 20$

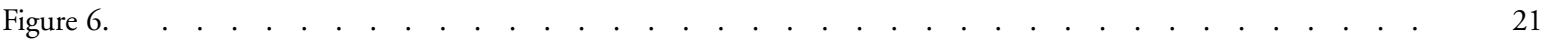

DISCUSSION . . . . . . . . . . . . . . . . . . . . . . . . . . . . . . . . . . . . . . 22

AUTHORS' CONCLUSIONS . . . . . . . . . . . . . . . . . . . . . . . . . . . . . . . . . .

ACKNOWLEDGEMENTS . . . . . . . . . . . . . . . . . . . . . . . . . . . . . . . . . . . . . . . .

REFERENCES . . . . . . . . . . . . . . . . . . . . . . . . . . . . . . . . . . . . . . 25

CHARACTERISTICS OF STUDIES . . . . . . . . . . . . . . . . . . . . . . . . . . . . . . . . . . . . . . .

DATA AND ANALYSES . . . . . . . . . . . . . . . . . . . . . . . . . . . . . . . . . . . . . . . . . . . . . . . 63

Analysis 1.1. Comparison 1 Compensatory strategy training versus wait-list control immediately post-intervention,

Outcome 1 Physical well-being.

Analysis 1.2. Comparison 1 Compensatory strategy training versus wait-list control immediately post-intervention,

Outcome 2 Psychological well-being. . . . . . . . . . . . . . . . . . . . . . . . . . . 64

Analysis 2.1. Comparison 2 Compensatory strategy training versus wait-list control 2-months post-intervention, Outcome

1 Physical well-being. . . . . . . . . . . . . . . . . . . . . . . . . . . . . . . . . . . . . . . . $\quad 64$

Analysis 2.2. Comparison 2 Compensatory strategy training versus wait-list control 2-months post-intervention, Outcome

2 Psychological well-being. . . . . . . . . . . . . . . . . . . . . . . . . . . . . . 65

APPENDICES . . . . . . . . . . . . . . . . . . . . . . . . . . . . . . . . . . . . . . 65

CONTRIBUTIONS OF AUTHORS . . . . . . . . . . . . . . . . . . . . . . . . . . . . . . . . . . . . 70

DECLARATIONS OF INTEREST . . . . . . . . . . . . . . . . . . . . . . . . . . . . . . . 70

SOURCES OF SUPPORT . . . . . . . . . . . . . . . . . . . . . . . . . . . . . . . . . . . . . . . . . . . . . . .

DIFFERENCES BETWEEN PROTOCOL AND REVIEW . . . . . . . . . . . . . . . . . . . . . . . . . . . . . . 70

Non-pharmacological interventions for cognitive impairment due to systemic cancer treatment (Review)

Copyright $\odot 2016$ The Cochrane Collaboration. Published by John Wiley \& Sons, Ltd. 


\title{
[Intervention Review]
}

\section{Non-pharmacological interventions for cognitive impairment due to systemic cancer treatment}

\author{
Charlene J Treanor ${ }^{1}$, Una C McMenamin ${ }^{1}$, Roisin F O’Neill ${ }^{1}$, Chris R Cardwell ${ }^{1}$, Mike J Clarke ${ }^{1}$, Marie Cantwell ${ }^{1}$, Michael Donnelly \\ ${ }^{1}$ Centre for Public Health, Queen’s University Belfast, Belfast, UK \\ Contact address: Charlene J Treanor, Centre for Public Health, Queen's University Belfast, Institute of Clinical Sciences Block B, Royal \\ Victoria Hospital Site, Grosvenor Road, Belfast, Northern Ireland, BT12 6BJ, UK. c.treanor@qub.ac.uk.
}

Editorial group: Cochrane Gynaecological, Neuro-oncology and Orphan Cancer Group.

Publication status and date: New, published in Issue 8, 2016.

Review content assessed as up-to-date: 29 September 2015.

Citation: Treanor CJ, McMenamin UC, O’Neill RF, Cardwell CR, Clarke MJ, Cantwell M, Donnelly M. Non-pharmacological interventions for cognitive impairment due to systemic cancer treatment. Cochrane Database of Systematic Reviews 2016, Issue 8. Art. No.: CD011325. DOI: 10.1002/14651858.CD011325.pub2.

Copyright (C) 2016 The Cochrane Collaboration. Published by John Wiley \& Sons, Ltd.

\begin{abstract}
A B S T R A C T
Background

It is estimated that up to $75 \%$ of cancer survivors may experience cognitive impairment as a result of cancer treatment and given the increasing size of the cancer survivor population, the number of affected people is set to rise considerably in coming years. There is a need, therefore, to identify effective, non-pharmacological interventions for maintaining cognitive function or ameliorating cognitive impairment among people with a previous cancer diagnosis.
\end{abstract}

\section{Objectives}

To evaluate the cognitive effects, non-cognitive effects, duration and safety of non-pharmacological interventions among cancer patients targeted at maintaining cognitive function or ameliorating cognitive impairment as a result of cancer or receipt of systemic cancer treatment (i.e. chemotherapy or hormonal therapies in isolation or combination with other treatments).

\section{Search methods}

We searched the Cochrane Centre Register of Controlled Trials (CENTRAL), MEDLINE, Embase, PUBMED, Cumulative Index of Nursing and Allied Health Literature (CINAHL) and PsycINFO databases. We also searched registries of ongoing trials and grey literature including theses, dissertations and conference proceedings. Searches were conducted for articles published from 1980 to 29 September 2015 .

\section{Selection criteria}

Randomised controlled trials (RCTs) of non-pharmacological interventions to improve cognitive impairment or to maintain cognitive functioning among survivors of adult-onset cancers who have completed systemic cancer therapy (in isolation or combination with other treatments) were eligible. Studies among individuals continuing to receive hormonal therapy were included. We excluded interventions targeted at cancer survivors with central nervous system (CNS) tumours or metastases, non-melanoma skin cancer or those who had received cranial radiation or, were from nursing or care home settings. Language restrictions were not applied.

Non-pharmacological interventions for cognitive impairment due to systemic cancer treatment (Review)

Copyright @ 2016 The Cochrane Collaboration. Published by John Wiley \& Sons, Ltd. 


\section{Data collection and analysis}

Author pairs independently screened, selected, extracted data and rated the risk of bias of studies. We were unable to conduct planned meta-analyses due to heterogeneity in the type of interventions and outcomes, with the exception of compensatory strategy training interventions for which we pooled data for mental and physical well-being outcomes. We report a narrative synthesis of intervention effectiveness for other outcomes.

\section{Main results}

Five RCTs describing six interventions (comprising a total of 235 participants) met the eligibility criteria for the review. Two trials of computer-assisted cognitive training interventions $(n=100)$, two of compensatory strategy training interventions $(n=95)$, one of meditation $(n=47)$ and one of physical activity intervention $(n=19)$ were identified. Each study focused on breast cancer survivors. All five studies were rated as having a high risk of bias. Data for our primary outcome of interest, cognitive function were not amenable to being pooled statistically. Cognitive training demonstrated beneficial effects on objectively assessed cognitive function (including processing speed, executive functions, cognitive flexibility, language, delayed-and immediate- memory), subjectively reported cognitive function and mental well-being. Compensatory strategy training demonstrated improvements on objectively assessed delayed, immediate- and verbal-memory, self-reported cognitive function and spiritual quality of life (QoL). The meta-analyses of two RCTs (95 participants) did not show a beneficial effect from compensatory strategy training on physical well-being immediately (standardised mean difference (SMD) $0.12,95 \%$ confidence interval (CI) -0.59 to $0.83 ; \mathrm{I}^{2}=67 \%$ ) or two months post-intervention (SMD - 0.21 , $95 \% \mathrm{CI}-0.89$ to $0.47 ; \mathrm{I}^{2}=63 \%$ ) or on mental well-being two months post-intervention (SMD $-0.38,95 \% \mathrm{CI}-1.10$ to $0.34 ; \mathrm{I}^{2}=$ $67 \%)$. Lower mental well-being immediately post-intervention appeared to be observed in patients who received compensatory strategy training compared to wait-list controls (SMD - 0.57, 95\% CI - 0.98 to $-0.16 ; \mathrm{I}^{2}=0 \%$ ). We assessed the assembled studies using GRADE for physical and mental health outcomes and this evidence was rated to be low quality and, therefore findings should be interpreted with caution. Evidence for physical activity and meditation interventions on cognitive outcomes is unclear.

\section{Authors' conclusions}

Overall, the, albeit low-quality evidence may be interpreted to suggest that non-pharmacological interventions may have the potential to reduce the risk of, or ameliorate, cognitive impairment following systemic cancer treatment. Larger, multi-site studies including an appropriate, active attentional control group, as well as consideration of functional outcomes (e.g. activities of daily living) are required in order to come to firmer conclusions about the benefits or otherwise of this intervention approach. There is also a need to conduct research into cognitive impairment among cancer patient groups other than women with breast cancer.

\section{PLAIN LANGUAGE SUMMARY}

\section{Interventions for cognitive impairment due to non-localised cancer treatment such as chemotherapy or hormonal therapy}

\section{The issue}

An increasing number of people are surviving and living longer with cancer due to earlier diagnosis, better treatments and an aging population. In turn, there is an increasing number of people with long-term or long-lasting effects of cancer and its treatment. For example, up to seven in 10 cancer survivors experience changes in ability regarding memory, learning new things, concentrating, planning and making decisions about their everyday life, as a result of cancer treatment. This is known as cognitive impairment and has a significant impact on the daily activities of cancer survivors. These changes may be caused by non-localised, systemic cancer treatment, such as chemotherapy and is often called 'chemo-fog' or 'chemobrain'.

\section{The aim of the review}

We reviewed studies that have tested interventions intended to improve cognitive impairment or to maintain cognitive function among people who have been treated with systemic cancer treatments.

\section{What are the main findings?}

We identified five eligible studies that described six interventions. These included two studies of computerised cognitive skills practice, two cognitive coping skills training programmes, one meditation intervention and one exercise intervention. All five studies included a total of 235 women who had been treated for breast cancer. The findings suggest that cognitive skills practice and cognitive coping skills training may be useful in improving patient reports and formal assessments of cognition, as well as quality of life. There was insufficient evidence to know if meditation and exercise interventions had any effect on cognition.

Non-pharmacological interventions for cognitive impairment due to systemic cancer treatment (Review) 
What is the quality of the evidence?

The quality of the evidence was low. There were problems with study designs and, so, we need to be cautious about our conclusions.

What are the conclusions?

There is not enough good quality evidence to know if any interventions improve cognitive impairment or maintain cognitive functioning among people who have received systemic treatment for cancer. There are several ongoing trials in the field, which may provide the necessary evidence in the future. 


\section{SUMMARY OF FINDINGSFOR THE MAIN COMPARISON [Explanation]}

\section{Compensatory strategy training compared with wait-list controls for cognitive impairment due to systemic cancer treatment}

Patient or population: Cancer patients with cognitive impairment due to systemic cancer treatment

Intervention: Compensatory Strategy Training

Comparison: Wait-list control

\begin{tabular}{|c|c|c|c|c|c|}
\hline \multirow[t]{3}{*}{ Outcomes } & \multicolumn{2}{|c|}{ Illustrative comparative risks* $(95 \% \mathrm{Cl})$} & \multirow{3}{*}{$\begin{array}{l}\text { Relative effect } \\
(95 \% \mathrm{Cl})\end{array}$} & \multirow{3}{*}{$\begin{array}{l}\text { No of Participants } \\
\text { (studies) }\end{array}$} & \multirow{3}{*}{$\begin{array}{l}\text { Quality of the evidence Comments } \\
\text { (GRADE) }\end{array}$} \\
\hline & \multirow{2}{*}{$\begin{array}{l}\text { Assumed risk } \\
\text { Control }\end{array}$} & Corresponding risk & & & \\
\hline & & $\begin{array}{l}\text { Compensatory strat- } \\
\text { egy training }\end{array}$ & & & \\
\hline $\begin{array}{l}\text { Physical well-being } \\
\text { SF-36 Physical Compo- } \\
\text { nent Summary Score } 0 \\
\text { to } 100 \text {, higher scores in- } \\
\text { dicate higher levels of } \\
\text { physical well-being } \\
\text { Immediately post-inter- } \\
\text { vention }\end{array}$ & $\begin{array}{l}\text { The mean physical well- } \\
\text { being in the control } \\
\text { group is } \\
43.1 \text { points }^{1}\end{array}$ & $\begin{array}{l}\text { The mean physical well- } \\
\text { being in the interven- } \\
\text { tion groups was } 1.16 \\
\text { points higher } \\
\text { ( } 5.72 \text { points lower to } 8 \text {. } \\
05 \text { points higher) }\end{array}$ & & $\begin{array}{l}95 \\
(2)\end{array}$ & $\begin{array}{l}\oplus \oplus \bigcirc \bigcirc \\
\text { low }^{a, b}\end{array}$ \\
\hline $\begin{array}{l}\text { Physical well-being } \\
\text { SF-36 Physical Compo- } \\
\text { nent Summary Score 0- } \\
100, \text { higher scores in- } \\
\text { dicate higher levels of } \\
\text { physical well-being } \\
\text { Two-months post-inter- } \\
\text { vention }\end{array}$ & $\begin{array}{l}\text { The mean physical well- } \\
\text { being in the control } \\
\text { group is } \\
43.1 \text { points }\end{array}$ & $\begin{array}{l}\text { The mean physical well- } \\
\text { being in the interven- } \\
\text { tion groups was } 2.04 \\
\text { points lower } \\
\text { ( } 8.63 \text { points lower to } 4 \text {. } \\
56 \text { points higher) }\end{array}$ & & $\begin{array}{l}95 \\
(2)\end{array}$ & $\begin{array}{l}\oplus \oplus \bigcirc \bigcirc \\
\text { low }^{a, b}\end{array}$ \\
\hline $\begin{array}{l}\text { Psychological well-be- } \\
\text { ing } \\
\text { SF-36 Mental Compo- } \\
\text { nent Summary Score } 0\end{array}$ & $\begin{array}{l}\text { The mean psycholog- } \\
\text { ical well-being in the } \\
\text { control group is } \\
50.5 \text { points }^{1}\end{array}$ & $\begin{array}{l}\text { The mean psychologi- } \\
\text { cal well-being in the in- } \\
\text { tervention groups was } \\
\mathbf{5 . 1 3} \text { points lower }\end{array}$ & & $\begin{array}{l}95 \\
(2)\end{array}$ & $\begin{array}{l}\oplus \oplus \bigcirc \bigcirc \\
\text { low }^{a, b}\end{array}$ \\
\hline
\end{tabular}


physical well-being

Immediately post-inter-

vention

Psychological well-be- The mean psycholog- The mean psychologi-

ing ical well-being in the cal well-being in the in-

SF-36 Mental Compo- control group is tervention groups was

nent Summary Score 050.5 points

3.42 points lowe

to 100 , higher scores in-

dicate higher levels of

(9.90 points lower to 3 .

physical well-being

Two-months post-inter-

vention

*The basis for the assumed risk (e.g. the median control group risk across studies) is provided in footnotes. The corresponding risk (and its $95 \%$ confidence interval) is based on the assumed risk in the comparison group and the relative effect of the intervention (and its $95 \% \mathrm{Cl}$ ).

Cl: Confidence interval; RR: Risk Ratio

${ }^{a}$ Risk of Bias (-1): One of the studies did not undertake intention-to-treat analysis and it is not clear if the randomisation process was fully blinded

${ }^{b}$ Imprecision(-1): The meta-analyses report wide confidence intervals

GRADE Working Group grades of evidence

High quality: Further research is very unlikely to change our confidence in the estimate of effect.

Moderate quality: Further research is likely to have an important impact on our confidence in the estimate of effect and may change the estimate.

Low quality: Further research is very likely to have an important impact on our confidence in the estimate of effect and is likely to change the estimate.

Very low quality: We are very uncertain about the estimate.

${ }^{1}$ Control values taken from the following reference (Imayama 2013)

Abbreviations: SF-36 $=$ Short Form health survey- 36 items 


\section{B A C K G R O U N D}

\section{Description of the condition}

Over the past few decades, survival rates for cancer have improved steadily. Cancer patients are living longer following treatment due to a number of factors. These include earlier detection of their cancer and the development and use of effective treatments (Coleman 2011). However, this increased survival means that long-term or delayed/late effects of cancer treatment are being observed more frequently among cancer survivors (Treanor 2013). One such longterm or late effect of cancer treatment is cognitive impairment. At present, there is no consensus about how to define cognitive impairment among cancer patients and there is no common method of diagnosis (Hess 2007). Changes in cognition are measured and defined in different ways. For example, patients can self-report changes or they can be assessed formally using neuropsychological test batteries to capture changes in cognition objectively. Objective tests are the gold standard method of assessment. Change in terms of impaired functioning may be defined in several ways and at different levels of severity, for example, one standard deviation (SD) change in scores from a previous test, or 1.5 or 2 $\mathrm{SD}$ difference in scores from an appropriate comparison group or population norms (Wefel 2011). Cognitive impairment caused by cancer treatment may include a breakdown or change in cognitive processes. Patients may have trouble remembering, learning new things, concentrating, co-ordinating movements or balance, making decisions that affect their everyday life; they may experience problems with the management or control system in the brain, also known as executive functioning (Nelson 2007). Neuroimaging studies among treated cancer patients have found structural changes and activity reduction in areas of the brain (including prefrontal/frontal cortex and temporal regions (including hippocampus/parahippocampus)) used for cognitive functions such as memory and executive functioning (Gehring 2012; Scherling 2013; Simó 2013).

It is estimated that up to 75 per cent of cancer survivors may experience cognitive impairment as a result of cancer treatment (Bower 2008; Ganz 2001; Harrington 2010; Stein 2008; Treanor 2014). Impairment may be short-term or long-lasting (10 or more years) (Ahles 2002; Bower 2008; Koppelmans 2012). The proportion of cancer patients who experience cognitive impairment varies across studies due to different study designs, treatments received by patients, treatment status (e.g. currently receiving treatment or posttreatment), and how cognitive impairment is defined and assessed (Gehring 2012). Regarding the specific treatments that are associated with the development of cognitive impairment, a strong association has been identified between chemotherapy and cognitive impairment. Often, chemotherapy-induced cognitive impairment is referred to as 'chemo-brain' or 'chemo-fog'.

Several suggestions have been made for the mechanism by which chemotherapy induces cognitive impairment. These include the following:

- damage to neurons or nerve cells (Ahles 2007; Merriman 2013; Nelson 2007; Raffa 2011);

- damage to deoxyribonucleic acid (DNA) structures (Ahles 2007; Conroy 2013; Joshi 2005; Merriman 2013; Nelson 2007; Vardy 2008);

- induced hormonal changes (Ahles 2007; Bender 2001; Merriman 2013);

- induced anaemia (Hess 2007; Nelson 2007);

- inflammatory response of the immune system (Ahles 2007; Ganz 2012; Janelsins 2012a; Merriman 2013; Nelson 2007)

Treatment-related cognitive impairment may not be limited to chemotherapy. The problem may occur also following hormone therapies and local therapies such as cranial radiation (Bender 2001; Ganz 2012; Nelson 2007; Nelson 2008; Vodermaier 2009). The focus of this review is on systemic therapy, so local radiotherapy is not included. Genetic susceptibility (e.g. presence of apolipoprotein E (apoE) $\epsilon 4$ allele) and level of cognitive reserve (which is dependent on a combination of educational, occupational and lifestyle factors) may also be associated with the development of treatment-induced cognitive impairment (Ahles 2007; Ahles 2012; Argyriou 2010; Merriman 2013; Nelson 2007). Other factors including symptoms of depression, anxiety, distress and fatigue may contribute to cognitive impairment (Ganz 2012; Hess 2007). Furthermore, studies have demonstrated that cognitive processes may be impaired prior to receiving treatment (Ganz 2012; Hess 2007) (for example, due to distress experienced at the time of cancer diagnosis and anxiety about treatment). The evidence is currently unclear as to how treatment-induced cognitive impairment and cognitive impairment related to normal aging differ.

\section{Description of the intervention}

This review examines the effects of non-pharmacological interventions designed to improve cognitive function or manage cognitive impairment following receipt of systemic cancer treatments in isolation or in combination with other treatments. Cranial radiation for central nervous system (CNS) tumours (see Cochrane review Day 2014) or metastases are not the focus of this review and were excluded. We undertook a brief scoping review to identify types of non-pharmacological interventions that have been studied with the aim of improving cognitive impairment or maintaining cognitive functioning among cancer survivors (see Why it is important to do this review).

Three main types of interventions were identified and form the focus of the review.

- Cognitive rehabilitation including cognitive training which includes repetitive practice of cognitive skills or processes via structured tasks or activities with the aim of improving cognition through practice by strengthening neural pathways (Ferguson 
2012; Martin 2011), and compensatory strategy training which aims to help a patient to manage or cope with their impaired cognitive functioning by learning techniques such as the use of mnemonics to aid memory (Gehring 2012).

- Physical activity interventions are hypothesised to work through improved oxygenation and blood flow to the brain, leading to improved cerebrovascular functioning (Nelson 2007), and stress reduction (Ganz 2012). Physical activity interventions include any form of exercise or physical activity which may or may not be aerobic in nature, and which may be undertaken for occupational or recreational purposes.

- Meditative/relaxation-based intervention is defined as a mental exercise that involves reaching a focused state of mind and may include breathing and visualisation exercises (Milbury 2013). Meditative/relaxation-based interventions may maintain cognitive functioning or improve cognitive impairment directly or indirectly through stress reduction, which may aid regulation of the immune system, particularly the regulation of cytokine production (Ganz 2012; Milbury 2013).

Pharmacological treatments of treatment-induced cognitive impairment are not eligible for this review. Two other reviews have reported on the commonly experienced side effects of pharmacological interventions as well as their benefits on cognitive functioning (Gehring 2012; Von Ah 2013). Interventions which include herbal compounds (e.g. gingko biloba), diet (e.g. high in antioxidants) or supplements (e.g. vitamin E) are also not eligible because they act on physiological processes in a similar manner to pharmacological agents. Previously published reviews in the area have grouped herbal, dietary and supplement interventions similarly, within the umbrella of pharmacological interventions (Fardell 2011).

\section{Why it is important to do this review}

Although cancer treatment-induced cognitive impairment is usually mild to moderate, it exerts a substantial impact on a survivor's ability to perform everyday tasks. In general, treatment-induced cognitive impairment may impact on their long-term quality of life (QoL) and ability to process information to make treatment decisions (Ahles 2002; Ganz 2012; Hess 2007). Impairments in cognitive functioning among younger survivors may impact on their ability to return to work or education, career progression and educational attainment (Nelson 2007). Older cancer survivors may question the balance of benefits and harms of cancer treatment in terms of survival gains and their already increased risk of cognitive impairment due to age (Nelson 2007), as well as the possibility of deficits in functioning and activities of daily living (Kvale 2009). The proportion of cancer patients that develop treatment-induced cognitive impairment varies and it is important to try to identify characteristics of at-risk patients so that well-informed decisions can be made about potential treatment-related harms whilst being mindful of uncertainty about which specific chemotherapy or hormonal agents are associated with an increased risk of developing cognitive impairment (Cheung 2012). Currently, the focus is on managing treatment-induced cognitive impairment among cancer patients generally, until specific characteristics and potential riskincreasing treatments are identified, which might lead to potential prevention strategies. This review is also important because cancer is framed usually as a chronic condition and, as noted above, the population of cancer survivors is increasing and, therefore, the number of cancer survivors living with treatment-induced cognitive impairment is rising.

Several published reviews of interventions (Fardell 2011; Gehring 2012; Hines 2014; Von Ah 2011; Von Ah 2013) and epidemiology (Craig 2014; Janelsins 2014; McDougall 2014) for cancer-related cognitive impairment among non-CNS tumour sites have limitations due to study selection, data extraction or methodological quality appraisal, or the extent of their search in multidisciplinary databases and grey literature. Moreover, these earlier reviews were limited to studies reported in English. We conducted a scoping exercise to inform the planning of our review and found that there are several new studies in this field that were not included in existing reviews. The growing number of studies of non-pharmacological interventions for treatment-induced cognitive impairment merits rigorous and systematic attention. Given the prevalence of this condition and the possible preference by cancer survivors for noninvasive, non-pharmacological methods of management or alleviation of cognitive dysfunction, it is important to systematically review published and unpublished evidence (with no restrictions by language) on the effects of non-pharmacological interventions to prevent or ameliorate cognitive impairment following chemotherapy in order to inform clinical and individual decision-making. Indeed, findings from a review of qualitative studies of cancer survivors with cognitive impairment report that already many individuals may use some of the strategies that form the basis of behavioural interventions (Myers 2013).

\section{O B J E C T I V E S}

The primary objective of this review is to evaluate the cognitive effects, non-cognitive effects, duration and safety of non-pharmacological interventions among cancer patients targeted at maintaining cognitive function or ameliorating cognitive impairment as a result of cancer or receipt of systemic cancer treatment (i.e. chemotherapy or hormonal therapies in isolation or combination with other treatments). Although it is expected that non-pharmacological interventions will pose minimal risk to patients, we examined each randomised trial to identify safety as an outcome and incorporate information on intervention safety where possible.

\section{METHOD S}




\section{Criteria for considering studies for this review}

\section{Types of studies}

We included only randomised controlled trials (RCTs). We excluded non-randomised studies and trials with a quasi-experimental method of allocation (e.g. alternation).

We contacted trial authors for further information about their method of randomisation when this was not discernible from the published report in order to decide whether or not to include their study.

\section{Types of participants}

\section{Inclusion criteria}

We included the following types of participants:

- patients diagnosed during adulthood (aged 16 years and older) with any tumour type, with exceptions noted under exclusion criteria;

- patients who received previous systemic treatment (i.e. chemotherapy or hormonal therapies) in isolation or in combination with other treatments;

- patients who received hormone therapy for prophylactic purposes following the treatment of their cancer;

- patients from community or clinic settings.

\section{Exclusion criteria}

We excluded the following types of participants:

- patients who received treatments such as cranial radiation;

- childhood-onset cancer survivors (aged under 16 years old) (childhood-specific or age-relevant cognitive functioning and patient-reported outcome measures to assess outcomes in this group differ from adult measures (Gross-King 2008)).

- patients who received palliative care (because treatment pathways and medication regimens differ between palliative and non-palliative care patients and these differences may influence intervention adherence (Addington 1995));

- patients with primary or metastatic cancer of the brain or central nervous system (CNS) (because of the direct impact of the tumour on the brain and thus cognitive processes (Gehring 2008; Gehring 2010));

- patients with non-melanoma skin cancer (because its epidemiology and treatment differs significantly from other cancers);

- patients who received prophylactic cranial radiation (because a Cochrane Review addressing interventions for cognitive impairment following cranial radiation is currently registered and the protocol is under development);

- patients from nursing or care home settings (because of the likelihood of co-morbid dementia or related conditions).
We planned to consider studies which had included both survivors of childhood-onset and adult-onset cancers if it was possible to extract data relating specifically to the subgroup of adult-onset cancer survivors. However, no studies of this kind were identified.

\section{Types of interventions}

We considered studies for inclusion in the review if they used nonpharmacological interventions (including cognitive rehabilitation, physical activity and meditative/relaxation activities) in order to maintain cognitive function or improve cognitive impairment in patients treated with systemic therapies for cancer. We included multi-component interventions that had a pharmacological element only if the major focus was on the non-pharmacological intervention.

Regarding control groups, we included studies with a 'no treatment' or 'usual care' group. We planned to include studies which included both an 'active' control group as well as a no treatment group and to use only data from the no treatment control group in comparison to the intervention group. However, no such studies were identified.

We did not apply any exclusion criteria regarding aspects of the intervention such as the duration, frequency of sessions or mode of delivery (e.g. face-to-face, computer- or web-based and whether they were delivered on an individual or group basis), but we planned to discuss differences in these features when making comparisons between studies included in the review, if a sufficient number of studies were identified. We included interventions based at home or in the community, in clinics or hospitals or, in research or controlled experimental 'laboratory' settings.

\section{Types of outcome measures}

\section{Primary outcomes}

- 'Objective' cognitive functioning measured using a validated, standardised test e.g. Repeatable Battery for the Assessment of Neuropsychological Status (RBANS)

- 'Subjective' cognitive functioning measured using a validated, self-report measure e.g. Functional Assessment of Cancer Treatment-Cognition Function Scale (FACT-Cog)

\section{Secondary outcomes}

- Quality of life (QoL) including health-related quality of life, well-being and daily functioning measured using a validated, self-report measure e.g. Short-Form Health Survey (SF-36)

- Mood-related outcomes including distress, depression or anxiety, using a validated, self-report measure e.g. Depression Anxiety Stress Scale (DASS)

- Fatigue measured using a validated, self-report measure e.g. Functional Assessment of Cancer Treatment-Fatigue Scale (FACT-F) 
- Sleep disturbance measured using a validated, self-report measure e.g. Medical Outcomes Study-Sleep Scale (MOS-Sleep)

- Adherence, assessed as an outcome to identify the extent to which patients follow the allocated intervention

- We planned to use adherence in sensitivity analyses or as part of the 'Risk of bias' assessment (for example, we planned to compare trials with at least $80 \%$ of patients assessed at endpoint compared to trials with less than $80 \%$ of patients assessed at end-point). However, an insufficient number of studies were identified in order to undertake a sensitivity analysis

- Adverse effects e.g. injury in physical activity interventions

- Treatment satisfaction

\section{Search methods for identification of studies}

We searched for papers in all languages and planned to arrange for non-English language papers to be translated, but no nonEnglish language papers remained following screening of titles and abstracts.

\section{Electronic searches}

We searched the following electronic databases to 29 September 2015:

- Cochrane Central Register of Controlled Trials

(CENTRAL) (Cochrane Library);

- MEDLINE (via OvidSP);

- Embase (via OvidSP);

- PsycINFO (via OvidSP);

- CINAHL (via EBSCO);

- PubMed (via National Center for Biotechnology Information).

We searched the databases for publications from 1980, which is the year in which studies examining impairments in cognitive function as a result of cancer treatment began to appear in the literature (Ahles 2012). The search strategies are available in the appendices (Appendix 1; Appendix 2; Appendix 3; Appendix 4; Appendix 5; Appendix 6). We identified all relevant articles in PubMed (where available) and used the 'related articles' feature and performed further searches for newly published articles which may not have been identified from the main database search.

\section{Searching other resources}

\section{Unpublished and grey literature}

We searched the following sources for ongoing trials:

- metaRegister of Controlled Trials (mRCT) (http:// www.controlled-trials.com/mrct/);

- Physician Data Query by the National Cancer Institute ( http://www.cancer.gov/cancertopics/pdq),
- ClinicalTrials.gov (http://clinicaltrials.gov/);

- National Cancer Institute's List of Cancer Clinical Trials ( http://www.cancer.gov/clinicaltrials);

- World Health Organization (WHO) International Clinical Trials Registry Platform (ICTRP) (http://apps.who.int/ trialsearch/).

We asked the principal investigators of any identified unpublished trials for relevant data. We sought information about trials from major co-operative groups active in this area. We identified conference proceedings and abstracts through ZETOC (http:// zetoc.mimas.ac.uk) and WorldCat Dissertations. Where available, we would have included data in the review from any ongoing trials (whilst noting that results may change as the trial progresses).

\section{Handsearching}

We checked or handsearched the following sources:

- citation lists of eligible studies (Horsley 2011);

- citation lists of previous reviews of interventions for cognitive impairment following cancer;

- papers which cited included studies;

- publications by experts in the field.

We searched websites for relevant conference reports from the following sources (from 1980 to 2014):

- International Cognition and Cancer Task Force (ICCTF);

- International Neuropsychological Society;

- British Journal of Cancer;

- British Cancer Research Meeting;

- Annual Meeting of European Society of Medical Oncology;

- Annual Meeting of the American Society of Clinical

Oncology;

- Other relevant conference proceedings identified through Web of Science.

\section{Data collection and analysis}

\section{Selection of studies}

One review author (CT) downloaded all titles and abstracts retrieved by electronic searching to a reference manager software package and removed any duplicates. Pairs of review authors (CT and MD, CT and RON and CC and UM) examined the remaining references independently by title and abstract first, followed by full-text articles. We excluded studies which clearly did not meet the inclusion criteria and obtained copies of the full text of potentially relevant references cited within these articles. The paired review authors (noted above) independently assessed the eligibility of retrieved articles. Disagreements were resolved by discussion between the two review authors or if necessary by an additional review author (MJC). We documented the reasons for exclusion. 


\section{Data extraction and management}

We extracted the following data from included studies.

- Authors, year of publication and journal citation (including language)

- Country

- Setting

- Inclusion and exclusion criteria

- Study design, methodology

- Study population:

$\circ$ total number randomised

$\circ$ age

- sex/gender

- co-morbidities

- cancer site

- stage (the International Federation of Gynecology and

Obstetrics staging system)

$\circ$ grade

$\circ$ treatment history

o education

- socio-economic status

- cognitive status at baseline

- Intervention details:

- definition/details

o intervention components (we created a taxonomy of intervention components by extracting data on the specific components involved in each intervention)

- safety

- adverse effects

- Comparison:

o definition/details

- Risk of bias in study (seeAssessment of risk of bias in included studies)

- Duration of follow-up

- Outcomes:

o we extracted the definition and unit of measurement (if relevant) for each outcome

o we extracted information about the measures and their properties including domains of cognition used to assess outcomes

o we recorded variables and their adjustment in the analyses when calculating adjusted estimates

- Results:

- number of participants allocated to each intervention group and control group, the total number analysed for each outcome, and the proportion of participants in the intervention and control groups that were lost to follow-up and their reasons

We planned to extract results as follows:

- Continuous outcomes (e.g. cognitive functioning measures) - baseline value and final mean value and standard deviation of the outcome of interest and the number of patients assessed at end-point in each group at end of follow-up in order to estimate the mean between-group difference and standard error.

- Dichotomous outcomes (e.g. adverse events):

$\circ$ hazard ratio (HR) or, if a HR was unavailable the number of patients in each treatment group that experienced the outcome of interest and the number of patients assessed for that outcome in order to calculate a risk ratio (RR). However, no dichotomous outcomes were reported in any of the included studies.

We extracted reported unadjusted and adjusted statistics. Our data analysis was guided by an intention-to-treat approach in which participants were analysed according to the groups to which they had been randomly assigned. We noted the time points at which outcomes were collected and reported.

\section{Assessment of risk of bias in included studies}

We assessed risk of bias in included studies using the Cochrane tool (Higgins 2011). We used RevMan to facilitate the presentation of our findings from the 'Risk of bias' assessment (Review Manager 2014). This assessment addressed selection bias, performance bias, detection bias, attrition bias, reporting bias and other potential sources of bias including comparability of intervention and control group cognitive function scores at baseline, as well as the validity and reliability of cognitive function assessment measures.

We used the following items to assess risk of bias:

- random sequence generation (selection bias);

- allocation concealment (selection bias);

- blinding of participants (performance bias);

- blinding of personnel (performance bias);

- blinding of assessment of outcomes (detection bias);

- incomplete outcome data (attrition bias);

- selective outcome reporting (reporting bias).

Three review authors worked in pairs (CT and RON or CT and UM) to apply the 'Risk of bias' tool independently. Any differences were resolved by discussion or with an additional review author (MD). We summarised results in a 'Risk of bias' graph. We had planned to examine funnel plots corresponding to meta-analysis of cognitive functioning (the primary outcome) to assess the potential for small-study effects such as publication bias if sufficient studies were included (e.g. more than 10), but too few studies were identified.

An overall risk of bias score was given to each study based on the following criteria.

- Low: all criteria scored as low risk of bias

- Moderate: one or two criteria unclear or high risk of bias

- High: more than two criteria scored unclear or high risk of bias

\section{Measures of treatment effect}


The majority of outcome variables were continuous and the studies used a variety of tools to assess cognitive function. We used the standardised mean difference (SMD) to compare treatment groups when different scales were used. Neuropsychological tests do not provide a global score of cognitive function usually, so trials tended to include multiple cognitive function test scores. We planned to conduct meta-analyses based on similar cognitive function domains measured across trials (e.g. executive functioning), if appropriate data were available from a sufficient number of trials of similar interventions, but few studies were identified. Therefore, we only undertook small meta-analyses comparing compensatory strategy training interventions when comparable outcomes were reported (e.g. physical and mental well-being). We planned to use the risk ratio (RR) with $95 \%$ confidence intervals (CIs) to compare treatment groups for dichotomous outcomes such as adverse events, but, dichotomous outcomes were not reported in any of the studies.

\section{Dealing with missing data}

We did not impute missing outcome data for cognitive functioning (the primary outcome) or for any of the secondary outcomes, but imputed data had been reported in two studies (Ferguson 2012; Milbury 2013). We asked trial authors for data on outcomes for participants whose data were not reported.

\section{Assessment of heterogeneity}

We estimated heterogeneity using the $\mathrm{I}^{2}$ statistic within the metaanalysis of two trials that we conducted.

\section{Data synthesis}

It was not possible to implement all the plans in our protocol because of an insufficient number of studies and the low methodological quality of the studies. We were not in a position to address each intervention type or category (e.g. cognitive rehabilitation, physical activity and relaxation/meditative) in separate meta-analyses, pool results of studies in meta-analyses using the Cochrane statistical software, (Review Manager 2014), or in trials with multiple treatment groups, divide the 'shared' comparison group into a number of treatment groups and treat comparisons between each treatment group and the split comparison group as independent comparisons. We used a random-effects model with inverse variance weighting for the meta-analyses (DerSimonian 1986). 'Summary of findings' tables were created in RevMan (Review Manager 2014) to summarise intervention effects and the quality of evidence using the Cochrane GRADE approach. The GRADE approach considers quality according to five factors: risk of bias, indirectness of evidence, inconsistency of evidence, imprecision of effect estimates and publication bias. The quality of evidence was downgraded from 'high' to 'moderate', 'low' or 'very low' quality according to limitations in each of the aforementioned factors.

\section{Subgroup analysis and investigation of heterogeneity}

We did not conduct the planned subgroup analyses for factors such as age, sex, cancer site, cancer stage, type of intervention, treatment history, cognitive status prior to study enrolment and duration of intervention because so few studies were identified.

\section{Sensitivity analysis}

Similarly, we did not perform sensitivity analyses (by, for example, re-running analyses without studies deemed to have a high risk of bias) because of the small number of included studies.

\section{RE S U L T S}

\section{Description of studies}

See: Characteristics of included studies; Characteristics of excluded studies; Characteristics of ongoing studies

\section{Results of the search}

\section{Electronic search}

A total of 13,618 titles were identified from the electronic searches (Figure 1). Following removal of duplicate titles, 8144 titles remained. Screening of titles resulted in the exclusion of 7889 papers. The remaining 255 abstracts were examined for inclusion and 215 of these were excluded. Forty full-text papers were obtained and fully screened for eligibility in the review. Four of these studies met our review's eligibility criteria. 
Figure I. Study flow diagram.

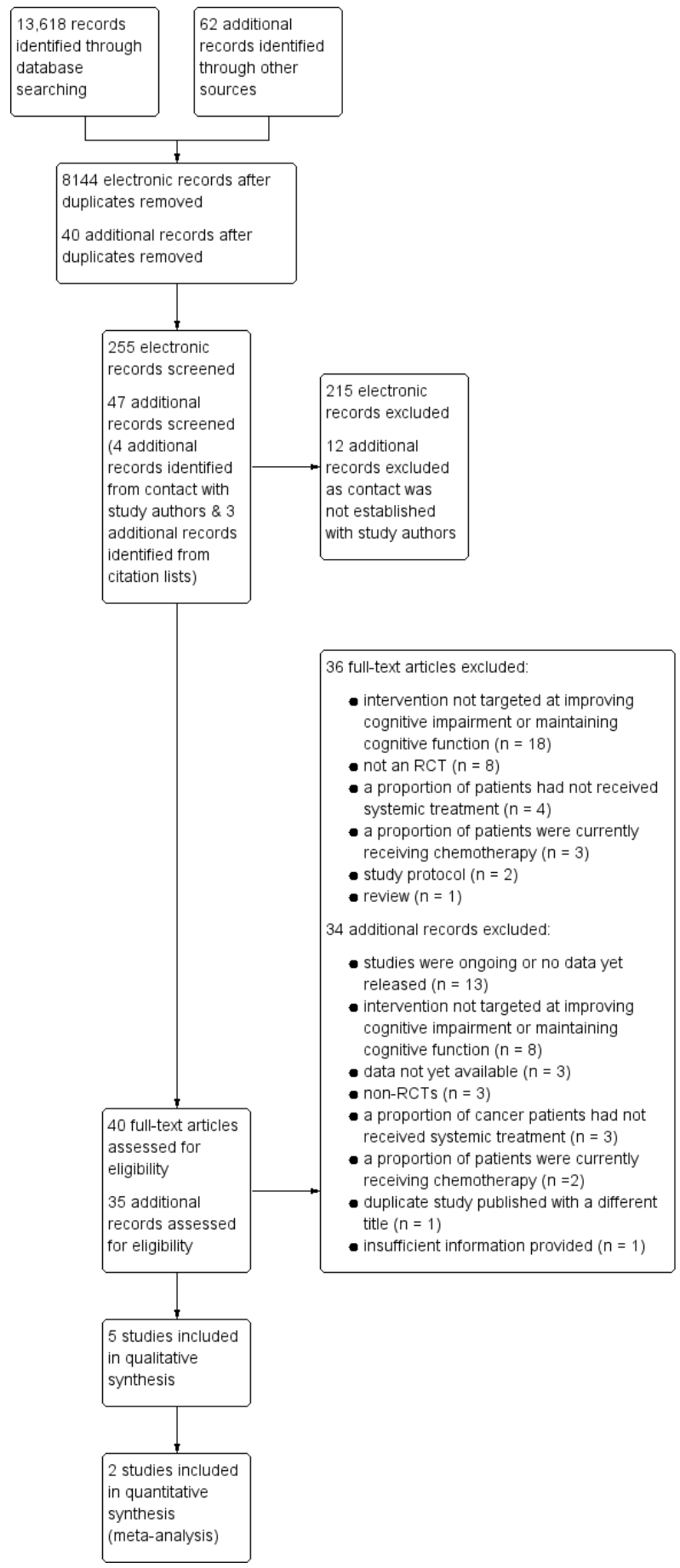

Non-pharmacological interventions for cognitive impairment due to systemic cancer treatment (Review) 


\section{Grey literature and unpublished sources}

Sixty-two potentially relevant studies were identified from unpublished and grey literature sources. One study was included, for which, a published conference poster was available.

\section{Other sources}

Three additional potentially relevant studies were identified from the citation lists of included papers but were excluded. No further studies were identified from papers which cited the included studies or related articles identified using PubMed.

\section{Included studies}

A total of five studies describing six interventions were included in the review. One study (Von Ah 2012) included two intervention groups and a shared wait-list control group; participants had an equal chance of being randomised into one of the three groups. Three studies (Ferguson 2012; Kesler 2013; Von Ah 2012) tested four cognitive rehabilitation interventions including two cognitive training interventions (Kesler 2013; Von Ah 2012), and two compensatory strategy training interventions (Ferguson 2012; Von Ah 2012). A fourth study tested the feasibility of Tibetan Sound Meditation on improving cognitive and non-cognitive outcomes. The fifth study (Campbell 2014) tested the effectiveness of aerobic exercise on improving cognitive outcomes.

In total, 235 participants were recruited in all five studies and randomised to an intervention group or to a wait-list control group. The wait-list control groups received standard care during the study and were offered the intervention at the end of the study period. All five studies recruited women who had survived breast cancer. The studies were conducted in two countries: four in the US (Ferguson 2012; Kesler 2013; Milbury 2013; Von Ah 2012) and, one in Canada (Campbell 2014). Four studies were published in peer-reviewed scientific journals (Ferguson 2012; Kesler 2013; Milbury 2013; Von Ah 2012), and Campbell 2014 was presented at a conference. All studies were reported in English.

Ferguson 2012 tested an eight-week cognitive behavioural therapy (CBT)-based Memory Attention Adaptation Training (MAAT) intervention which targeted improvement of memory and attention. The study enrolled women with stages I to IIIa breast cancer who had completed chemotherapy at least 18-months previously and who self-reported cognitive changes since treatment. The intervention was delivered face-to-face (with telephone contact between visits) by a clinical health psychologist. MAAT incorporated education, self-awareness training, self-regulation training (including relaxation) and cognitive compensatory strategy training. This study was underpowered and linear interpolation methods were used to account for missing data in order to undertake an intention-to-treat analysis. ANCOVA models were undertaken controlling for education and IQ to test for intervention effects on objective cognitive outcomes (verbal memory, speed of processing), self-reported cognitive function and quality of life (QoL). Unexpectedly, the MAAT intervention targeting attention did not include an objective assessment of attention.

Von Ah 2012 examined the effects of a computerised cognitive training intervention named 'Insight' and a compensatory strategy training intervention named 'ACTIVE', which targeted memory compared to wait-list controls. The interventions involved 10 onehour sessions delivered in a group setting by a trained interventionist over a six-week period. This study did not specify the stage of cancer but required their participants to be disease-free and treated for primary, non-metastatic breast cancer and have completed chemotherapy at least one year previously. The Insight programme is commercially available, the version adapted for use in this trial targeted executive functions. The ACTIVE intervention included sessions on compensatory strategy training for memory and strategy practice to enhance self-efficacy. The authors conducted general linear mixed models to assess differences between intervention and control groups using age, education, betweengroup treatment effects, within-group time effects and baseline values for each respective outcome as covariates.

Kesler 2013 reported the results of a 12-week, home-based, commercially-available, computerised cognitive training intervention targeting executive functions among females with stages I to IIIa breast cancer. Participants were recruited irrespective of cognitive function status but had to have completed chemotherapy at least 18 months previously. Women allocated to the intervention received written instructions and weekly telephone/email contact for 48 sessions. Using ANCOVA models, a number of covariates including baseline cognitive flexibility scores, age, level of education, radiation, distress scores, hormonal therapy and time since chemotherapy were initially added to the models to assess the effects of the intervention on executive functions; however, the covariates were later removed as they did not significantly impact upon the relationship between cognitive training and executive functions. The primary outcome of interest in the study was cognitive flexibility measured by the Wisconsin Card Sorting Task and a Bonferroni correction was applied for all additional ANCOVA models to control for the effects of multiple testing. The authors also calculated corrected effect sizes to counteract potential practice effects of the neuropsychological test measures by subtracting the within-group control group effect size from that of the intervention group.

Milbury 2013 assessed the feasibility and effectiveness of Tibetan Sound Meditation on cognitive function (self-reported, visuomotor co-ordination, processing speed, attention, working memory, verbal fluency and memory), and non-cognitive outcomes 
(fatigue, depression, sleep disturbances, spiritual well-being and health-related quality of life) among women with stages I to IIIa breast cancer who were treated with chemotherapy up to five years previously. Each participant was eligible if they self-reported cognitive impairment using a partial version of the Functional Assessment of Cancer Therapy- Cognitive functioning sub scale (FACT$\mathrm{Cog}$ ). Tibetan Sound Meditation is a meditative practice involving breathing techniques, visualisation, meditative sounds and cognitive tasks. The 6-week intervention was delivered by a trained meditation instructor to between one and three participants who were provided also with a CD and written instructions to practice at home. Objective assessments of cognition were not undertaken immediately post-intervention in order to counteract practice effects. Statistical analyses involved between-group ANOVA models controlling for baseline values of each respective outcome. There were limitations to this study as a formal sample size calculation was not reported in the paper and the authors stated that the study was statistically under-powered which may account for the absence of significant intervention effects (Milbury 2013). This intervention is currently being evaluated in a larger randomised controlled trial (RCT) including neuro-imaging techniques as an additional objective measure of cognition (Cohen 2014).

In a Canadian proof of concept study, 19 women who had completed chemotherapy for early-stage (I-IIIa) breast cancer at least three months previously were allocated to 24 weeks of aerobic exercise $(n=10)$ or to a delayed exercise control group $(n=9)$ (Campbell 2014). To be eligible, participants had to self-report changes in cognitive function which had persisted since treatment. Researchers undertook paired t-tests and ANCOVA models controlling for baseline scores to observe changes in self-reported cognitive function, objectively assessed memory, learning, verbal fluency, processing speed and executive functions over time. The 24week long intervention (including twice-weekly contacts) involved supervised and independent aerobic exercise sessions but it is not clear if this was delivered face-to-face or in a group setting and the type of professional involved in the intervention was not described. The results of this study were reported in a conference poster and have not yet been published in a peer-reviewed journal (as of August 2015). Correspondence was made with the author to obtain further information regarding, for example, randomisation.

Where necessary, study authors were contacted to provide data in a different format than was reported in the original papers. For example, Von Ah 2012 reported effect sizes (including 95\% confidence intervals) for composite scores of their objective measures, but did not report the means and standard deviations on composite scores or individual measures at post-intervention time points that were required in order to undertake a meta-analysis. Non-imputed values of outcomes were requested for one study (Ferguson 2012). At the time of writing of this review, requests for alternatively presented data were unfulfilled. Therefore, findings as reported in the original papers were included in this review.

\section{Components and techniques of interventions}

Two review authors (CT and MD) developed a taxonomy of similar and unique intervention components and techniques across the six interventions. A standardised pro forma was created, guided by the COMPASS criteria (Hodges 2011) for defining psychological interventions and the Behaviour Change Techniques (BCT) taxonomy (Michie 2013). Two techniques were common across all six interventions: instruction on how to perform the behaviour and demonstration (Campbell 2014; Ferguson 2012; Kesler 2013; Milbury 2013; Von Ah 2012). Behavioural practice/rehearsal was common to five interventions (Ferguson 2012; Kesler 2013; Milbury 2013; Von Ah 2012). Several techniques were common to three interventions: social support (unspecified) due to the group setting delivery of the intervention (Kesler 2013; Milbury 2013; Von Ah 2012), feedback on behaviour (Ferguson 2012; Kesler 2013; Von Ah 2012), generalisation of a target behaviour from a supervised setting to everyday settings (Campbell 2014; Ferguson 2012; Milbury 2013), and graded tasks of increasing difficulty (Campbell 2014; Kesler 2013; Von Ah 2012). Two interventions, CBT MAAT compensatory training (Ferguson 2012) and Tibetan Sound Meditation (Milbury 2013) included reducing negative emotions as a technique. Prompts/cues were used in two interventions (Ferguson 2012; Kesler 2013) via telephone contact from a member of the research team.

The remaining techniques were unique to intervention types. The physical activity intervention included the unique technique of goal setting as each individual was expected to reach the target exercise prescription by week eight of the intervention (Campbell 2014), whereas, framing/reframing was a technique unique to Tibetan Sound Meditation (Milbury 2013). Each compensatory strategy training intervention comprised the following techniques: instruction on how to perform- and, demonstration of- the behaviour via teaching the participants compensatory strategies and; behavioural practice/rehearsal of strategies was encouraged (Ferguson 2012; Von Ah 2012). Other techniques (some of which were unique) in the CBT-based MAAT intervention include: feedback on behaviour via phone-call to adapt or adjust techniques, self-monitoring of behaviour whereby participants were encouraged to keep a daily planner, information about antecedents of behaviour and health consequences via education, prompts/cues, generalisation of target behaviour, reduction of negative emotions via relaxation, mental rehearsal of successful performance through visualisation and self-talk using verbal rehearsal (Ferguson 2012). Both computerised cognitive training interventions contained common techniques: instruction on how to perform the behaviour, demonstration of how to perform the behaviour, behavioural practice/rehearsal, graded tasks, feedback on behaviour and feedback on outcomes of behaviour (Kesler 2013; Von Ah 2012). The interventions differed in their use of specific techniques: prompts/cues via weekly telephone calls were used in one study (Kesler 2013), whereas, social support (unspecified) due to the group setting of intervention delivery was used in the second 
study (Von Ah 2012).

\section{Outcomes}

The five studies used a range of different outcome measures. Three studies only provided participant assessments at one month (Milbury 2013) and two months (Ferguson 2012; Von Ah 2012) post-intervention in addition to end-of-intervention assessments. The other two studies provided participant assessments only at the end of the intervention (Campbell 2014; Kesler 2013).

\section{Cognitive outcomes}

Although there was some overlap in the cognitive functioning domains objectively assessed across the studies, a variety of outcome measures were used. Some measures were used to measure more than one cognitive function.

\section{Processing speed}

The most commonly measured aspect of cognition was processing speed which was measured in all five studies using: the Wechsler Adult Intelligence Scale (WAIS) digit symbol-coding subset (Ferguson 2012; Milbury 2013); the trail making letter-number, colour-word interference, colour-word and switching trials of the Delis-Kaplan Executive Function System (D-KEFS) (Ferguson 2012); three subtests of the Useful Field of View were summed to calculate a composite processing speed score (Von Ah 2012); trials A and B and trial A-B difference of the Trail Making Test (Campbell 2014) and; the WAIS version four symbol search subset (Kesler 2013).

\section{Executive functions}

Executive functions were assessed in two studies using the DKEFS letter fluency test (Kesler 2013) and the Trail Making Test (Campbell 2014). Other aspects of Executive function measured include: working memory, assessed, using the WAIS version four digit span subtest (Kesler 2013; Milbury 2013); attention using the WAIS digit symbol-coding and digit span subsets (Milbury 2013) and; cognitive flexibility using the Wisconsin Card Sorting Task (WCST) (Kesler 2013). Verbal fluency was assessed in two studies using the Controlled Oral Word Association Test (COWAT) ( Campbell 2014; Milbury 2013). Language was assessed in one study using the letter fluency subtest of the D-KEFS (Kesler 2013).

\section{Memory and learning}

Memory and learning were measured in one study using the total recall, delayed recall, retention and delayed recognition index subtests of the HVLT (Campbell 2014). Visuomotor co-ordination was assessed by one study using the WAIS digit symbol subset (Milbury 2013). One study created composite scores for memory outcomes, composite scores for immediate memory recall were calculated from the sum of recall trials 1-5, short delay and recognition scores of the RAVLT and immediate recall of the Rivermead Behavioral paragraph Recall Test (RBPRT) (Von Ah 2012). Composite scores were also calculated for delayed memory recall from the long-term delay scores of the RAVLT and RBPRT (Von Ah 2012). Alternate test forms of the CVLT (Ferguson 2012), DKEFS and HVLT (Kesler 2013) were used to counteract practice effects across two studies.

\section{Verbal memory}

Verbal memory was assessed in three studies using: summed raw score of trials 1-5 of the California Verbal Learning Test (CVLT) version two (Ferguson 2012); trials 1-5, list B and recall of the Rey Adult Verbal Learning Test (RAVLT) (Milbury 2013) and; the Hopkin's Verbal Learning Test (HVLT) (Kesler 2013).

\section{Self-reported cognitive function}

All five studies included outcome measures to allow participants to self-report cognitive functioning. The most commonly used outcome measure was the FACT-Cog which provides data on perceived cognitive concerns, perceived cognitive abilities, impact on QoL and comments from others (Campbell 2014; Milbury 2013; Von Ah 2012). In addition, three further outcome measures of subjective cognitive function were administered; two of which refer to specific domains of cognition. The additional measures include: Squire Subjective Memory Questionnaire (Von Ah 2012), the Behavioral Rating Inventory of Executive Functioning (Kesler 2013) and Multiple Abilities Subjective Questionnaire measuring five domains of cognition including language, visual perception, verbal-, visual- memory and attention (Ferguson 2012).

\section{Non-cognitive outcomes}

A number of additional outcomes were assessed including quality of life, depression, anxiety, fatigue and sleep disturbances. Quality of life was assessed as a secondary outcome in three studies: overall quality of life scores were provided using the Quality of life-Cancer Survivor (QOL-CS) and the Quality of life Index-Cancer version (QLI-C) scales (Von Ah 2012); domain scores for physical-, psychological-, social- and spiritual- quality of life were measured using the QOL-CS (Ferguson 2012) and spiritual quality of life only using the Functional Assessment of Cancer Therapy- Spiritual sub scale (FACT-Spiritual) (Milbury 2013). Physical- and mental-health status were assessed using the SF-36 in two studies (Milbury 2013; Von Ah 2012). 
The Center for Epidemiologial Studies- Depression scale (CESD) was used to assess depression in three studies (Ferguson 2012; Milbury 2013; Von Ah 2012). The Spielberger State Trait Anxiety Inventory (STAI) was used to assess state anxiety in one study (Von Ah 2012) and state and trait anxiety in a further study (Ferguson 2012). Fatigue was assessed in two studies using the Functional Assessment of Cancer Therapy- Fatigue (FACT-F) scale (Von Ah 2012) and Brief Fatigue Inventory (BFI) (Milbury 2013). The Clinical Assessment of Depression was used to assess psychological distress including depression, anxiety and cognitive fatigue in one study (Kesler 2013). Depression, anxiety and fatigue are related to cognitive function and were unlikely to improve or decline directly as a result of the cognitive- and compensatory-strategy training interventions, therefore their assessment was undertaken in order to control for these factors in analysis in each of the three studies (Ferguson 2012; Kesler 2013; Von Ah 2012). One study only assessed sleep disturbances using the Pittsburgh Sleep Quality Index (PSQI) (Milbury 2013). The study assessing the effectiveness of the Tibetan Sound Meditation intervention hypothesised also that improvements would be observed in quality of life, fatigue, mood and sleep outcomes for participants (Milbury 2013).

\section{Treatment satisfaction}

Three studies assessed satisfaction with the intervention: a studyspecific measure was used in one study (Ferguson 2012), the Client Satisfaction Questionnaire was used in a second study (Von Ah 2012) and a third study required participants to keep a brief evaluation of their satisfaction and acceptability of weekly sessions (Milbury 2013). Acceptability of the intervention was assessed in an additional study using a study-specific questionnaire (Von Ah 2012).

\section{Safety}

Safety issues and adverse effects related to the intervention were captured in one study only (Kesler 2013). This study reported no safety issues or adverse events.

\section{Excluded studies}

\section{Electronic database search}

Thirty-six studies were excluded following examination of the full text for reasons specified in the Characteristics of excluded studies table.

\section{Grey literature and unpublished sources}

Twenty-two studies were excluded as they were duplicated registered titles or studies that were identified by the electronic database search. Contact was made with the Principal Investigator or named contact researcher when there were insufficient essential details in a paper. We contacted the researcher to obtain data or an update on study progress for 40 studies in the grey literature or unpublished sources. Two replies referred to four additional studies which had not been identified from other sources. Thereafter, 34 studies were excluded. Reasons for exclusion are specified in the Characteristics of excluded studies table.

Regarding the four additional studies that were forwarded to the review team by three of the contacted authors, three studies were excluded because the tested interventions were not targeted at maintaining cognitive function or improving cognitive impairment and the other study was excluded because patients who had not received systemic treatment were included and we were unable to separate these patients from those patients who had received systemic treatment.

\section{Other sources}

Three studies were excluded for the following reasons: the intervention was not targeted at improving cognitive impairment or maintaining cognitive functioning $(\mathrm{n}=2)$ and one study was not an RCT.

\section{Ongoing studies}

Thirteen ongoing studies were identified from trial registries. Interventions included: computerised cognitive training $(n=4)$, compensatory strategy training $(\mathrm{n}=3)$, physical activity $(\mathrm{n}=2)$, cognitive training $(n=1)$ and meditation $(n=1)$. One trial combined computerised cognitive training and telephone compensatory strategy training. A further trial included three interventions encompassing (i) computerised cognitive training, compensatory strategy training and relaxation, (ii) active journal writing, compensatory strategy training and relaxation and (iii) computerised cognitive training only.

\section{Risk of bias in included studies}

All five studies were assessed for risk of bias using the 'Risk of bias' tool provided in RevMan 5.3 (Review Manager 2014). We assessed the following aspects of the studies: random sequence generation, allocation concealment, blinding of personnel/participants, blinding of outcome assessors, incomplete outcome data, selective reporting, baseline imbalance in cognition scores (both objectively assessed and subjectively reported) and reliability and validity of cognition outcome assessments (Figure 2). Overall, studies were categorised as having a high risk of bias.

Non-pharmacological interventions for cognitive impairment due to systemic cancer treatment (Review) 
Figure 2. 'Risk of bias' graph: review authors' judgements about each risk of bias item presented as percentages across all included studies.

\begin{tabular}{|r|} 
Random sequence generation (selection bias) \\
Allocation concealment (selection bias) \\
Blinding of participants and personnel (performance bias) \\
Blinding of outcome assessment (detection bias) \\
Incomplete outcome data (attrition bias) \\
Selective reporting (reporting bias) \\
Baseline imbalances in cognition scores: Objective outcomes \\
Baseline imbalances in cognition scores: Subjective outcomes \\
Validity of cognitive function measures: Objective outcomes \\
Validity of cognitive function measures: Subjective outcomes \\
Reliability of cognitive function measures: Objective outcomes \\
Reliability of cognitive function measures: Subjective outcomes \\
\hline Low risk of bias \\
\hline Ligh risk of bias
\end{tabular}

\section{Allocation}

\section{Random sequence generation}

The criteria for the review required studies to be randomised. Each of the four published studies described how participants were allocated to groups using computer-generated lists (Ferguson 2012; Kesler 2013), stratified blocks (Campbell 2014; Von Ah 2012) and; minimisation (Milbury 2013). Contact with the author of the unpublished study confirmed that an appropriate random sequence generation method was used, namely block randomisation (Campbell 2014). All studies were scored as having a low risk of bias relating to random sequence allocation.

\section{Allocation concealment}

Four studies described clearly a method of allocation concealment that was judged to be of low risk of bias. They used computerbased allocation methods (Ferguson 2012; Kesler 2013), serially numbered, opaque envelopes (Campbell 2014), or allocation was undertaken by personnel not involved in the study (Von Ah 2012). One study did not include sufficient detail to make a judgement, so we categorised this as having an 'unclear' risk of bias (Milbury 2013).

\section{Blinding}

\section{Performance bias}

Due to the nature of the non-pharmacological interventions being delivered, it was not possible for study participants to be blinded to group allocation. Therefore, each study was scored as 'low risk' because it is unlikely that knowledge of group allocation by researcher or participant would influence outcomes (Campbell 2014; Ferguson 2012; Kesler 2013; Milbury 2013; Von Ah 2012).

\section{Detection bias}

Three studies included a clear statement that outcome assessors were blinded to the group allocation of participants and were therefore rated as having a 'low' risk of detection bias (Ferguson 2012; Kesler 2013; Von Ah 2012). Information provided on a registered trial database about the unpublished study indicated that outcome assessors were blind to group allocation of study participants (Campbell 2014). The final study was rated as having 'unclear' risk of bias because insufficient information about the outcome assessors was reported (Milbury 2013). 


\section{Incomplete outcome data}

Two studies were rated as having a 'low' risk of attrition bias because all dropouts were accounted for in both the intervention and control groups and similar reasons for dropout were reported (Campbell 2014; Ferguson 2012). Furthermore, intentionto-treat analysis was undertaken for three studies (Campbell 2014; Ferguson 2012; Milbury 2013). Ferguson 2012 used linear interpolation methods to impute missing data and did not undertake sensitivity analysis. Two further studies were rated as 'high' risk of bias because they did not undertake intention-to-treat analysis (Kesler 2013; Von Ah 2012). The final study was rated as 'unclear' risk of bias as the reason for the dropout of one control group participant was not reported and they did not describe their method of intention-to-treat analysis (Milbury 2013).

\section{Selective reporting}

Three studies were rated as having an 'unclear' risk of bias due to the failure to report data related to: results of significance testing in their tables (Milbury 2013), potential confounding variables in tables (Ferguson 2012) and, means and standard deviations for individual test measures and composite scores at follow-up time points (Von Ah 2012). The remaining two studies received a 'low' risk of bias score because all outcome measure data were reported in both study text and tables (Campbell 2014; Kesler 2013).

\section{Other potential sources of bias}

Other potential sources of bias in this review may result from baseline imbalances in objectively measured and subjectively reported cognitive function scores due to the possible failure of the randomisation strategy. Additionally, there is a poor correlation between objective and subjective assessments of cognitive function (Green 2005). Often, the cognitive function assessment measures that are used among cancer patients or survivors have been taken from other populations e.g. brain trauma, therefore, the use of potentially unreliable or invalid measures among the cancer population presents a potential risk of bias.

Four (Campbell 2014; Ferguson 2012; Kesler 2013; Milbury 2013) of the five studies were rated as having an 'unclear' risk of bias relating to baseline imbalances in objectively assessed cognitive function due to a failure to report the absence (or presence) of between-group differences in objectively assessed cognitive function at baseline. Only one study (Von Ah 2012) reported that there were no between-group baseline differences in objectively assessed cognitive function and therefore was rated as having 'low' risk of bias. Similarly for between-group differences in subjectively reported cognitive function at baseline, only one study stated clearly whether or not any differences between-groups were present (Ferguson 2012) and, therefore, was rated as having a 'low' risk of bias. The other studies were rated as having an 'unclear' risk of bias as no clear statement of baseline differences were reported (Campbell 2014; Kesler 2013; Milbury 2013; Von Ah 2012).
The studies reported infrequently on the reliability and validity of cognitive function assessment measures, therefore, the risk of bias was judged to be 'unclear' for the validity (Ferguson 2012; Milbury 2013; Von Ah 2012) and reliability (Ferguson 2012; Milbury 2013; Von Ah 2012) of objective outcome measures and, the validity (Campbell 2014; Ferguson 2012; Milbury 2013; Von Ah 2012) and reliability (Campbell 2014; Ferguson 2012; Kesler 2013; Milbury 2013; Von Ah 2012) of subjective outcome measures. For the validity and reliability of objective outcome measures, a rating of 'low' risk of bias was given to two studies because they reported on the psychometric information related to the measures (Kesler 2013) or chose their outcome measures based on the guidelines provided by the ICCTF (Campbell 2014). One study only provided psychometric information relating to their outcome measure to assess subjective cognitive function and thus it was rated as having a 'low' risk of bias (Kesler 2013).

\section{Effects of interventions}

\section{See: Summary of findings for the main comparison}

We were able to undertake meta-analyses from two studies ( $\mathrm{n}=95$ participants) comparing physical and mental well-being immediately after, and 2 months after receipt of compensatory strategy training.

\section{Computer-assisted cognitive training}

The two computer-assisted cognitive training interventions ( Kesler 2013; Von Ah 2012) recruited 100 participants in total. The studies reported on two overlapping outcomes only: processing speed and self-reported cognitive function.

\section{Objectively assessed cognitive outcomes}

Kesler 2013 found a statistically significant improvement in processing speed compared to the control group immediately post-intervention (between-group effect size $(d)=0.87, \mathrm{P}=0.009)$. Similarly, Von Ah 2012 found significant improvements in processing speed compared to the control group immediately post-intervention $(d=0.55,95 \%$ confidence interval $(\mathrm{CI})=0.01$ to $1.08, \mathrm{P}$ value $=0.04)$ and two -months post-intervention $(d=0.67,95 \%$ $\mathrm{CI}=0.14$ to $1.21, \mathrm{P}$ value $=0.016)$. This study also calculated reliable improvement scores; a participant demonstrated reliable improvement if their performance on a measure improved by at least one standard error of measurement. Compared to $43 \%$ and $61 \%$ of wait-list controls, $68 \%$ and $67 \%$ of intervention participants demonstrated reliable improvement immediately and two months post-intervention, respectively.

Significant intervention effects compared to wait-list controls were found on a number of other objective assessments of cognitive function immediately post-intervention including executive functions $(d=0.82, \mathrm{P}$ value $=0.003)$, cognitive flexibility $(d=0.58, \mathrm{P}$ $=0.008)$ and language $(d=0.82, \mathrm{P}$ value $=0.003)($ Kesler 2013) . 
Despite working memory (a domain of executive functions) being targeted by the Kesler 2013 cognitive training intervention, no improvement was observed compared to the control group. This may be due to choice of outcome measure; the digit span test to measure working memory relies on auditory stimuli which may not be sufficient to capture the effects of the visually-orientated intervention on working memory.

Kesler 2013 reported a trend towards a beneficial effect of the intervention compared to wait-list controls on verbal memory immediately post-intervention $(d=0.56, \mathrm{P}$ value $=0.07)$. Although the intervention did not target specifically verbal memory, the authors reported that this observed trend may be due to the downstream effects of improvements in executive functions i.e. the cognitive domains targeted by the intervention. Transfer effects of the Insight intervention were observed on immediate memory recall immediately- $(d=0.75,95 \% \mathrm{CI}=0.22$ to $1.29, \mathrm{P}$ value $=0.007)$ and two months post-intervention $(d=0.82,95 \% \mathrm{CI}=0.28$ to 1.35 , $\mathrm{P}$ value $=0.001)$, and on delayed memory recall two months postintervention $(d=0.72,0.18$ to $1.26, \mathrm{P}$ value $=0.001)$ compared to controls. In terms of reliable improvement, for immediate memory recall immediately, and two months post-intervention $41 \%$ and $30 \%$ of intervention participants demonstrated reliable improvement, compared to $10 \%$ and $18 \%$ of controls, respectively. Compared to $11 \%$ of controls, $33 \%$ of intervention participants demonstrated reliable improvement on delayed memory recall two months post-intervention (Von Ah 2012).

\section{Subjective cognitive function}

A beneficial effect on self-reported cognitive functioning was found for the intervention compared to the control group. An improvement was not observed on the global composite score of the BRIEF cognitive functioning measure, but improvements were observed on two BRIEF subscales including planning and/or organisation $(d=0.44, \mathrm{P}$ value $=0.02)$ and task monitoring $(d=$ 0.43 , P value $=0.03)$. It is not clear why the authors calculated corrected effect sizes for the BRIEF subscales as it is unlikely that patient-reported outcome measures are at risk of practice effects. This study did not assess intervention effects at additional time points so there is no information on the sustainability of intervention effects (Kesler 2013). Compared to wait-list controls, significant improvements were found for self-reported cognitive functioning on the FACT-Cog $(d=0.55,95 \% \mathrm{CI}=0.01$ to 1.08$)$ and $\operatorname{SSMQ}(d=0.44,95 \% \mathrm{CI}=-0.09$ to 0.98$)$ measures immediately post-intervention, but this effect was not observed at two months post-intervention.

\section{Non-cognitive outcomes}

The Insight intervention also demonstrated beneficial effects on QoL. There was a beneficial effect of the Insight intervention on perceived mental health immediately- $(d=0.72,0.19$ to $1.26, \mathrm{P}$ value $=0.01)$, and two months post-intervention $(d=0.60,0.07$ to 1.13 , P value $=0.03)$ compared to wait-list controls. Nevertheless, overall quality of life was not improved as a result of the Insight intervention (Von Ah 2012).

\section{Compensatory strategy training}

The two compensatory strategy training interventions (Ferguson 2012; Von Ah 2012) recruited 99 participants in total. Data from 95 participants could be used in the meta-analyses of physical and mental well-being. The two studies measured two overlapping outcomes: processing speed and self-reported cognitive functioning with findings in similar directions.

\section{Objectively assessed cognitive outcomes}

A beneficial effect of the ACTIVE intervention was found with improvements in immediate- $(d=0.59,95 \% \mathrm{CI}=0.05$ to $1.13, \mathrm{P}$ value $=0.036)$ and delayed $-(d=0.70,95 \% \mathrm{CI}=0.16$ to $1.24, \mathrm{P}$ value $=0.013)$ memory recall compared to controls at two months post-intervention. This effect was not observed immediately postintervention which may reflect findings of similarly published literature. Thirty-nine per cent and $42 \%$ of intervention participants demonstrated reliable improvement two months post-intervention on immediate- and delayed-memory recall compared to $18 \%$ and $11 \%$ of controls, respectively (Von Ah 2012). A significant group by time interaction $(\mathrm{F}(2,76)=53.16$, P value $<0.05)$ with significant improvements in verbal memory compared to the waitlist control group immediately post-intervention (intervention $d$ $=-0.36$ versus control $d=0.14, \mathrm{P}$ value $<0.001)$ and two-months post-intervention (intervention $d=-0.81$ versus control $d=-0.18$, P value $<0.001)$ were observed. Many of the MAAT intervention compensatory strategies involved verbalisation and vocalisations which may result in this observed effect. Relaxation techniques may also have contributed to improvements in verbal memory.

No improvements were observed on processing speed as a result of the ACTIVE (Von Ah 2012) or MAAT intervention (Ferguson 2012).

\section{Subjective cognitive function}

Compared to wait-list controls, a beneficial effect of the ACTIVE intervention was found on subjectively reported cognitive function assessed by the FACT-Cog $(d=0.59$, P value $=0.036)$ and SSMQ ( $d=0.71$, P value $=0.012)$ measures immediately post-intervention and the FACT-Cog $(d=0.65, \mathrm{P}$ value $=0.021)$ and SSMQ $(d$ $=0.84, \mathrm{P}$ value $=0.003)$ measures two-months post-intervention (Von Ah 2012). There were no MAAT intervention effects for self-reported cognitive functioning. The study authors report also that the FACT-Cog (which was not yet developed at the time of the study) may be more effective to assess self-reported cognitive function than the MASQ (Ferguson 2012). 
Non-cognitive outcomes

We considered the analysis of physical and mental health to be of low quality and that it should be interpreted with caution. See Summary of findings for the main comparison for more information.

When we performed meta-analyses of these two studies, there was no apparent effect of compensatory strategy training compared to wait-list controls on physical well-being immediately post-intervention (standardised mean difference (SMD) 0.12, 95\% CI 0.59 to 0.83 ), although between-study heterogeneity in this effect was moderate $\left(\mathrm{I}^{2}=67 \%\right)$ (Analysis 1.1 ; Figure 3 ). Similarly, two- months post-intervention there was no apparent effect of compensatory strategy training compared to controls on physical wellbeing (SMD $-0.21,95 \%$ CI -0.89 to $0.47 ; \mathrm{I}^{2}=63 \%$ ) (Analysis 2.1; Figure 4). The effect of compensatory strategy training intervention on psychological well-being post-intervention favoured the wait-list control group (SMD $-0.57,95 \%$ CI -0.98 to -0.16 ; I $2=0 \%$ ), with no observed between-study heterogeneity (Analysis 1.2; Figure 5). The favourable effect of the compensatory strategy training intervention on psychological well-being among the control group was no longer observed two months post-intervention (SMD -0.38, 95\% CI -1.10 to $0.34 ; \mathrm{I}^{2}=67 \%$ ) (Analysis 2.2; Figure 6).

Figure 3. Forest plot of comparison: I Compensatory strategies, outcome: I.I Physical well-being at postintervention.

\begin{tabular}{|c|c|c|c|c|c|c|c|c|c|c|c|}
\hline \multirow[b]{2}{*}{ Study or Subgroup } & \multicolumn{3}{|c|}{ Intervention } & \multicolumn{3}{|c|}{ Control } & \multirow{2}{*}{\multicolumn{2}{|c|}{ Std. Mean Difference }} & \multirow{2}{*}{\multicolumn{3}{|c|}{$\begin{array}{c}\text { Std. Mean Difference } \\
\text { IV, Random, } 95 \% \text { Cl }\end{array}$}} \\
\hline & Mean & SD & Total & Mean & SD & Total & Weight & & & & \\
\hline Von Ah 2012 & 45.71 & 5.98 & 26 & 43.18 & 4.72 & 29 & $52.5 \%$ & $0.47[-0.07,1.00]$ & & & \\
\hline $\begin{array}{l}\text { Heterogeneity: Tau } \\
\text { Test for overall effec }\end{array}$ & $\begin{array}{l}0.18 ; C \\
Z=0.33\end{array}$ & $\begin{array}{l}\mathrm{h}^{2}=3 . \\
(\mathrm{P}=0\end{array}$ & $\begin{array}{l}00, d f= \\
74)\end{array}$ & $=1(P=$ & $0.08) ;$ & $\left.\right|^{2}=67^{\circ}$ & & & $\begin{array}{c}-1 \\
\text { Favours [control] }\end{array}$ & Favours [int & $\begin{array}{l}1 \\
\text { tervention] }\end{array}$ \\
\hline
\end{tabular}

Figure 4. Forest plot of comparison: 2 Compensatory strategies versus wait-list control 2-months postintervention, outcome: 2.I Physical well-being.

\begin{tabular}{|c|c|c|c|c|c|c|c|c|c|c|}
\hline \multirow[b]{2}{*}{ Study or Subgroup } & \multicolumn{3}{|c|}{ Intervention } & \multicolumn{3}{|c|}{ Control } & \multicolumn{2}{|r|}{ Std. Mean Difference } & \multirow{2}{*}{\multicolumn{2}{|c|}{$\begin{array}{l}\text { Std. Mean Difference } \\
\text { IV, Random, } 95 \% \mathrm{Cl}\end{array}$}} \\
\hline & Mean & SD & Total & Mean & SD & Total & Weight & IV, Random, $95 \% \mathrm{Cl}$ & & \\
\hline Von Ah 2012 & 45.03 & 6.17 & 26 & 44.49 & 2.81 & 29 & $53.3 \%$ & $0.11[-0.42,0.64]$ & & \\
\hline Total $(95 \% \mathrm{Cl})$ & & & 45 & & & 50 & $100.0 \%$ & $-0.21[-0.89,0.47]$ & & \\
\hline $\begin{array}{l}\text { Heterogeneity: Tau } \\
\text { Test for overall effec }\end{array}$ & $\begin{array}{l}0.15 ; \mathrm{Cr} \\
\mathrm{Z}=0.61\end{array}$ & $\begin{array}{l}\mathrm{h}^{2}=2 \\
(\mathrm{P}=0\end{array}$ & $\begin{array}{l}71, \mathrm{df}= \\
.54)\end{array}$ & $=1(\mathrm{P}=$ & $0.10)$ & $\left.\right|^{2}=63^{\circ}$ & & & $\begin{array}{cc}-1 & 0 \\
\text { Favours [control] } & \text { Favours [int }\end{array}$ & $\begin{array}{l}1 \\
\text { ntervention] }\end{array}$ \\
\hline
\end{tabular}

Figure 5. Forest plot of comparison: I Compensatory strategies versus wait-list control immediately postintervention, outcome: I.2 Psychological well-being.

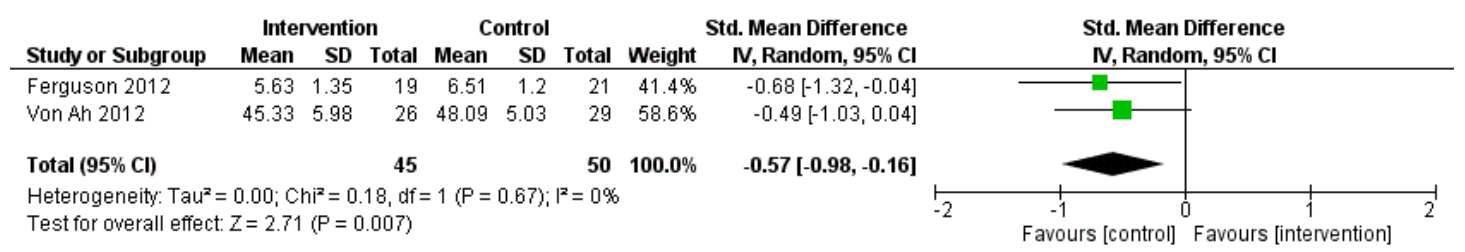

Non-pharmacological interventions for cognitive impairment due to systemic cancer treatment (Review) 
Figure 6. Forest plot of comparison: 2 Compensatory strategies versus wait-list control 2-months postintervention, outcome: 2.2 Psychological well-being.

\begin{tabular}{|c|c|c|c|c|c|c|c|c|c|c|c|}
\hline \multirow[b]{2}{*}{ Study or Subgroup } & \multicolumn{3}{|c|}{ Intervention } & \multicolumn{3}{|c|}{ Control } & \multicolumn{2}{|r|}{ Std. Mean Difference } & \multirow{2}{*}{\multicolumn{3}{|c|}{$\begin{array}{l}\text { Std. Mean Difference } \\
\text { IV, Random, } 95 \% \mathrm{Cl}\end{array}$}} \\
\hline & Mean & SD & Total & Mean & SD & Total & Weight & IN, Random, $95 \% \mathrm{Cl}$ & & & \\
\hline Von Ah 2012 & 44.91 & 6.82 & 26 & 45.11 & 5.13 & 29 & $53.3 \%$ & $-0.03[-0.56,0.50]$ & & & \\
\hline Total $(95 \% \mathrm{Cl})$ & & & 45 & & & 50 & $100.0 \%$ & $-0.38[-1.10,0.34]$ & & & \\
\hline $\begin{array}{l}\text { Heterogeneity: Tau } \\
\text { Test for overall effec }\end{array}$ & $\begin{array}{l}0.18 ; \mathrm{Cl} \\
\mathrm{Z}=1.03\end{array}$ & $\begin{array}{l}h i^{2}=3 \\
(P=0\end{array}$ & $\begin{array}{l}.01, \mathrm{df}= \\
0.30)\end{array}$ & $=1(P$ & .08) & $P^{2}=67^{\circ}$ & & & $\begin{array}{c}-1 \\
\text { Favours [control] }\end{array}$ & Favours [int & $\begin{array}{l}1 \\
\text { atervention] }\end{array}$ \\
\hline
\end{tabular}

A significant time by group interaction $(\mathrm{F}(2,76)=3.44$, P value $<$ 0.05 ) was observed for the MAAT intervention on spiritual quality of life compared to wait-list controls immediately post-intervention (intervention $d=-0.35$ versus control $d=0.14$ ) and two months post-intervention (intervention $d=-0.11$ versus control $d=0.15)$ in a repeated measures ANCOVA model controlling for education and IQ. The authors report that this observed improvement may reflect participants' perceived optimism, hopefulness and purpose in life represented by the spiritual QoL items (Ferguson 2012).

\section{Meditation/relaxation intervention}

The trial of Tibetan Sound Meditation intervention found a nonstatistically significant beneficial effect on processing speed $(d=$ 0.25 , $\mathrm{P}$ value $=0.09)$ and verbal memory $(d=0.56, \mathrm{P}$ value $=$ 0.06 ) at one month post-intervention compared to wait-list controls (Milbury 2013). In the short term, immediately post-intervention, the Tibetan Sound Meditation intervention had a beneficial effect on a number of secondary outcomes including: reduced depressive symptomology $(d=0.59, \mathrm{P}$ value $=0.05)$; improved perceived mental health $(d=0.57$, P value $=0.04)$, and improved spiritual quality of life $(d=0.52$, P value $=0.05)$ compared to waitlist controls. Despite the moderate effects sizes reported, effects were not sustained at one month post-intervention. The authors reported that the primary aim of the study was to gain insight into the feasibility and initial efficacy of the intervention; and 30\% of breast cancer survivors in their sample experienced objectively assessed cognitive impairment, which may have contributed to the lack of sustained improvements due to ceiling effects.

\section{Physical activity intervention}

Statistically significant improvements $(P$ value $<0.05)$ in a subtest of processing speed/executive functions, a subtest of verbal fluency, a sub scale (impact on QoL) of the FACT-Cog were observed for participants enrolled in a physical activity intervention compared to a wait-list control. However, these findings were no longer significant when baseline scores were controlled (Campbell 2014).

\section{Adherence to treatment}

Where reported, adherence to the interventions was high. Kesler 2013 defined adherence to their intervention as completion of four sessions per week as well as accuracy in completion of exercises. Participants completed a mean of four sessions $(\mathrm{SD}=0.42)$ which took a mean of 13.0 weeks to complete $(\mathrm{SD}=0.92$, range $=12$ to $15)$ including cognitive assessments. Moreover, accuracy increased over time as demonstrated by a strong positive association (mean $r=0.72$ ). Adherence to Tibetan Sound Meditation intervention had a high level of adherence $(\mathrm{M}=9.71, \mathrm{SD}=1.90$, range $=7$ to 12) (Milbury 2013). All participants completed at least $75 \%$ of the meditation sessions and $23.5 \%$ completed all 12 sessions. Participants were also encouraged to practice at home outside of the scheduled meditation sessions: $33.4 \%$ practiced at home every day, $46.5 \%$ practiced at home twice a week, $10.1 \%$ practiced at home once a week and $9.5 \%$ did not practice at home. The remaining three studies did not report on adherence to their respective interventions (Campbell 2014; Ferguson 2012; Von Ah 2012).

\section{Treatment satisfaction}

There was a high level of participant satisfaction with receipt of compensatory strategy training (Ferguson 2012; Von Ah 2012), computer-assisted cognitive training (Von Ah 2012) and Tibetan Sound Meditation (Milbury 2013). General satisfaction with Ferguson 2012 MAAT intervention was high ( $M=7.0, S D=1.05)$; a score of zero represents 'not at all satisfied' and a score of eight represents 'completely satisfied'. The MAAT intervention was rated by participants as more helpful in compensating than improving memory in every day life, with higher scores indicating higher levels of helpfulness $(M=6.7, S D=1.54$ versus $M=5.2, S D=1.59)$. The top five ranked strategies included: applied relaxation, use of a schedule or daily planner, verbal rehearsal, pacing of activities and self-instructional training. Von Ah 2012 administered the CSQ to participants who received the ACTIVE and Insight interventions. Seventy-three per cent of ACTIVE participants and $89 \%$ of Insight participants rated their respective interventions as satisfactory. Participants agreed or strongly agreed that the interventions were understandable (ACTIVE: 96\%; Insight: 89\%) and enjoy- 
able (ACTIVE: 81\%; Insight: 73\%). Eighty per cent and $81 \%$ of participants in the ACTIVE and Insight interventions, respectively, disagreed or strongly disagreed that an alternative intervention was preferable. Moreover, participants disagreed or strongly disagreed that they would have preferred the intervention to be delivered in an alternative format (ACTIVE: 100\%; Insight: 96\%). The majority of participants disagreed or strongly disagreed that the respective ACTIVE and Insight interventions were too difficult $(77 \% ; 89 \%)$, took too much time $(92 \% ; 100 \%)$ or were boring $(96 \% ; 100 \%)$. Seventy-four per cent and $84 \%$ of participants in Milbury 2013 Tibetan Sound Meditation intervention rated it as very useful and definitely beneficial, respectively. Participants expressed positive experiences also in response to openended questions about the intervention.

\section{DISCUSSION}

\section{Summary of main results}

Five studies ( $n=235)$ describing six interventions targeting maintenance of cognitive functioning or amelioration of cognitive impairment following systemic cancer treatment were included in this review. Two computer-assisted cognitive training interventions ( $\mathrm{n}=100)$ (Kesler 2013; Von Ah 2012), two compensatory strategy training interventions $(\mathrm{n}=95)$ (Ferguson 2012; Von Ah 2012), one meditation intervention $(\mathrm{n}=47)$ (Milbury 2013) and one physical activity intervention $(\mathrm{n}=19)$ (Campbell 2014) were identified. Each study recruited only women who had been treated for breast cancer and some targeted specific areas of cognition including processing speed (Von Ah 2012), memory (Von Ah 2012), executive functions (Kesler 2013) and both memory and attention (Ferguson 2012). Common areas of cognition were assessed across studies though each area was assessed using a variety of outcome measures. Thus, we were only able to undertake limited meta-analyses. No beneficial effect of compensatory strategy training was found for physical well-being immediately or two months postintervention or mental well-being two months post-intervention. Low certainty evidence suggests that compensatory strategy training may be associated with a reduction in mental well-being immediately post-intervention. If this is a true effect, it may be explained by the participant's perceptions of limited benefits as assessed by objective assessments of cognitive domains other than memory for participants in the intervention group. For example, difficulties in maintaining attention and executive functions such as planning and managing multiple tasks are experienced frequently by a significant proportion of cancer survivors (Jansen 2005; Wefel 2011). An improvement on a number of objectively assessed cognitive outcomes, self-reported cognitive function and mental well-being was found for computerised cognitive training. Compensatory strategy training resulted in improvements in objectively assessed memory, self-reported cognitive function and spiritual quality of life (QoL). Benefits were observed in terms of participants' perceptions of their cognitive abilities and quality of life as well as in terms of the more often found result relating to improvements in neuropsychological test scores. Given their nature of repetitive practice of cognitive skills, cognitive training interventions have the potential for effects to transfer to other cognitive domains. This was observed in one study (Kesler 2013), but, is unlikely to occur within compensatory strategy training interventions. The physical activity and meditation interventions failed to find a beneficial effect on cognitive outcomes compared to a wait-list control group, although improvements in depressive symptoms, perceived mental health and spiritual QoL were observed for Tibetan Sound Meditation. Overall, adherence to interventions was good and interventions were highly rated by participants in terms of satisfaction.

\section{Overall completeness and applicability of evidence}

The opportunity to pool data or draw robust conclusions about the effects of tested intervention was limited due to the small number of studies and the variation across them in terms of interventions and outcome measures. The incomplete and unclear presentation of data in papers limited the extent to which we were able to conduct additional meta-analyses. Our requests for additional data were unsuccessful. The studies were limited to women only who had been treated for breast cancer and it is uncertain whether the findings are informative for intervention effectiveness, adherence or satisfaction for men treated for cancer or women treated for other types of cancer. Moreover, participants were at least three months post-chemotherapy and the extent to which interventions would be effective if delivered earlier, for example, at the end of treatment is untested. Also, because participants in the studies tended to be relatively young ( 53 years old, on average) and to have a high level of education, it is unclear how cognitive rehabilitation interventions would impact on cancer survivors with lower levels of education or on older or younger cancer survivors.

Reports about the interventions and control conditions in the studies contained only minimal descriptions and posed difficulties with respect to replication. We created a mini-taxonomy of the main techniques allied to each intervention component in an attempt to describe and appraise how the interventions 'work' and to facilitate between-study comparisons. Many techniques were used in common across interventions.

None of the studies assessed the cost-effectiveness of their interventions, and there was limited attention given to safety or adverse events for participants. Cognitive training programmes were commercially available and there was some access to a programme's resources at no cost. 


\section{Quality of the evidence}

We considered the quality of evidence for the physical and mental well-being outcomes of compensatory strategy training. Evidence was rated low quality due to the risk of bias and imprecision of estimates. Therefore, results should be interpreted with caution. In the absence of a GRADE assessment for many outcomes of interest in the review, readers should consider the methodological quality of individual studies. None of the studies were rated as having a low risk of bias in all domains. Overall, selection bias, performance bias and detection bias were well-reported and, in general, we categorised these as low risk of bias. Although, we assessed the risk of performance bias as low given the inability of participants to be blinded to non-pharmacological interventions, we acknowledge that it is possible that participants' knowledge of allocation may affect reporting of outcomes. Each study failed to report sufficient information that would permit an adequate judgement of all 'Risk of bias' items. Attrition bias, reporting bias and baseline imbalances in cognitive function between groups were infrequently reported. Although many of the self-report measures of cognitive functioning were not cancer-specific, the reliability and validity of their use among cancer populations were less well reported than objective measures for which no cancer-specific measures which have been developed. Two studies (Kesler 2013; Von Ah 2012) had a high risk of bias regarding selective reporting. It appeared that the measurement properties of the assessments and their appropriateness for use with particular cancer populations and settings was not given due consideration.

Only two studies (Ferguson 2012; Von Ah 2012) reported an a priori sample size calculation and one study reported a sample size calculation retrospectively (Milbury 2013). One study (Von Ah 2012) was found to have sufficient power to observe whether or not the intervention that they were testing had an effect. Intentionto-treat analysis was not undertaken in two studies (Kesler 2013; Von Ah 2012). Caution is therefore warranted when interpreting review findings given the limited evidence and individual study limitations noted above.

\section{Potential biases in the review process}

A sensitive search filter rather than a specific filter was developed to ensure that a wide breadth of interventions was identified due to the range of different types of non-pharmacological interventions for improving cognitive impairment or maintaining cognitive function. This resulted in the screening of a large number of reports. The diverse types of interventions made it difficult to synthesise results and compare studies.

We were interested in interventions that targeted individuals whose problems were chronic or long-lasting due to completed systemic cancer therapy. Trials that included individuals who: (i) had not received systemic treatment and, or (ii) were currently undergoing active treatment were excluded. Nevertheless, it is possible that individuals at various points on the cancer care trajectory may also benefit from cognitive rehabilitation-targeted interventions. Cognitive impairment related to cancer may arise, for example, due to factors related to becoming a cancer patient such as fatigue, depression and anxiety. Increasingly, there is evidence that cancerrelated cognitive impairment may be present prior to treatment commencement and independent of factors such as fatigue, depression and anxiety. Some authors have hypothesised that similar mechanisms for cancer development and impaired cognitive function, such as, cytokine production may play a role (Lange 2014).

\section{Agreements and disagreements with other studies or reviews}

Non-pharmacological interventions have been investigated among other cancer populations or treatment groups who experience changes in cognition. This research is limited, but findings suggest non-pharmacological interventions may be effective for individuals with childhood cancers (Castellino 2014), central nervous system (CNS) tumours (Gehring 2008; Gehring 2010), or who have received cranial radiation (Day 2014). Other reviews of interventions for cancer- or treatment-related cognitive impairment have reported similar findings to our review (Fardell 2011; Gehring 2012; Hines 2014; Janelsins 2014; Von Ah 2014). One recent review (Chan 2015) identified pharmacological and nonpharmacological interventions for chemotherapy-related cognitive impairment among breast cancer patients and concluded that non-pharmacological interventions were promising. This differs slightly from the conclusions drawn from our review whereby we stated that there is insufficient evidence available. There were some differences in eligibility criteria, definitions of interventions and sources between reviews which may have resulted in the minor differences in conclusion between the reviews particularly as Chan 2015 identified more studies under their umbrella 'cognitive training' intervention term encompassing cognitive training and compensatory strategy training which were differentiated within our review. Nevertheless, both reviews state that further research in this area is warranted. As our review focused on cognitive impairment related to systemic cancer treatment, we excluded studies because participants had not received chemotherapy or hormonal therapy or were in current receipt of chemotherapy. These studies reported beneficial effects of their interventions as noted below. Three group cognitive rehabilitation interventions targeting breast cancer (Ercoli 2015) or diverse cancer sites (Cherrier 2013; King 2015) found improvements in objectively assessed (Ercoli 2015; King 2015) and subjectively reported cognitive function (Cherrier 2013; Ercoli 2015; King 2015), as well as quality of life (Cherrier 2013) and cognitive self-efficacy (King 2015). A group yoga intervention for individuals from diverse cancer sites (Derry 2015) and Medical Qigong (Oh 2012) for women with breast cancer found improvements in self-reported cognitive function. 
Similar to our review, other Cochrane reviews of cognitive rehabilitation interventions among other disease groups identified a small number of studies, of low quality. There was no reported beneficial effect of intervention on cognition among individuals with schizophrenia (McGrath 2000), Alzheimer's disease, vascular dementia (Bahar-Fuchs 2013) ,or memory (das Nair 2007), executive function (Chung 2013) and attention deficits as a result of stroke (Loetscher 2013). Rehabilitation targeting memory did not have a beneficial effect on outcomes for individuals with multiple sclerosis (das Nair 2012). Promising effects of cognitive rehabilitation on divided attention have been reported among individuals with stroke (Loetscher 2013), memory among healthy individuals and individuals with mild cognitive impairment (Martin 2011). Cognitive training on memory and cognitive training combined with neuropsychological rehabilitation has also had beneficial effects on immediate-, delayed-verbal memory and attention among individuals with multiple sclerosis (Rosti-Otajärvi 2014). It may be difficult to make like-with-like comparisons about the effectiveness of interventions across disease groups given the different aetiological pathways and potential for cognitive functioning to be re-mediated or restored after diagnosis and/or treatment.

\section{AUTHORS, CONCLUSIONS}

\section{Implications for practice}

The limited evidence available at present makes it difficult to draw firm recommendations for healthcare providers that would help patients maintain or recover cognitive functions following receipt of chemotherapy. Further research is needed to resolve uncertainties about the effects of available interventions. Tentatively, the review findings suggest that cognitive- and compensatory strategy-training may have potential benefits for improving cognitive functioning and quality of life outcomes among breast cancer survivors. Also, evidence on the effectiveness of physical activity and meditation interventions on cognitive function outcomes is too weak to extract any implications for clinical practice. Although, not an objective of the review, it is not clear if face-to-face or groupdelivered interventions would have most benefit or which type of healthcare professional would be best placed to deliver such interventions.

\section{Implications for research}

We identified only a small number of trials and these were not of high quality. Nevertheless, the number of ongoing, registered trials, suggest that more rigorous research in this area might be available in future. Larger, multi-site trials are needed with longer follow-up periods in order to test robustly the effectiveness of interventions. Moreover, trials that are adequately powered with a formal sample size calculation conducted a priori are needed.
Future studies should consider methods to blind participants to group allocation such as the use of attentional control groups. It is recognised that due to the cognitive rehabilitation nature of the interventions identifying an appropriate attentional control may be difficult. It is important to consider the extent to which practice effects may occur as a result of multiple neuropsychological testing and how this factor may lead to improvements in test scores which may be independent of any true intervention effects. For example, if patients remember the content and responses of neuropsychological tests, develop strategies or have increased confidence to complete the tests, this may contribute to practice effects. Future studies should continue to consider use of alternative test battery forms, test measures with good test-retest reliability to capture with more precision true changes in cognition which may help to control or lessen the impact of practice effects (Calamia 2012; Vardy 2008; Wefel 2011).

Many of the included studies required participants to self-report deterioration in cognitive functioning since cancer diagnosis and cancer treatment. It is widely known that self-reported cognitive functioning demonstrates a stronger association with fatigue, distress and related factors than objective measures of cognitive functioning (Green 2005). Whilst some of the studies assessed retrospectively the proportion of study participants who demonstrated objectively assessed cognitive impairment, there is a need also to do so prior to study enrolment in future trials. As with most cancer survivorship research and, indeed, research on treatment-related cognitive impairment among non-CNS adult-onset cancers, breast cancer represents the most widely studied cancer survivor cohort. However, cognitive impairment following systemic cancer treatment is a phenomenon relevant to survivors of other cancers and they too should be considered in future trials.

Further work is needed to determine the psychometric properties of measures of cognitive functioning within cancer patient or survivor populations to ensure that they are appropriate for use, as cognitive impairments among this group occur more subtly than the groups for which the measures were initially designed. There was little agreement across trials about the choice of outcome measures for specific cognitive domains and often, measures were used to assess more than one cognitive domain. The International Cognition and Cancer Task Force published recommendations for outcome measure selection (Wefel 2011) and adherence to these would permit ease of comparison and meta-analysis in future reviews. Measuring activities of daily living (ADLs) and instrumental ADLs are important outcomes to be captured in future trials.

Future research should consider also incorporating neuroimaging techniques into their evaluation design to demonstrate structural and functional changes in the brain as an additional objective assessment of changes in cognitive functioning. Although research in this area is in its infancy, in the future it may be beneficial to test the effectiveness of interventions targeting maintenance of 
cognitive function or amelioration of cognitive impairment in a preventative setting, particularly among cancer patients who may have increased susceptibility to the neurotoxic effects of chemotherapy (e.g. presence of apoE $\epsilon 4$ allele). At present, there is no standard care for treatment-related cognitive impairment and the cost-effectiveness of implementing cognitive rehabilitation interventions in clinical practice is warranted in future studies, given limited healthcare resources.

\section{ACKNOWLEDGEMENTS}

We thank Jane Hayes for designing the search strategy, Tracey Harrison, Gail Quinn and Robin Grant for editorial advice and their help with several aspects of this review.
We wish to thank the Northern Ireland Health and Social Care Research and Development Division of the Public Health Agency, UK for funding CT to undertake the review via a Cochrane Training Fellowship.

This project was supported by the National Institute for Health Research (NIHR), via Cochrane Infrastructure funding to the Cochrane Gynaecological, Neuro-oncology and Orphan Cancer Group. The views and opinions expressed therein are those of the authors and do not necessarily reflect those of the Systematic Reviews Programme, NIHR, National Health Service or the Department of Health, UK.

We acknowledge members of the Northern Ireland Cancer Consumer Forum for their comments and input into the lay summary.

We would like to thank our external peer reviewers, some of whom include Helen Bulbeck and Julia Day.

\section{R E F E R E N C E S}

\section{References to studies included in this review}

Campbell 2014 \{unpublished data only\}

Campbell KL, Kam JWY, Boyd LA, Handy TC, Lim H,

Hayden S, et al. Effect of exercise on cancer-associated cognitive dysfunction: a proof of concept RCT. American Society of Clinical Oncology. May 2014.

Ferguson 2012 \{published data only\}

Ferguson RJ, McDonald BC, Roque MA, Furstenburg CT, Horrigan S, Ahles TA, et al. Development of CBT for chemotherapy-related cognitive change: results of a waitlist control trial. Psycho-Oncology 2012;21(2):176-86.

Kesler 2013 \{published data only\}

Kesler S, Hadi Hosseini SM, Heckler C, Janelsins M, Palesh $\mathrm{O}$, Mustian $\mathrm{K}$, et al. Cognitive training for improving executive functioning in chemotherapy-treated breast cancer survivors. Clinical Breast Cancer 2013;13(4):299-306.

Milbury 2013 \{published data only\} Milbury K, Chaoul A, Biegler K, Wangyal T, Spelman A, Meyers CA, et al. Tibetan sound meditation for cognitive dysfunction: Results of a randomized controlled pilot trial. Psycho-Oncology 2013;22:2354-63.

Von Ah 2012 \{published data only\} Von Ah D, Carpenter JS, Saykin A, Monahan P, Wu J, Yu $\mathrm{M}$, et al. Advanced cognitive training for breast cancer survivors: a randomized controlled trial. Breast Cancer Research and Treatment 2012;135:799-809.

\section{References to studies excluded from this review}

Alvarez 2013 \{published data only\}

Alvarez J, Meyer FL, Granoff DL, Lundy A. The effect of EEG on reducing postcancer cognitive impairment. Integrative Cancer Therapies 2013;12:475-87.
Antony 2013 \{unpublished data only\}

Antony M. Relationship between exercise and cognitive functioning in breast cancer survivors following chemotherapy. WorldCat 2013.

Beatty 2010 \{published data only\} Beatty L, Oxlad M, Koczwara B, Wade TD. A randomised pilot of a self-help workbook intervention for breast cancer survivors. Supportive Care in Cancer 2010;18:1597-603.

Beebe 2014 \{published data only\} Beebe C. Effects of a twelve-week aerobic and cognitive training intervention on cognitive function in cancer survivors following radiation therapy. WorldCat 2014.

Bernstein 2012 \{published data only (unpublished sought but not used)\}

Bernstein L, Dissanayake D, Tirona KM, Nyhof-Young JM, Catton PA. Investigating the effectiveness of a psycho-educational behavioral intervention for cancerrelated cognitive dysfunction in women with breast and gynecological cancer: Knowledge, self-efficacy, and behavioral change. Cancer Research. 2012; Vol. 72.

Boesen 2005 \{published data only\}

Boesen EH, Ross L, Friederiksen K, Thomsen BL, Dahlstrøm K, Schmidt G, et al. Psychoeducational intervention for patients with cutaneous malignant melanoma: a replication study. Journal of Clinical Oncology 2005;23(6):1270-7.

Boesen 2011 \{published data only\}

Boesen EH, Karlsen R, Christensen J, Paaschburg B, Nielsen D, Bloch IS, et al. Psychosocial group intervention for patients with primary breast cancer: a randomised trial. European Journal of Cancer 2011;47:1363-72. 
Bollman 2008 \{unpublished data only\}

Bollman K. Nintendo DS brain age2 : a cognitive intervention against 'chemobrain' in breast cancer patients. WorldCat 2008

Cherrier 2013 \{published data only\} Cherrier MM, Anderson K, David D, Higano CS, Gray $\mathrm{H}$, Church $\mathrm{A}$, et al. A randomized trial of cognitive rehabilitation in cancer survivors. Life Sciences 2013;93: $617-22$.

Cherrier 2015 \{published data only\} Cherrier M, Askren MK, Anderson K, David D, Singh A, Murphy K, et al. Neural and behavioral response to cognitive training in cancer survivors with cognitive symptoms. Journal of the International Neuropsychological Society. 2015; Vol. 21:s293.

Cimprich 1993 \{published data only\} Cimprich B. Development of an intervention to restore attention in cancer patients. Cancer Nursing 1993;16: 83-92.

Cimprich 2003 \{published data only\} Cimprich B, Ronis DL. An environmental intervention to restore attention in women with newly diagnosed breast cancer. Cancer Nursing 2003;26:284-92.

Culos-Reed 2006 \{published data only\} Culos-Reed SN, Carlson LE, Daroux LM, Hately-Aldous S. A pilot study of yoga for breast cancer survivors: physical and psychological benefits. Psycho-Oncology 2006;15: 891-7.

Derry 2015 \{published data only\} Derry HM, Jaremka LM, Bennett JM, Peng J, Andridge R, Shapiro C, et al. Yoga and self-reported cognitive problems in breast cancer survivors: a randomized controlled trial. Psycho-Oncology 2015;24(8):958-66.

Dolbeault 2009 \{published data only\}

Dolbeault S, Cayrou S, Brédart A, Viala AL, SAltel P, Gauvain-Piquard A, et al. The effectiveness of a psychoeducational group after early-stage breast cancer treatment: results of a randomized French study. Psycho-Oncology 2009; 18:647-56.

Doorenbos 2006 \{published data only\}

Doorenbos A, Given B, Verbitsky N. Physical functioning effect of behavioral intervention for symptoms among individuals with cancer. Nursing Research 2006;55:161-71.

Duong 1997 \{unpublished data only\}

Duong DN. Evaluation of the self-help interventions program (ship): psychoeducational interventions for patients with breast cancer. WorldCat 1997.

Ercoli 2013 \{published data only\}

Ercoli LM, Castellon SA, Hunter AM, Kwan L, KahnMills BA, Cernin PA, et al. Assessment of the feasibility of a rehabilitation intervention program for breast cancer survivors with cognitive complaints. Brain Imaging and Behavior 2013;7:543-53.

Ercoli 2015 \{published data only\}

* Ercoli LM, Petersen L, Hunter AM, Castellon SA, Kwan L, Kahn-Mills BA, et al. Cognitive rehabilitation group intervention for breast cancer survivors: results of a randomized clinical trial. Psycho-Oncology 2015; Vol. Epub ahead of print.

Ferguson 2007 \{published data only\}

Ferguson RJ, Ahles TA, Saykin AJ, McDonald BC, Furstenberg CT. Cognitive-behavioural management of chemotherapy-related change. Psycho-Oncology 2007;16: 772-7.

Ferguson 2014 \{published and unpublished data\} Ferguson RF, La Brie S, Garrett AM. A randomized control trial of videoconference CBT for breast cancer survivors with cognitive dysfunction. International Cognition and Cancer Task Force conference proceedings. 2014.

Freeman 2015 \{published data only\}

Freeman LW, White R, Ratcliff CG, Sutton S, Stewart M, Palmer JL, et al. A randomized trial comparing live and telemedicine deliveries of an imagery-based behavioral intervention for breast cancer survivors: reducing symptoms and barriers to care. Psycho-Oncology 2015;24(8):910-8.

Galiano-Castillo 2013 \{published data only\} Galiano-Castillo N, Ariza-García A, Cantarero-Villanueva I, Fernández-Lao C, Díaz-Rodríguez L, Legerén-Alvarez M, et al. Telehealth system (e-CUIDATE) to improve quality of life in breast cancer survivors: rationale and study protocol for a randomized controlled trial. Trials 2013;14:187.

Goedendorp 2014 \{published data only\} Goedendorp MM, Knoop H, Gielissen MFM, Verhagen CAHHVM, Bleijenberg G. The effects of cognitive behavioral therapy for postcancer fatigue on perceived cognitive disabilities and test performance. Journal of Pain and Symptom Management 2014;47:35-44.

Gopinath 2011 \{published data only (unpublished sought but not used)\}

Gopinath SK, Rao RM, Sanjeevarao VH, Diwakar RB, Basavalingaiah AS, Patil S, et al. Effects of an integrated yoga program on mood states, distress, quality of life, diurnal cortisol rhythms and natural killer cell counts in metastatic breast cancer survivors. Cancer Research. 2011; Vol. 71.

Hartmann 2007 \{published data only\} Hartmann U, Muche R, Reuss-Borst M. Effects of a stepby-step inpatient rehabilitation programme on quality of life in breast cancer patients. A prospective randomised study. Onkologie 2007;30:177-82.

Hartmann 2014 \{published data only\} Hartmann S. Physical activity and neuropsychological outcomes in a cancer population. ClinicalTrials.gov 2014

Haynes 2013 \{published data only (unpublished sought but not used)\} Haynes S, Ryan E, Wood H, Fallon J, Cook E, Bolutayo K, et al. Rehabilitation of cognitive changes in breast cancer survivors. Psycho-Oncology. 2013; Vol. 22 (supplement 2) (abstract P2-35):115-116.

Hunter 2014 \{published data only\} Hunter AM, Kwan L, Ercoli LM, Mills BK, Cook IA, Ganz PA, et al. Quantitative electroencephalography biomarkers 
of cognitive complaints after adjuvant therapy in breast cancer survivors: a pilot study. Psycho-Oncology 2014;23(6): $713-5$.

Janelsins 2012b \{published data only (unpublished sought but not used)\}

Janelsins MC, Peppone LJ, Heckler CE, Sprod L, Mohile $\mathrm{SG}$, Chandwani KD, et al. YOCAS yoga, fatigue, memory difficulty, and quality of life: Results from a URCC CCOP randomized, controlled clinical trial among 358 cancer survivors. Journal of Clinical Oncology. 2012; Vol. 30 (abstract 9142).

\section{Johns 2015 \{published data only\}}

Johns SA, Von Ah D, Brown LF, Beck-Coon K, Talib TL, Alvea JM, et al. Randomized controlled pilot trial of mindfulness-based stress reduction for breast and colorectal cancer survivors: effects on cancer-related cognitive impairment. Journal of Cancer Survivorship 2015; Vol. Epub ahead of print.

\section{Johnston 2011 \{published data only\}}

Johnston MF, Hays RD, Subramanian SK, Elashoff RM, Axe EK, Li JJ, et al. Patient education integrated with acupuncture for relief of cancer-related fatigue randomized controlled feasibility study. BMC Complementary and Alternative Medicine 2011;11:49.

Kervick 2005 \{published data only (unpublished sought but not used)\} Kervick R, Kaemingk KL. Assessing the efficacy of a cognitive intervention for breast and colon cancer survivors. Psycho-Oncology. 2005; Vol. 14:S31.

Kim 2008 \{published data only (unpublished sought but not used)\} Kim S, Stasio C, Spina LM, Tinker DE, Mahncke HW. Enhanced quality of life in individuals with "chemobrain" after using a brain-plasticity-based training program. International Psycho-Oncology Society 2008.

King 2015 \{published data only\}

King S, Green H. Group psychological intervention for improving cognitive function in cancer survivors: a randomized controlled trial. Frontiers in Oncology 2015;5: 72 .

Kolidas 2012 \{published data only (unpublished sought but not used)\} Kolidas EA. Impact of yoga on cognitive function among an ethnically diverse sample of breast cancer patients. WorldCat dissertations.

Korstjens 2006 \{published data only\} Korstjens I, Mesters I, van der Peet E, Gijsen B, van den Borne B. Quality of life of cancer survivors after physical and psychosocial rehabilitation. European Journal of Cancer Prevention 2006;15:541-7.

Korstjens 2011 \{published data only\} Korstjens I, Mesters I, May AM, van Weert E, van den Hout JHC, Ros W, et al. Effects of cancer rehabilitation on problem-solving, anxiety and depression: A RCT comparing physical and cognitive-behavioural training versus physical training. Psychology and Health 22011;26: $63-82$.
Larkey 2015 \{published data only (unpublished sought but not used)\} Larkey LK, Roe DJ, Weihs KL, Jahnke R, Lopez AM, Rogers CE, et al. Randomized controlled trial of Qigong/ Tai Chi easy on cancer-related fatigue in breast cancer survivors. Annals of Behavioral Medicine 2015; Vol. 49, issue $2: 165-76$

Lee 2012a \{published data only\} Lee CE, Kilgour A, Lau YKJ. Efficacy of walking exercise in promoting cognitive-psychosocial functions in men with prostate cancer receiving androgen deprivation therapy. BMC Cancer 2012;12:324.

Lee 2012b \{published data only\} Lee CE, Leslie WD, Lau YKJ. A pilot study of exercise in men with prostate cancer receiving androgen deprivation therapy. BMC Cancer 2012;12:103.

Lengacher 2012 \{published data only\} Lengacher CA, Reich RR, Post-White J, Moscoso M, Shelton MM, Barta M, et al. Mindfulness based stress reduction in post-treatment breast cancer patients: an examination of symptoms and symptoms clusters. Journal of Behavioral Medicine 2012;35:86-94.

Lengacher 2015 \{published data only\} Lengacher C, Reich R, Ramesar S, Paterson C, Moscoso $\mathrm{M}$, Alinat $\mathrm{C}$, et al. A pilot study of subjective cognitive functioning following the mobile mindfulness-based stress reduction for breast cancer (mMBSR(BC)) survivors program. Psycho-Oncology. 2015.

Lesiuk 2015 \{published data only\} Lesiuk T. The effect of mindfulness-based music therapy on attention and mood in women receiving adjuvant chemotherapy for breast cancer: a pilot study. Oncology Nursing Forum 2015;42:276-82.

Luctkar-Flude 2015 \{published data only\} Luctkar-Flude M, Groll D. A systematic review of the safety and effect of neurofeedback on fatigue and cognition. Integrated Cancer Therapies 2015;14(4):318-40.

McDougall 2001 \{published data only\} McDougall GJ. Memory improvement program for elderly cancer survivors. Geriatric Nursing 2001;22(4):185-90.

\section{McDougall 2011 \{published data only\}} McDougall GJ, Becker H, Acee TW, Vaughan PW, Delville CL. Symptom management of affective and cognitive disturbance with a group of cancer survivors. Archives of Psychiatric Nursing 2011;25(1):24-35.

Mehnert 2011 \{published data only\} Mehnert A, Veers S, Howaldt D, Braumann K, Koch U, Schulz K. Effects of a physical exercise rehabilitation group program on anxiety, depression, body image, and health-related quality of life among breast cancer patients. Onkologie 2011;34:248-53.

\section{Mendoza 2015 \{published data only\}} Mendoza HJ, Gray HJ, Felleman DD, Murphy B, Singh $\mathrm{KM}$, Anderson A. Attention concerns of cancer survivors participating in a cognitive training intervention. Journal of 
the International Neuropsychological Society. 2015; Vol.

21:s270.

Miki 2014 \{published data only\}

Miki E, Kataoka T, Okamura H. Feasibility and efficacy of speed-feedback therapy with a bicycle ergometer on cognitive function in elderly cancer patients in Japan. Psycho-Oncology 2014;23:906-13.

Oh 2012 \{published data only\}

Oh B, Butow PN, Mullan BA, Clarke SJ, Beale PJ, Pavlakis N. Effect of medical Qigong on cognitive function, quality of life, and a biomarker of inflammation in cancer patients: a randomized controlled trial. Supportive Care in Cancer 2012;20:1235-42.

Penedo 2003 \{published data only\}

Penedo FJ, Dahn JR, Molton I, Gonzalez JS, Kinsinger D, Roos BA, et al. Cognitive-behavioral stress management improves stress-management skills and quality of life in men recovering from treatment of prostate carcinoma. Cancer 2004; 100:192-200.

Peterson 2015 \{published data only\}

Peterson, BM. Effects of a twelve-week aerobic and cogntive training intervention on cognitive function in cancer survivors. WorldCat 2015.

Poppelreuter 2008 \{published data only\} Poppelreuter M, WEis J, Mumm A, Orth HB, Bartsch $\mathrm{HH}$. Rehabilitation of therapy-related cognitive deficits in patients after hematopoietic stem cell transplantation. Bone Marrow Tranplantation 2008;41:79-90.

Poppelreuter 2009 \{published data only\} Poppelreuter M, Weis J, Bartsch HH. Effects of specific neuropsychological training programs for breast cancer patients after adjuvant chemotherapy. Journal of Psychosocial Oncology 2009;27:274-96.

Rea 2011 \{published data only (unpublished sought but not used)\} Rea HL. The effects of mindfulness training and mild exercise on symptoms and quality of life in female cancer survivors. WorldCat dissertations 2011.

Rottmann 2012 \{published data only\} Rottmann N, Dalton SO, Bidstrup PE, Würtzen H, Høybye MT, Ross L, et al. No improvement in distress and quality of life following psychosocial cancer rehabilitationL a randomised trial. Psycho-Oncology 2012;21:505-14.

Rummans 2006 \{published data only\} Rummans TA, Clark MM, Sloan JA, Frost MH, Bostwick $\mathrm{JM}$, Atherton PJ, et al. Impacting quality of life for patients with advanced cancer with a structured multidisciplinary intervention: a randomized controlled trial. Journal of Clinical Oncology 2006;24:635-42.

Schuurs 2013 \{published data only\}

Schuurs A, Green HJ. A feasibility study of group cognitive rehabilitation for cancer survivors: enhancing cognitive function and quality of life. Psycho-Oncology 2013;22: $1043-9$.

Singh 2014 \{published data only\}

Singh A, Cherrier M, Askren MK, Gray H, Anderseon K, David D, et al. Impact of age on response to a cognitive rehabilitation intervention. International Cognition and Cancer Task Force conference proceedings 2014.

Srivastava 2015 \{published data only\}

Srivastava J, Kaushik, S, Shukla H. Effect of yoga on ppost-chemotherapy cognitive impairment in breast cancer patients: a systematic review. Psycho-Oncology 2015;34: 272-3.

Steindorf 2014 \{published data only\}

Steindorf K, Schmidt ME, Klassen O, Ulrich CM, Oelmann J, Habermann N, et al. Randomized, controlled trial of resistance training in breast cancer patients receiving adjuvant radiotherapy: results on cancer-related fatigue and quality of life. Annals of Oncology 2014;25:2237-43.

Vadiraja 2009 \{published data only\} Vadiraja HS, Rao MR, Nagarathna R, Nagendra HR, Rekha $M$, Vanitha N, et al. Effects of yoga program on quality of life and affect in early breast cancer patients undergoing adjuvant radiotherapy: a randomized controlled trial. Complementary Therapies in Medicine 2009;17:274-80.

Weis 2009 \{published data only\}

Weis J, Poppelreuter M, Bartsch HH. Cognitive deficits as long-term side-effects of adjuvant therapy in breast cancer patients: 'subjective' complaints and 'objective' neuropsychological test results. Psycho-Oncology 2009;18: $775-82$.

Weis 2011 \{published data only\}

Weis J, Poppelreuter M, Bartsch HH. Rehabilitation of therapy-related cognitive deficits in patients with breast cancer. Psicooncologia 2011;8:371-84.

Winters-Stone 2011 \{published data only\} Winters-Stone KM, Dobek J, Nail L, Bennett JA, Leo MC, Naik A, et al. Strength training stops bone loss and builds muscle in post-menopausal breast cancer survivors: a randomized controlled trial. Breast Cancer Research Treatment 2011;127:447-56.

Winters-Stone 2013 \{published data only\} Winters-Stone KM, Dobek J, Nail L, Bennett JA, Leo $\mathrm{MC}$, Torgrimson-Ojerio $\mathrm{B}$, et al. Impact and resistance training improve bone health and body composition in pre-menopausal breast cancer survivors: a randomized controlled trial. Osteoporosis International 2013;24: 1637-46.

Winters-Stone 2014a \{published data only\} Winters-Stone KM, Bennett JA, Naill LM, Luoh SWL. Strength training lessens self-reported memory problems among breast cancer survivors. International Cognition and Cancer Task-Force. 2014.

Winters-Stone 2014b \{published data only\} Winters-Stone KM, Laudermilk M, Woo K, Brown JC, Schmitz KH. Influence of weight training on skeletal health of breast cancer survivors with or at risk of breast cancerrelated lymphedema. Journal of Cancer Survivorship 2014;8: 260-8.

Wu 2014 \{published data only\}

Wu LM, Diefenbach MA, Tanenbaum M, Herbert K. Computerized cognitive training program for prostate 
cancer patients: Preliminary results from an ongoing feasibility study. International Cognition and Cancer Task Force conference proceedings. 2014.

\section{References to ongoing studies}

Cohen 2014 \{unpublished data only\}

Cohen L. Effects of meditation on cognitive function and quality of life. ClinicalTrials.gov 2014.

Damholdt 2013 \{unpublished data only\} Damholdt MF. Internet- -delivered cognitive training for breast cancer survivors with cognitive complaints. WHO Trials register.

Dhillon 2012 \{unpublished data only\}

Dhillon H. Cognitive rehabilitation for breast cancer survivors with perceived cognitive impairment. WHO trials register 2012.

\section{Gokal 2012 \{unpublished data only\}}

Gokal K. Can physical activity enhance emotion, memory, attention and concentration in breast cancer patients receiving chemotherapy?. WHO trials register 2012. Gokal K, Munir F, Wallis D, Ahmed S, Boiangiu I, Kancherla K. Can physical activity help to maintain cognitive functioning and psychosocial wellbeing among breast cancer patients treated with chemotherapy? A randomised controlled trial: study protocol. BMC Public Health 2015;15:414.

Gray 2014 \{unpublished data only\}

Gray H. Memory and thinking skills workshop in improving cognitive rehabilitation in gynecologic and breast cancer survivors. National Cancer Institute Trials Registry 2014.

Green \{unpublished data only\}

Green. Randomized controlled trial comparing a web-based version of the Responding to Cognitive Concerns ( $\mathrm{ReCog}$ ) cognitive-behavioural intervention to waitlist for subjective and objective cognitive functioning in cancer survivors. WHO Trials.

Joly-Lobbedez 2013 \{unpublished data only\}

Joly-Lobbedez F. Cancer and disorders of cognitive functions and quality of life: "Cognitive Rehabilitation in Patients Suffering From Cancer and Treated With Chemotherapy". WHO trials register 2013.

Kesler \{unpublished data only\}

Kesler S. Cognitive enhancement program in improving cognitive function in breast cancer survivors. WHO trials register 2013.

Matthews 2007 \{published data only (unpublished sought but not used)\}

Matthews CE. The activity intervention for chemobrain. WHO trials register 2007.

\section{Myers \{unpublished data only\}}

Myers. Emerging From the Haze ${ }^{\mathrm{TM}}$ - Measuring the impact of a psycho-education program on perceived cognition after breast cancer treatment. ClinicalTrials.gov 2015.
Niedeggen 2009 \{published data only (unpublished sought but not used)\}

Niedeggen M. Cognitive training to improve cognitive function following chemotherapy. WHO trials register 2009.

Ryan 2010 \{published data only (unpublished sought but not used)\} Ryan E. Rehabilitation of working memory in breast cancer survivors post-chemotherapy. WHO trials register 2010.

Vardy 2009 \{published data only\}

Evaluation of a web-based cognitive rehabilitation programme in cancer survivors with self reported cognitive impairment. WHO Trials Register 2009.

\section{Additional references}

\section{Addington 1995}

Addington-Hall J, McCarthy M. Dying from cancer: results of a national population-based investigation. Palliative Medicine 1995;95:295-305.

\section{Ahles 2002}

Ahles TA, Saykin AJ, Furstenberg CT, Cole B, Mott LA, Skalla K, et al. Neuropsychologic impact of standard-dose systemic chemotherapy in long-term survivors of breast cancer and lymphoma. Journal of Clinical Oncology 2002; 20:485-93.

Ahles 2007

Ahles TA, Saykin AJ. Candidate mechanisms for chemotherapy-induced cognitive changes. National Review of Cancer 2007;7:194-202.

Ahles 2012

Ahles TA, Root JC, Ryan EL. Cancer and cancer treatmentassociated cognitive change: an update on the state of the science. Journal of Clinical Oncology 2012;30:3675-86.

\section{Argyriou 2010}

Argyriou AA, Assimakopoulos K, Iconomou G, Giannakopoulou F, Kalofonos HP. Either called "chemobrain" or "chemofog", the long-term chemotherapyinduced cognitive decline in cancer survivors is real. Journal of Pain and Symptom Management 2010;41:126-39.

Bahar-Fuchs 2013

Bahar-Fuchs A, Clare L, Woods B. Cognitive training and cognitive rehabilitation for mild to moderate Alzheimer's disease and vascular dementia. Cochrane Database of Systematic Reviews 2013, Issue 6. [DOI: 10.1002/ 14651858.CD003260.pub2]

Bender 2001

Bender CM, Paraska KK, Sereika SM, Ryan CM, Berga SL. Cognitive function and reproductive hormones in adjuvant therapy for breast cancer: a critical review. Journal of Pain and Symptom Management 2001;21:407-24.

\section{Bower 2008}

Bower JE. Behavioral symptoms in patients with breast cancer and survivors. Journal of Clinical Oncology 2008;26: $768-77$.

\section{Calamia 2012}

Calamia M, Markon K, Tranel D. Scoring higher the second time around: meta-analyses of practice effects in 
neuropsychological assessment. Clinical Neuropsychologist 2012;26:543-70.

\section{Castellino 2014}

Castellino SM, Ullrich NJ, Whelon MJ, Lange BJ. Developing interventions for cancer-related cognitive dysfunction in childhood cancer survivors. Journal of the National Cancer Institute 2014;106:1-16.

\section{Chan 2015}

Chan RJ, McCarthy, AL, Devenish J, Sullivan KA, Chan A. Systematic review of pharmacological and nonpharmacological interventions for cognitive alternations after chemotherapy for breast cancer. European Journal of Cancer 2015;51:437-50.

\section{Cheung 2012}

Cheung YT, Chui WK, Chan A. Neuro-cognitive impairment in breast cancer patients: Pharmacological considerations. Critical review in Oncology/Hematology 2012;83:99-111.

\section{Chung 2013}

Chung CSY, Pollock A, Campbell T, Durward BR, Hagen S. Cognitive rehabilitation for executive dysfunction in adults with stroke or other adult non-progressive acquired brain damage. Cochrane Database of Systematic Reviews 2013, Issue 4. [DOI: 10.1002/14651858.CD008391.pub2]

\section{Coleman 2011}

Coleman MP, Forman D, Bryant H, Butler J, Rachet B, Maringe C, et al. Cancer survival in Australia, Canada, Denmark, Norway, Sweden and the UK, 1995-2007 (the International Cancer Benchmarking Partnership): an analysis of population-based cancer registry data. Lancet 2011;377:127-38.

\section{Conroy 2013}

Conroy SK, McDonald BC, Smith DJ. Alternations in brain structure and function in breast cancer survivors: Effect of post-chemotherapy interval and relation to oxidative DNA damage. Breast Cancer Research and Treatment 2013;137: 493-502.

\section{Craig 2014}

Craig CD, Monk BJ, Farley JH, Chase DM. Cognitive impairment in gynecologic cancers: a systematic review of current approaches to diagnosis and treatment. Supportive Care in Cancer 2014;22:279-87.

das Nair 2007

das Nair R, Lincoln N. Cognitive rehabilitation for memory deficits following stroke. Cochrane Database of Systematic Reviews 2007, Issue 3. [DOI: 10.1002/ 14651858.CD002293.pub2]

das Nair 2012

das Nair R, Ferguson H, Stark DL, Lincoln NB. Memory rehabilitation for people with multiple sclerosis. Cochrane Database of Systematic Reviews 2012, Issue 3. [DOI: 10.1002/14651858.CD008754.pub2]

Day 2014

Day J, Zienius K, Gehring K, Grosshans D, Taphoorn $\mathrm{M}$, Grant $\mathrm{R}$, et al. Interventions for preventing and ameliorating cognitive deficits in adults treated with cranial irradiation. Cochrane Database of Systematic Reviews 2014, Issue 12. [DOI: 10.1002/14651858.CD011335.pub2]

\section{DerSimonian 1986}

DerSimonian R, Laird N. Meta-analysis in clinical trials. Controlled Clinical Trials 1986;7:177-88.

\section{Fardell 2011}

Fardell JE, Vardy J, Johnston IN, Winocur G. Chemotherpay and cognitive impairment: Treatment options. Clinical Pharmacology and Therapeutics 2011;90: 366-74.

\section{Ganz 2001}

Ganz PA. Late effects of cancer and its treatment. Seminars of Oncology Nursing 2001;17:241-8.

\section{Ganz 2012}

Ganz PA. "Doctor, will the treatment you are recommending cause chemobrain?”. Journal of Clinical Oncology 2012;30: 229-31.

\section{Gehring 2008}

Gehring K, Sitskoorn MM, Aaronson NK, Taphaorn MJB. Interventions for cognitive deficits in adults with brain tumours. Lancet Neurology 2008;7:548-60.

\section{Gehring 2010}

Gehring K, Aaronson NK, Taphoorn MJ, Sitskoorn MM. Interventions for cognitive deficits in patients with a brain tumor: an update. Expert Review of Anticancer Therapy 2010;10:1779-95.

\section{Gehring 2012}

Gehring K, Roukema JA, Sitskoorn MM. Review of recent studies on interventions for cognitive deficits in patients with cancer. Expert Reviews of Anticancer Therapy 2012;12: 255-69.

\section{Green 2005}

Green HJ, Packenham KI, Gardiner RA. Cognitive deficits associated with cancer: A model of subjective and objective outcomes. Psychology, Health \& Medicine 2005;10:145-60.

\section{Gross-King 2008}

Gross-King M, Booth-Jones M, Couluris M. Neurocognitive impairment in children treated for cancer: how do we measure cognitive outcomes?. Journal of Pediatric Oncology Nursing 2008;25:227-32.

\section{Harrington 2010}

Harrington CB, Hansen JA, Moskowitz M, Todd BL, Feuerstein M. It's not over when it's over: long-term symptoms in cancer survivors - a systematic review. International Journal of Psychiatric Medicine 2010;40: 163-81.

Hess 2007

Hess LM, Insel KC. Chemotherapy-related change in cognitive function: a conceptual model. Oncology Nursing Forum 2007;34:981-94.

\section{Higgins 2011}

Higgins JPT, Green S (editors). Cochrane Handbook for Systematic Reviews of Interventions Version 5.1.0 [updated 
March 2011]. The Cochrane Collaboration, 201. Available from www.cochrane-handbook.org.

\section{Hines 2014}

Hines S, Ramis MA, Pike S, Chang AM. The effectiveness of psychosocial interventions for cognitive dysfunction in cancer patients who have received chemotherapy: a systematic review. Worldviews on Evidence-Based Nursing 2014;11:187-93.

\section{Hodges 2011}

Hodges LJ, Walker J, Kleiboer AM, Ramirez AJ, Richardson A, Velikova G, et al. What is a psychological intervention? A metareview and practical proposal. Psycho-Oncology 2011; 20:470-8.

\section{Horsley 2011}

Horsley T, Dingwall O, Sampson M. Checking reference lists to find additional studies for systematic reviews. Cochrane Database of Systematic Reviews 2011, Issue 8. [DOI: 10.1002/14651858.MR000026.pub2]

Imayama 2013

Imamaya I, Alfano CM, Neuhouser ML, George SM, Wilder Smith A, Baumgartner RN, et al. Weight, inflammation, cancer-related symptoms and health-related quality of life among breast cancer survivors. Breast Cancer Research and Treatment 2013;140:159-76.

\section{Janelsins 2012a}

Janelsins MC, Mustian KM, Palesh OG, Mohile SG, Peppone LJ, Sprod LK, et al. Differential expression of cytokines in breast cancer patients receiving different chemotherapies: Implications for cognitive impairment research. Supportive Care in Cancer 2012;20:831-9.

\section{Janelsins 2014}

Janelsins MC, Kesler SR, Ahles TA, Morrow GR. Prevalence, mechanisms, and management of cancer-related cognitive impairment. International Review of Psychiatry 2014;26:102-13.

Jansen 2005

Jansen CE, Miaskowski C, Dodd M, Dowling G, Kramer $\mathrm{J}$. A meta-analysis of studies of the effects of cancer chemotherapy on various domains of cognitive function. Cancer 2005; 104:2222-33.

\section{Joshi 2005}

Joshi G, Sultana R, Tangpong J, Cole MP, St Clair DK, Vore $\mathrm{M}$, et al. Free radical mediated oxidative stress and toxic side effects in brain induced by the anti cancer drug adriamycin: insight into chemobrain. Free Radical Research 2005;39:1147-54.

Koppelmans 2012

Koppelmans V, Breteler MM, Boogerd W, Seynaeve C, Gundy C, Schagen SB. Neuropsychological performance in survivors of breast cancer more than 20 years after adjuvant chemotherapy. Journal of Clinical Oncology 2012;30: $1080-6$.

Kvale 2009

Kvale EA, Clay OJ, Ross-Meadows LA, McGee JS, Edwards JD, Unverzagt FW, et al. Cognitive speed of processing and functional declines in older cancer survivors: an analysis of data from the ACTIVE trial. European Journal of Cancer Care 2009;19:110-7.

Lange 2014

Lange M, Rigal O, Clarisse B, Giffard B, Sevin E, Barillet $M$, et al. Cognitive dysfunctions in elderly cancer patients: A new challenge for oncologists. Cancer Treatment Reviews 2014;40:810-7.

\section{Loetscher 2013}

Loetscher T, Lincoln NB. Cognitive rehabilitation for attention deficits following stroke. Cochrane Database of Systematic Reviews 2013, Issue 5. [DOI: 10.1002/ 14651858.CD002842.pub2]

\section{Martin 2011}

Martin M, Clare L, Altgassen AM, Cameron MH, Zehnder F. Cognition-based interventions for healthy older people and people with mild cognitive impairment. Cochrane Database of Systematic Reviews 2011, Issue 1. [DOI: 10.1002/14651858.CD006220.pub2]

\section{McDougall 2014}

McDougall GJ Jr, Oliver JS, Scogin F. Memory and cancer: a review of the literature. Archives of Psychiatric Nursing 2014;28:180-6.

\section{McGrath 2000}

McGrath J, Hayes RL. Cognitive rehabilitation for people with schizophrenia and related conditions. Cochrane Database of Systematic Reviews 2000, Issue 3. [DOI: 10.1002/14651858.CD000968]

\section{Merriman 2013}

Merriman JD, Von Ah D, Miaskowski C, Aouizerat BE. Proposed mechanisms for cancer- and treatment-related cognitive changes. Seminars in Oncology Nursing 2013;29: 260-9.

\section{Michie 2013}

Michie S, Richardson M, Johnston M, Abraham C, Francis J, Hardeman W, et al. The behavior change technique taxonomy (v1) of 93 hierarchically clustered techniques: Building an international consensus for the reporting of behavior change interventions. Annals of Behavioral Medicine 2013;46:81-95.

\section{Myers 2013}

Myers JS. Cancer- and chemotherapy-related cognitive changes: the patient experience. Seminars in Oncology Nursing 2013;29:300-7.

\section{Nelson 2007}

Nelson CJ, Nandy N, Roth AJ. Chemotherapy and cognitive deficits: mechanisms, findings and, potential interventions. Palliative and Supportive Care 2007;5: 273-80.

\section{Nelson 2008}

Nelson CJ, Lee JS, Gamboa MC, Roth AJ. Cognitive effects of hormone therapy in men with prostate cancer: a review. Cancer 2008;113:1097-106. 


\section{Raffa 2011}

Raffa RB. A proposed mechanism for chemotherapy-related cognitive impairment ('chemo-fog'). Journal of Pharmacy and Therapeutics 2011;36:257-9.

\section{Review Manager 2014 [Computer program]}

The Nordic Cochrane Centre, The Cochrane Collaboration. Review Manager (RevMan). Version 5.3. Copenhagen: The Nordic Cochrane Centre, The Cochrane Collaboration, 2014.

\section{Rosti-Otajärvi 2014}

Rosti-Otajärvi EM, Hämäläinen PI. Neuropsychological rehabilitation for multiple sclerosis. Cochrane Database of Systematic Reviews 2014, Issue 2. [DOI: 10.1002/ 14651858.CD009131.pub3]

\section{Scherling 2013}

Scherling CS, Smith A. Opening up the window into "chemobrain": a neuroimaging review. Sensors 2013;13: 3169-203.

\section{Simó 2013}

Simó M, Rifa-Ros X, Rodriquez-Fornells A, Bruna J. Chemobrain: A systematic review of structural and functional neuroimaging studies. Neuroscience and Biobehavioral Reviews 2013;37:1311-21.

\section{Stein 2008}

Stein KD, Syrjala KL, Andrykowski MA. Physical and psychological long-term and late effects of cancer. Cancer Supplement 2008;112:2577-92.

\section{Treanor 2013}

Treanor C, Santin O, Mills M, Donnelly M. Cancer survivors with self-reported late effects: Their health status, care needs and service utilisation. Psycho-oncology 2013;22: 2428-35.

\section{Treanor 2014}

Treanor C, Donnelly M. Late effects of cancer and cancer treatment- a rapid review. Journal of Community and Supportive Oncology 2014; Vol. 12:137-48.

\section{Vardy 2008}

Vardy J, Wefel T, Ahles T, Tannock IF, Shagen SF. Cancer and cancer-therapy related cognitive dysfunction: an international perspective from the Venice cognitive workshop. Annals of Oncology 2008;19(4):623-9.

\section{Vodermaier 2009}

Vodermaier A. Breast cancer treatment and cognitive function: the current state of evidence, underlying mechanisms and potential treatments. Women's Health 2009;5:503-16.

\section{Von Ah 2013}

Von Ah D, Storey S, Jansen CE, Allen DA. Coping strategies and interventions for cognitive changes in patients with cancer. Seminars in Oncology Nursing 2013;29:288-99.

\section{Von Ah 2011}

Von Ah D, Jansen C, Hutchinson AD, Schiavone RM. Putting evidence into practice: evidence-based interventions for cancer and cancer treatment-related cognitive impairment. Clinical Journal of Oncology Nursing 2011;15:607-15.

\section{Von Ah 2014}

Von Ah D, Jansen CE, Allen DH. Evidence-based interventions for cancer- and treatment-related cognitive impairment. Clinical Journal of Oncology Nursing 2014;18: $17-25$.

\section{Wefel 2011}

Wefel JS, Vardy J, Ahles T, Schagen SB. International Cognition and Cancer Task Force recommendations to harmonise studies of cognitive function in patients with cancer. Lancet Oncology 2011;12:703-8.

* Indicates the major publication for the study 


\title{
CHARACTERISTICS OF STUDIES
}

\section{Characteristics of included studies [ordered by study ID]}

\author{
Campbell 2014
}

Methods

Participants
Randomised controlled trial

Intention-to-treat analysis: ITT was undertaken as no participants were missing postintervention

Loss to follow-up: numbers and reasons (partially) reported in flowchart

\begin{tabular}{|c|c|}
\hline Participants & $\begin{array}{l}\text { Inclusion Criteria } \\
\text { Females, postmenopausal, aged } 40-65 \text { years old diagnosed with stages I-IIIA breast cancer } \\
\text { who have received chemotherapy at least three-months previously and had completed } \\
\text { all treatment within the last three years, currently using hormonal therapies who were } \\
\text { reporting cognitive changes since chemotherapy receipt and who were undertaking less } \\
\text { than } 90 \text { minutes of physical activity per week in the last } 6 \text { months and who were physically } \\
\text { able to undertake moderate to vigorous physical activity } \\
\text { Exclusion Criteria } \\
\text { Self-report of greater than } 90 \text { minutes per week of moderate physical activity within the } \\
\text { last } 6 \text { months, or a MMSE score less than } 23 \text { or a co-morbid condition which may alter } \\
\text { cognitive testing results (i.e. a clinically diagnosed major depression, anxiety disorder, or } \\
\text { other psychiatric condition, meeting DSM IV criteria) or history of substance abuse or } \\
\text { other neurological disorder (i.e. head injury, epilepsy, tumour, neurodegenerative disease) } \\
\text { or ruled ineligible for fMRI scanning (i.e. metal implants) } \\
\text { Randomisation method: Sequentially numbered opaque envelopes, based on a ran- } \\
\text { domisation schedule prepared by a research. assistant not involved with the study using } \\
\text { varying blocks of } 4 \text { to } 6 \\
\text { No. of participants: } 19 \text { (I: } 10 \text {; C: } 9 \text { ) } \\
\text { Cancer site(s): Breast stages I-IIIA } \\
\text { Age: I: mean=53.2 (SD = 5.1); C: } 51.4 \text { (SD = } 7.0) \\
\text { Sex: Female } \\
\text { Treatment history: All patients received chemotherapy and had completed treatment } \\
\text { within the last three years. All participants were currently receiving hormonal treatments } \\
\text { Co-morbidities: None reported. } \\
\text { Education: Some college are or less (I: } 3 \text { ( } 30 \%) / \text { C: } 3 \text { ( } 33 \%) \text { ); College graduate (I: } 4 \\
\text { ( } 40 \% \text { ) C: } 5 \text { ( } 56 \% \text { ); Post-college graduate or above (I: } 3 \text { ( } 30 \% \text { ); C: } 1 \text { ( } 11 \%) \text { ) } \\
\text { Socio-economic status: None reported. } \\
\text { Cognitive impairment at baseline: Participants had to self-report persistent cognitive } \\
\text { changes following chemotherapy } \\
\text { Country: Canada }\end{array}$ \\
\hline
\end{tabular}

Interventions
Definition: Aerobic exercise intervention

To assess the effectiveness of the intervention on cancer-related cognitive function and QoL

Duration: 24 weeks, progressively increased with expectation to rest full exercise prescription by week 8 . Participants were required to attend two 45 -minute supervised sessions and two independent 30-minute sessions at home, per week

Components: Aerobic exercise (150 minutes/week of aerobic exercise at $60 \%$ to $70 \%$ of heart rate reserve- individualised based on baseline VO2 peak test), including supervised 
sessions and home sessions

\section{Techniques}

Goal setting: all participants to reach full exercise prescription by week 8

Graded tasks: all participants to reach full exercise prescription by week 8

Generalisation of a target behaviour: to transfer exercise from supervised sessions to home

Instruction on how to perform behaviour: supervised sessions

Demonstration of the behaviour: supervised sessions

Materials: None reported

Setting: Supervised setting (no details of where) and independent, home-based sessions

Therapist/training: Not reported

Theoretical basis/mechanism: None reported

Comparison group: Delayed exercise group

Assessed at baseline and post-intervention

Subjective cognitive functioning: *FACT-Cog (version 3) 4 domains: Perceived cognitive impairments; Impact on QoL; Comments of others; Perceived cognitive abilities Objective cognitive functioning: ${ }^{* *}$ Stroop test to assess attention and processing speed; Hopkin's Verbal Learning Test (total recall; delayed recall; retention and; delayed recognition index) to assess memory and learning; COWAT " $F$ " " $A$ " " $S$ " word and animal naming to assess verbal fluency; Trail Making Test (trials A, trials B and trials difference) to assess processing speed and executive functioning

Adherence: None reported

Safety issues: None reported

Adverse effects: None reported

${ }^{*}$ Appears to be the primary outcome in the Conference poster.

** Stated as primary outcome on protocol on trial register.

$\mathrm{I}=9 / \mathrm{C}=7$ of the participants underwent $\mathrm{fMRI}$ tests whilst being administered the Stroop Task at baseline and post-intervention

Objective measures were selected based on recommendations by the International Cancer and Cognition Task Force

\section{Risk of bias}

\begin{tabular}{|c|c|c|}
\hline Bias & Authors' judgement & Support for judgement \\
\hline $\begin{array}{l}\text { Random sequence generation (selection } \\
\text { bias) }\end{array}$ & Low risk & $\begin{array}{l}\text { "Individuals were randomized using se- } \\
\text { quentially numbered opaque envelopes, us- } \\
\text { ing varying blocks of } 4-6 \text { " (Author corre- } \\
\text { spondence) }\end{array}$ \\
\hline Allocation concealment (selection bias) & Low risk & $\begin{array}{l}\text { "Prepared by a research assistant not in- } \\
\text { volved with the study" (Author correspon- } \\
\text { dence) }\end{array}$ \\
\hline
\end{tabular}

Blinding of participants and personnel Low risk (performance bias)

Unable to blind participants to a physical All outcomes activity intervention 


\section{Campbell 2014 (Continued)}

\author{
Blinding of outcome assessment (detection Low risk \\ bias)
}

Objective outcomes

Incomplete outcome data (attrition bias) Low risk All outcomes
Neuropsychological test measurements were undertaken by a trained tester. Information about trial on clinicaltrials.gov indicates that outcome assessors were blinded

All participants accounted for throughout study, however, not all participants completed fMRI assessment at end of the study and reasons for non-completion were not accounted for. Nevertheless the results from the $\mathrm{fMRI}$ are not reported in this review

All outcomes are reported.

\begin{tabular}{lll}
\hline Selective reporting (reporting bias) & Low risk & All outcomes are reported.
\end{tabular}

Baseline imbalances in cognition scores Unclear risk

None reported.

Objective outcomes

Baseline imbalances in cognition scores Unclear risk

None reported.

Subjective outcomes

Validity of cognitive function measures Low risk

Objective outcomes

Based on International Cognition and Cancer Task Force recommendation, measures with good psychometric properties for non-CNS cancers

Validity of cognitive function measures Unclear risk None reported.

Subjective outcomes

Reliability of cognitive function measures Low risk

Objective outcomes

Based on International Cognition and Cancer Task Force recommendation- measures with good psychometric properties for non-CNS cancers

Reliability of cognitive function measures Unclear risk None reported.

Subjective outcomes

Ferguson 2012

\begin{tabular}{ll} 
Methods & $\begin{array}{l}\text { Randomised controlled trial } \\
\text { Intention-to-treat analysis: ITT was undertaken using linear interpolation methods } \\
\text { used to infer missing data to maintain power for the analysis } \\
\text { Lost to follow-up: numbers reported in flowchart and reasons reported in text }\end{array}$ \\
\hline Participants & $\begin{array}{l}\text { Inclusion criteria } \\
\text { Females at least } 18 \text { years of age diagnosed with stages I-II breast cancer, at least } 18 \text { months } \\
\text { post-treatment and currently disease-free with previous chemotherapy receipt with self- } \\
\text { reported problems with memory or attention following chemotherapy and who were } \\
\text { able to speak and read English }\end{array}$ \\
\hline
\end{tabular}


Ferguson 2012 (Continued)

\section{Exclusion criteria}

Current psychiatric disorder, neuro-behavioural risk factors, history of CNS disease or receipt of treatment for CNS cancer

Participants were recruited via newspaper advertisements, letters to cancer survivors from the Comprehensive Breast Program at Dartmoth-Hitchcock Medical Center and fliers to other medical oncology offices

Randomisation method: computer-generated assignment

No. of participants: 40 (I: 19/ C: 21)

Cancer site(s): Stages I-II breast cancer

Age: $\mathrm{I}:$ mean $=51.21(\mathrm{SD}=7.3) ; \mathrm{C}:$ mean $=49.43(\mathrm{SD}=5.1)$

Sex: Female

Treatment history: All patients received chemotherapy and were at least 18 months post-chemotherapy. Use of hormonal therapies (I: 11/C: 12)

Co-morbidities: None reported

Education: Completed some years of college or less (I: 3 (30\%)/ C: 3 (33\%)); College graduate (I: 4 (40\%)/ C: 5 (56\%)); Post-college graduate or above (I: 3 (30\%); C: 1 $(11 \%))$

Socio-economic status: None reported

Cognitive impairment at baseline: Participants had to self-report persistent memory or attention problems following chemotherapy

Country: USA

Definition: Brief CBT Memory and Attention Adaptation Training (MAAT).

To assess the efficacy of MAAT on self-reported and objective cognitive dysfunction related to cancer, as well as QoL

Duration: Twice-weekly 30- to 50-minute sessions for 8 weeks delivered face-to-face with telephone follow-up in between clinics. Participants were encouraged to apply the strategies to daily situations

Components: Four CBT components incorporated into MAAT: Education; Self-awareness training; Self-regulation training and; Cognitive compensatory strategy training. MAAT workbook given to each participant

\section{Techniques}

Feedback on behaviour: telephone contact to reinforce use or modification of strategies Self-monitoring of behaviour: participants to record 'at-risk' situations which contribute to cognitive impairment Instruction on how to perform behaviour: learn compensatory strategies, workbook Information about antecedents of behaviour: education about findings and current knowledge regarding cancer-related cognitive impairment and participants to identify 'at-risk' situations which lead to cognitive difficulties

Information about the health consequences: education about findings and current knowledge regarding cancer-related cognitive impairment

Demonstration of the behaviour: taught compensatory strategies

Prompts/cues: telephone contact, external cueing

Behavioural practice/rehearsal: rehearse compensatory strategies

Generalisation of a target behaviour: application of strategies to everyday life

Reduce negative emotions: applied relaxation (Self-regulation training) and stress-management

Mental rehearsal of successful performance: visualisation strategies

Self-talk: verbal rehearsal, covert verbal self-instruction (self-instructional training)

Materials: Clinician's manual, participant booklet 
Theoretical basis/mechanism: CBT/Compensatory strategy training

Setting: Face-to-face, Dartmouth Medical Centre

Therapist/Training: Clinical Psychologist

Comparison: Wait-list control

Outcomes

Outcomes were assessed at baseline, post-intervention and two-months intervention with the exception of depression, anxiety and treatment satisfaction

Subjective cognitive function: *MASQ 5 domains (language; visuo-perceptual; verbal memory; visual memory; attention)

Objective cognitive function: CVLT (total raw scores across trials 1-5) to assess verbal memory; D-KEFS (trail-making letter trial; colour-word interference; colour-word and switching trials) and WAIS-III (digit symbol-coding subset) to assess processing speed Other outcomes: QOL-CS 41-item scale, 5 domains (physical; psychological; social and; spiritual) to assess quality of life; CES-D to measure depression; STAI to measure anxiety; Treatment satisfaction measured by a study-specific measure

Adherence: None reported

Safety issues: None reported

Adverse effects: None reported

Notes

*Primary outcome in Ferguson study.

Alternate forms of the CVLT were used to counteract practice effects

Linear interpolation methods used to account for 5 dropouts over the course of the study

Risk of bias

\begin{tabular}{|c|c|c|}
\hline Bias & Authors' judgement & Support for judgement \\
\hline $\begin{array}{l}\text { Random sequence generation (selection } \\
\text { bias) }\end{array}$ & Low risk & $\begin{array}{l}\text { "Participants...randomized to treatment } \\
\text { and waitlist conditions using computer } \\
\text { generated assignment." Pg } 178\end{array}$ \\
\hline
\end{tabular}

Allocation concealment (selection bias) Low risk

None reported, however, due to the computerised nature of the allocation it is unlikely that study personnel or participants can predict which allocation is next, however, it may be manipulated by re-running the software for a given participant

Blinding of participants and personnel Low risk (performance bias)

Not possible to blind the participants to All outcomes group allocation. "It was impossible to blind the clinician to the treatment or control assignments." Pg 179

Blinding of outcome assessment (detection Low risk bias)

Objective outcomes

"The research assistant completing all assessment and testing was blind to participant group membership.” Pg 178

Non-pharmacological interventions for cognitive impairment due to systemic cancer treatment (Review) 


\section{Ferguson 2012 (Continued)}

\begin{tabular}{|c|c|c|}
\hline $\begin{array}{l}\text { Incomplete outcome data (attrition bias) } \\
\text { All outcomes }\end{array}$ & Low risk & $\begin{array}{l}\text { Reasons for dropout reported and number } \\
\text { of dropouts across groups was similar. Pg } \\
180 \text { Intention-to-treat analysis was imple- } \\
\text { mented and linear interpolation methods } \\
\text { were used to impute missing values }\end{array}$ \\
\hline Selective reporting (reporting bias) & Unclear risk & $\begin{array}{l}\text { Anxiety and depression may not have been } \\
\text { outcome measures but were measured to } \\
\text { gauge any changes in mood over the course } \\
\text { of the study period. However, no numerical } \\
\text { data or detailed data included }\end{array}$ \\
\hline $\begin{array}{l}\text { Baseline imbalances in cognition scores } \\
\text { Objective outcomes }\end{array}$ & Unclear risk & $\begin{array}{l}\text { No baseline differences between groups are } \\
\text { reported. }\end{array}$ \\
\hline
\end{tabular}

Baseline imbalances in cognition scores Low risk

Subjective outcomes

Trend for increased cognitive impairment in intervention group compared to control group, but this is not significant. Pg 182

Validity of cognitive function measures Unclear risk

Measures chosen for ability to discriminate Objective outcomes between survivors who have or have not received chemotherapy. Pg 179

Validity of cognitive function measures Unclear risk

No information reported on the validity of Subjective outcomes outcome.

Reliability of cognitive function measures Unclear risk No information reported related to reliaObjective outcomes bility of outcome measures

Reliability of cognitive function measures Unclear risk No information reported related to reliaSubjective outcomes bility of outcome measure

Kesler 2013

\begin{tabular}{ll}
\hline Methods & $\begin{array}{l}\text { Randomised controlled trial } \\
\text { Intention-to-treat: ITT was not undertaken } \\
\text { Loss to follow-up: numbers and reasons reported in text }\end{array}$ \\
\hline Participants & $\begin{array}{l}\text { Inclusion criteria } \\
\text { Females at least } 40 \text { years of age diagnosed with stages I-IIIA breast cancer with a history } \\
\text { of breast cancer treatment including surgery and chemotherapy at least } 18 \text { months post- } \\
\text { chemotherapy receipt with home Internet connection. Participants were not excluded if } \\
\text { they had received radiotherapy or hormonal therapy } \\
\text { Exclusion criteria } \\
\text { Chemotherapy receipt prior to cancer treatment or colour blindness or major sensory } \\
\text { deficit or neurological or major medical condition which may affect cognitive function } \\
\text { or history of inpatient, psychiatric hospitalisation or current psycho-stimulant or CNS }\end{array}$
\end{tabular}


Kesler 2013 (Continued)

depressant medication use (with the exception of use of common antidepressants)

Participants were recruited from advertisements and physician referral.

Randomisation method: randomised by computerised coin toss software

Participants: 41 (I: 21/ C: 20)

Cancer site(s): Breast cancer stages I (I: 25/ C: 26); II (I: 50/ C: 42); III (I: 25/ C: 32)

Age: I: mean $=55+/-7$; : mean $=56+/-6$

Sex: Female

Treatment history: All patients received chemotherapy and were at least 18 months post-chemotherapy. Receipt of radiotherapy (I: 70\%/ C: 63\%) and; use of hormonal therapies (I: 60\%/C: 63\%)

Co-morbidities: None reported

Education: I: 16 years $+/-2 /$ C: 16 years $+/-3$

Socio-economic status: None reported

Cognitive impairment at baseline: Participants did not have to report cognitive impairment to be eligible for the study

Country: USA

Interventions

Definition: Computer-based cognitive training program for executive functioning (provided by Lumos labs (Lumiosity))

To assess the feasibility and effectiveness of a home-, computer-based, cognitive training program on executive functioning

Components: Thirteen cognitive training exercises targeting cognitive flexibility, working memory, processing speed and verbal fluency. Adaptive program which increased in difficulty. Initially low difficulty with cues and explanations; change in difficulty based on algorithms considering inter- and intra- session performance including speed and accuracy. Immediate visual and auditory feedback and reinforcement regarding performance

\section{Techniques}

Feedback on behaviour: Immediate visual and auditory feedback

Feedback on outcome(s) of behaviour: Immediate visual and auditory feedback

Instruction on how to perform the behaviour: written or animated instructions before each task

Demonstration of the behaviour: written or animated instructions before each task

Prompts/cues: Weekly telephone calls to enhance compliance to programme

Behavioural practice/rehearsal: completion of computer exercises

Graded tasks: Adaptive ability

Materials: Written instructions, computer, online computer programme

Duration: 48 sessions over a 12-week period (4 sessions a week) lasting 20-30 minutes

Theoretical basis/mechanism: None reported

Setting: Home

Personnel: Clinical Neuropsychologist at initial assessment

Comparison: Wait-list control

Outcomes

Outcomes were assessed at baseline and post-intervention

Subjective cognitive function: Behavioral Rating Inventory of Executive Functioning (BRIEF) 3 scores (global executive functioning composite score; task monitoring and; plan and'/or organise to assess self-reported executive functioning

Objective cognitive function: *WCST to assess cognitive flexibility; D-KEFS letter fluency test to assess executive functioning and language; HVLT-R to assess verbal mem-

Non-pharmacological interventions for cognitive impairment due to systemic cancer treatment (Review) 
Kesler 2013 (Continued)

ory; WAIS (digit span) to assess working memory and; WAIS (symbol search) to assess processing speed

Secondary outcomes: CAD to assess depression, anxiety and cognitive fatigue.

Adherence: Time and date of each exercise, session performance and duration of each exercise and session were recorded. Adherence was seen as 4 sessions per week with a linear positive trend in performance

Safety issues: None reported

Adverse effects: None reported

Notes $\quad$ *Primary outcome in paper.

Alternate forms of DKEFS and HVLT were used to counteract practice effects

\section{Risk of bias}

\begin{tabular}{l|ll} 
Bias & Authors' judgement & Support for judgement \\
\hline $\begin{array}{l}\text { Random sequence generation (selection } \\
\text { bias) }\end{array}$ & Low risk & $\begin{array}{l}\text { “...randomized by computer coin toss soft- } \\
\text { ware” } \operatorname{Pg} 301\end{array}$ \\
\hline
\end{tabular}

Allocation concealment (selection bias) Low risk

None reported, however, due to the computerised nature of the allocation it is unlikely that study personnel or participants can predict which allocation is next

Blinding of participants and personnel Low risk (performance bias)

Unable to blind participants to a cognitive All outcomes

Blinding of outcome assessment (detection Low risk bias)

Objective outcomes training intervention

\begin{tabular}{|c|c|c|}
\hline $\begin{array}{l}\text { Blinding of outcome assessment (detection } \\
\text { bias) } \\
\text { Objective outcomes }\end{array}$ & Low risk & $\begin{array}{l}\text { "Testing was administered by trained re- } \\
\text { search staff members who were blinded to } \\
\text { the intervention assignment and time point } \\
\text { of the participants" Pg } 303\end{array}$ \\
\hline
\end{tabular}

Incomplete outcome data (attrition bias) High risk All outcomes
All participants accounted for with reasons given. Dropouts were similar across groups. Pg. 303 Table 2 which presents the key results section results does not highlight the differences in numbers pre- and post-intervention. Missing data were not imputed and intention-to-treat analysis was not undertaken

All outcomes were reported in the paper.

\begin{tabular}{llll}
\hline Selective reporting (reporting bias) & Low risk & All outcomes were reported in the paper. \\
\hline $\begin{array}{l}\text { Baseline imbalances in cognition scores } \\
\text { Objective outcomes }\end{array}$ & Unclear risk & None reported. \\
\hline
\end{tabular}

Baseline imbalances in cognition scores

Unclear risk

None reported. 
Kesler 2013 (Continued)

\begin{tabular}{|c|c|c|}
\hline $\begin{array}{l}\text { Validity of cognitive function measures } \\
\text { Objective outcomes }\end{array}$ & Low risk & $\begin{array}{l}\text { "The WCST...discriminates between BC } \\
\text { survivors who were treated with chemo- } \\
\text { therapy and non cancer controls" } \\
\text { "The HVLT-R and verbal fluency tests } \\
\text { have previously been shown to discriminate } \\
\text { between BC patients and survivors, and are } \\
\text { among the tests recommended by the Inter- } \\
\text { national Cognition and Cancer Task Force. } \\
\text {.." } \\
\text { 'Digit span also has been shown to discrim- } \\
\text { inate between BC survivors and controls' } \\
\text { Pg } 303\end{array}$ \\
\hline
\end{tabular}

Validity of cognitive function measures Low risk Subjective outcomes
"The BRIEF not only discriminates between $\mathrm{BC}$ and controls but also correlates significantly with deficits in prefrontal cortex among BC survivors” Pg 303

"The WCST has been shown to be robustly sensitive to abnormalities in executive-prefrontal neurocircuitry...and discriminates between BC survivors who were treated with chemotherapy and non cancer controls” Pg 303

No information reported.

Milbury 2013

Methods

Participants
Randomised controlled trial

Intention-to-treat analysis: ITT was undertaken

Loss to follow-up: numbers reported in flowchart and reasons reported in text

\section{Inclusion criteria}

Females aged 18 years and over diagnosed with stages I-IIIA breast cancer, proficient in English who had received chemotherapy 6 to 60 months previously, were currently using hormonal therapies, reporting cognitive impairment post-treatment and lived within 2 hours driving distance of institution

\section{Exclusion criteria}

Documented diagnosis of thought disorder (e.g. schizophrenia) or neurological injury or a MMSE of less than or equal to 23 or metastatic/recurrent cancer or prior regular meditation practice

Participants were identified from institution's electronic medical records and posted invitations to the study

Randomisation method: minimisation, an adaptive randomisation method evenly balanced according to age, time since diagnosis, menopausal status, receptor status, of dis- 
ease, surgical procedure, type of hormone treatment stage other medications with possible cognitive effects, and baseline self-report cognitive function scores

Participants: 47 (I: 23/ C: 24)

Cancer site(s): Breast cancer stages I (I: 6/ C: 6); II (I: 13/ C: 13); III (I: 4/ C: 5)

Age: $\mathrm{I}$ : mean $=53.0(\mathrm{SD}=6.6)$; : mean $=54.1(\mathrm{SD}=8.6)$

Sex: Female

Treatment history: All patients received chemotherapy and were between 6 to 60 months post-chemotherapy and current use of hormonal therapy. Receipt of radiotherapy (I: $17 /$ C: 19) and; surgery (I: 20/C: 24)

Co-morbidities: None reported

Education: Some college or higher (I: 22/ C: 18)

Socio-economic status: None reported

Cognitive impairment at baseline: Participants had to have cognitive impairment relating to chemotherapy assessed by 4 items of the FACT-Cog

Country: USA

Interventions

Definition: Tibetan Sound Meditation (TSM) delivered by trained meditation instructors

To assess the feasibility and efficacy of TSM to improve cognitive functioning and QoL

Duration: Twice weekly (one-hour) sessions over a 6-week period

Components: Breathing, awareness and concentration techniques. Visualisation and sound exercises with three, separate but inter-related stages and associated cognitive activity including: stage one acknowledging, cleansing and releasing negative thoughts; stage two identifying and retrieving a positive supportive quality and; stage 3 integrating quality into everyday life

\section{Techniques}

Social support (unspecified): group setting for delivery of intervention

Instruction on how to perform the behaviour: supervision, CD and written instructions

Demonstration of the behaviour: supervision, $\mathrm{CD}$ and written instructions

Behavioural practice/rehearsal: attendance at session and home practice

Generalisation of target behaviour: transference of practice from supervised sessions to home

Reduce negative emotions: meditation 'releasing negative thoughts', breathing

Framing/reframing: identifying a positive, supportive quality

Materials: $\mathrm{CD}$, printed instructions

Theoretical basis/mechanism: Mind-body practice may target cognitive impairment via stress reduction and regulation of immune system

Setting: Instructor-led sessions at institution, participants also encouraged to practice at home

Personnel: Meditation instructors

Comparison: Wait-list control
Self-report outcomes were assessed at baseline, post-intervention and one-month postintervention

Objective cognitive function outcomes were assessed at baseline and one-month postintervention in order to counteract practice effects

Subjective cognitive function: ${ }^{*}$ FACT-Cog (version 3) 4 domains: Perceived cognitive impairments; Impact on QoL; Comments of others; Perceived cognitive abilities

Objective cognitive function: ${ }^{*}$ Digit Symbol Test to assess visuo-motor co-ordination, 
Milbury 2013 (Continued)

processing speed and attention; ${ }^{*}$ Digit $S$ pan Test to assess working memory and attention; ${ }^{*}$ RAVLT to assess verbal memory and; *COWAT to assess verbal fluency

Secondary outcomes: SF-36 (physical and mental component summary scores) to assess health-related QoL; FACT-spiritual to assess spiritual QoL; CES-D to assess depression; BFI to assess fatigue; PSQI to assess sleep disturbances; weekly, brief evaluation of classes to assess satisfaction with intervention

Adherence: Class attendance and frequency of home practice

Safety issues: None reported

Adverse effects: None reported

$\begin{array}{ll}\text { Notes } & \text { *Primary outcome measures in study. } \\ & \text { Participants were rewarded with a small gift to the value of } \$ 25 \text { for completing each } \\ \text { assessment }\end{array}$

Risk of bias

\begin{tabular}{|c|c|c|}
\hline Bias & Authors' judgement & Support for judgement \\
\hline $\begin{array}{l}\text { Random sequence generation (selection } \\
\text { bias) }\end{array}$ & Low risk & $\begin{array}{l}\text { “...participants were randomly assigned to } \\
\text { either the TSM or WLC group by a form of } \\
\text { adaptive randomization called minimiza- } \\
\text { tion [63] so that the groups were evenly } \\
\text { balanced according to age, time since di- } \\
\text { agnosis, menopausal status, receptor status, } \\
\text { stage of disease, surgical procedure, type of } \\
\text { hormone treatment (e.g. tamoxifen vs. AIs) } \\
\text {, other medications with possible cognitive } \\
\text { effects (e.g. Effexor), and baseline subjec- } \\
\text { tive reports of cognitive function (FACT- } \\
\text { Cog total score).” Pg } 2356\end{array}$ \\
\hline
\end{tabular}

Allocation concealment (selection bias) Unclear risk

No further information reported about randomisation procedure: likely that with the use of minimisation in a small, singlecentred study, allocation could be predicted if previous allocation is known

Blinding of participants and personnel Low risk (performance bias)

Unable to blind participants to a TSM intervention.

All outcomes

Blinding of outcome assessment (detection Unclear risk

No details reported.

bias)

Objective outcomes

Incomplete outcome data (attrition bias) Unclear risk All outcomes
"One person who dropped out from control prior to Time point 3 assessment was unaccounted for. All other drop-outs were accounted for.” Pg 2358 Intention-to-treat 
Milbury 2013 (Continued)

\begin{tabular}{|c|c|c|}
\hline & & $\begin{array}{l}\text { analysis undertaken, no description of how } \\
\text { missing values were imputed }\end{array}$ \\
\hline Selective reporting (reporting bias) & Unclear risk & $\begin{array}{l}\text { Raw means, SDs and effect sizes only were } \\
\text { reported for all outcomes in tables } 2 \text { and } \\
3 \text {. No P values or confidence interval re- } \\
\text { ported, we relied on author's reporting of } \\
\text { significant group differences in text in rela- } \\
\text { tion to intervention effectiveness }\end{array}$ \\
\hline $\begin{array}{l}\text { Baseline imbalances in cognition scores } \\
\text { Objective outcomes }\end{array}$ & Unclear risk & $\begin{array}{l}\text { "There were also no significant differences } \\
\text { in patient characteristics (except for ethnic- } \\
\text { ity) or any of the objective and subjective } \\
\text { outcome variables (see Table 1)." pg } 2357 . \\
\text { However, cognition scores are not reported } \\
\text { in Table } 1 \text { and no P values or confidence } \\
\text { intervals are reported in the Tables } 2 \text { and } \\
3 \text { where information relating to these out- } \\
\text { comes are found }\end{array}$ \\
\hline $\begin{array}{l}\text { Baseline imbalances in cognition scores } \\
\text { Subjective outcomes }\end{array}$ & Unclear risk & $\begin{array}{l}\text { "There were also no significant differences } \\
\text { in patient characteristics (except for ethnic- } \\
\text { ity) or any of the objective and subjective } \\
\text { outcome variables (see Table 1)." pg } 2357 \\
\text { However, cognition scores are not reported } \\
\text { in Table } 1 \text { and no P values or confidence } \\
\text { intervals are reported in the Tables } 2 \text { and } \\
3 \text { where information relating to these out- } \\
\text { comes are found }\end{array}$ \\
\hline $\begin{array}{l}\text { Validity of cognitive function measures } \\
\text { Objective outcomes }\end{array}$ & Unclear risk & None reported. \\
\hline $\begin{array}{l}\text { Validity of cognitive function measures } \\
\text { Subjective outcomes }\end{array}$ & Unclear risk & None reported. \\
\hline $\begin{array}{l}\text { Reliability of cognitive function measures } \\
\text { Objective outcomes }\end{array}$ & Unclear risk & None reported. \\
\hline $\begin{array}{l}\text { Reliability of cognitive function measures } \\
\text { Subjective outcomes }\end{array}$ & Unclear risk & None reported. \\
\hline
\end{tabular}

Non-pharmacological interventions for cognitive impairment due to systemic cancer treatment (Review) 
Methods

Participants
Randomised controlled trial

Intention-to-treat analysis: ITT was not undertaken

Loss to follow-up: numbers and reasons reported in flowchart

\section{Inclusion criteria}

Females aged 40 years and over diagnosed with breast cancer, currently disease-free, postmenopausal, able to read, write and understand English who at least one-year post-treatment with a history of chemotherapy receipt for non-metastatic breast cancer, reporting cognitive impairment post-treatment which negatively impacted their daily lives

\section{Exclusion criteria}

Substantial cognitive impairment (MMSE < 24), history of cranial radiation or intrathecal therapy, stroke, encephalitis, traumatic brain injury, brain surgery, Alzheimer's disease or Parkinson's disease, current active major depression, substance abuse, history of bipolar disorder, psychosis, schizophrenia or learning disability, history of, or current other cancer (with the exception of basal cell skin cancer) or uncorrected vision problems Participants were sequentially recruited from Midwestern Cancer Centre and affiliated clinics and advertisements were posted to research registry participants

Participants: 88 (I1: 29/ I2: 30/ C: 29)

Cancer site(s): Breast $89 \%$ of total sample were stage II and under.

Age: $\mathrm{I} 1:$ mean $=55.19(\mathrm{SD}=7.58) ; \mathrm{I} 2: 56.93(\mathrm{SD}=7.83) ; \mathrm{C}:$ mean $=57.21(\mathrm{SD}=9$. 80)

Sex: Female

Treatment history: All participants received chemotherapy and surgery and $74 \%$ of participants also received radiotherapy

Co-morbidities: None reported

Education: $\mathrm{I} 1$ : mean $=15.96$ years $(\mathrm{SD}=1.87)$; $\mathrm{I} 2$ : mean $=15.63$ years $(\mathrm{SD}=2.50)$; $\mathrm{C}:$ mean $=15.43(\mathrm{SD}=2.27)$

Socio-economic status: None reported

Cognitive impairment at baseline: Participants had to report cognitive impairment and its impact on daily life

Country: USA

Interventions

\section{Intervention one}

Definition: Memory Training (adapted from the Advanced Cognitive Training for Independent and Vital Elderly)

To assess the acceptability/satisfaction and efficacy of memory training on improving cognitive function

Components: Sessions 1-5: Instruction and strategies to practice techniques for remembering (including multiple mnemonic techniques). Sessions 6-10 provided additional practice exercises to promote self-efficacy with regards to performance

\section{Techniques:}

Social support (unspecified): group setting for delivery of intervention Instruction on how to perform the behaviour: teaching and instruction of compensatory strategies

Demonstration of the behaviour: teaching and instruction of compensatory strategies

Behavioural practice/rehearsal: strategy practice exercises

Materials: none reported

Theoretical basis/mechanism: none reported

Duration: 10 one-hour sessions over a 6-8 week period 
Von Ah 2012 (Continued)

Setting: Group-based setting with 3-5 participants in each

Personnel: Trained interventionists

Comparison: Wait-list control

Intervention two

Definition: Speed of processing training (commercially available computer-based 'Insight' program from Posit Science)

To assess the acceptability/satisfaction and efficacy of speed of processing training on improving cognitive function

Components: Progressively difficult information-processing tasks whereby stimulus duration is systematically reduced

Techniques

Feedback on behaviour: programme gives feedback in terms of performance

Feedback on outcome(s) of behaviour: programme gives feedback in terms of performance

Social support (unspecified): intervention delivered in group setting

Behavioural practice/rehearsal: practice exercises

Graded tasks: increasingly difficult exercises

Materials: None reported

Theoretical basis/mechanism: None reported

Duration: 10 one-hour sessions over a 6- to 8-week period

Setting: Group-based setting with 3 to 5 participants in each

Personnel: Trained interventionists

Comparison: Wait-list control

Outcomes

Outcomes assessed at baseline, post-intervention and 2-month post-intervention

Subjective cognitive function: FACT-Cog (version 2) and Squire Subjective Memory Questionnaire

Objective cognitive function: *Composite score of RAVLT (sum recall (trials 1-5), short delay, recognition score) and *Rivermead Behavioural Paragraph Recall Test (RBPRT) (immediate recall) to measure immediate memory recall; composite score of RAVLT (long-term delay score) and RBPRT (long-term delay score) to assess delayed recall; composite score of Useful Field of View (3 subtests) to measure speed of processing Secondary outcomes: SF-36 (physical and mental component summary scores), QOLCS and QLI-C to assess QoL; FACT-F to assess fatigue; CES-D to assess depression; STAI to assess anxiety; acceptability using a study-specific scale and Client Satisfaction Questionnaire to measure satisfaction with intervention

Adherence: Completion rates

Safety issues: None reported.

Adverse effects: None reported.

*Primary outcomes measured in study.

Participants received $\$ 25$ for each data collection visit.

\section{Risk of bias}

\begin{tabular}{|c|c|c|}
\hline Bias & Authors' judgement & Support for judgement \\
\hline $\begin{array}{l}\text { Random sequence generation (selection } \\
\text { bias) }\end{array}$ & Low risk & $\begin{array}{l}\text { "Subjects were randomized using non- } \\
\text { stratified blocks of } 9 . " \operatorname{Pg} 800\end{array}$ \\
\hline
\end{tabular}

Non-pharmacological interventions for cognitive impairment due to systemic cancer treatment (Review)

Copyright @ 2016 The Cochrane Collaboration. Published by John Wiley \& Sons, Ltd. 
Von Ah 2012 (Continued)

\begin{tabular}{|c|c|c|}
\hline Allocation concealment (selection bias) & Low risk & $\begin{array}{l}\text { "Biostatisticians provided a password pro- } \\
\text { tected randomization list to the non- } \\
\text { blinded project manager who had primary } \\
\text { responsibility for randomization. Partici- } \\
\text { pants were notified by telephone of group } \\
\text { assignment and intervention dates." Pg } 800\end{array}$ \\
\hline $\begin{array}{l}\text { Blinding of participants and personnel } \\
\text { (performance bias) } \\
\text { All outcomes }\end{array}$ & Unclear risk & $\begin{array}{l}\text { "Participants were notified of group allo- } \\
\text { cation and intervention dates"” Pg } 800 \text { It } \\
\text { is not possible to blind participants from } \\
\text { group allocation } \\
\text { "...single-blind study.." Pg } 800 \\
\text { "Each intervention...delivered by separate } \\
\text { trained and certified interventionists to } \\
\text { avoid diffusion of treatments." Pg } 800 \\
\text { “...non-blinded project manager who had } \\
\text { responsibility for randomization." Pg } 800\end{array}$ \\
\hline $\begin{array}{l}\text { Blinding of outcome assessment (detection } \\
\text { bias) } \\
\text { Objective outcomes }\end{array}$ & Low risk & $\begin{array}{l}\text { “...neuropsychological testing and ques- } \\
\text { tionnaires collected by a trained and } \\
\text { blinded staff member." Pg. } 800\end{array}$ \\
\hline
\end{tabular}

Incomplete outcome data (attrition bias) High risk All outcomes

All participants accounted for and reasons reported. Pg 803 Missing data were not imputed and intention-to-treat analysis was not undertaken

Selective reporting (reporting bias) Unclear risk

Authors created composite objective cognition scores from a number of individual measures; means and SDs on individual measures and composite scores are not reported at both follow-ups, although, reliable improvement and net effect sizes are reported

Baseline imbalances in cognition scores Low risk

"There were no significant group differObjective outcomes ences at baseline in...cognitive abilities (immediate and delayed memory and processing speed).” Pg 802

Baseline imbalances in cognition scores Unclear risk Subjective outcomes

No mention of subjective cognitive outcomes when describing baseline group differences

Validity of cognitive function measures Unclear risk None reported. 
Von Ah 2012 (Continued)

\begin{tabular}{l|l|l}
\hline $\begin{array}{l}\text { Validity of cognitive function measures } \\
\text { Subjective outcomes }\end{array}$ & Unclear risk & None reported. \\
\hline $\begin{array}{l}\text { Reliability of cognitive function measures } \\
\text { Objective outcomes }\end{array}$ & Unclear risk & None reported. \\
\hline $\begin{array}{l}\text { Reliability of cognitive function measures } \\
\text { Subjective outcomes }\end{array}$ & Unclear risk & None reported. \\
\hline
\end{tabular}

Abbreviations: $\mathbf{B C}=$ Breast cancer; BRIEF = Behavioral Rating Inventory of Executive Functioning; BFI = Brief Fatigue Inventory; CAD = Clinical Assessment of Depression; $\mathbf{C B T}=$ Cognitive behavioural therapy; $\mathbf{C D}=$ Compact Disc; $\mathbf{C N S}=$ Central Nervous System; CES-D = Centre for Epidemiological Studies- Depression scale; C = control; COWAT = Controlled Oral Word Association Test; CVLT = California Verbal Learning Test-II; D-KEFS = Delis-Kaplan Executive Function System; DSM IV = Diagnostic Statistical Manual (version IV); FACT-Cog = Functional Assessment of Cancer Therapy- Cognition subscale; FACT-F = Functional Assessment of Cancer Therapy-Fatigue subscale; FACT-Spiritual = Functional Assessment of Cancer Therapy-Spiritual subscale; $\mathbf{f M R I}$ = functional Magnetic Resonance Imaging; HVLT-R= Hopkin's Verbal Learning Test- Revised; ITT = Intention-to-treat; $\mathbf{I}$ = intervention; MMSE = Mini-Mental Status Examination; MASQ = Multiple Ability Self-report Questionnaire; PQSI = Pittsburgh Sleep Quality Index; QLI-C = Quality of life index- cancer version;QoL = Quality of Life; QOL-CS = Quality of life- Cancer Survivor; RAVLT = Rey Auditory Verbal Learning Trial; SD = Standard Deviation; SF-36 = Short Form Health Survey- 36 item; STAI = State Trait Anxiety Index; VO2 = Volume oxygen; WLC = wait-list control; WAIS-III = Wechsler Adult Intelligence-III; WCST $=$ Wisconsin Card Sorting Test

\section{Characteristics of excluded studies [ordered by study ID]}

\begin{tabular}{ll}
\hline Study & Reason for exclusion \\
\hline Alvarez 2013 & Not a randomised controlled trial: participants acted as own wait-list controls \\
\hline Antony 2013 & Unable to establish contact with author \\
\hline Beatty 2010 & Intervention not targeted at improving cognitive impairment or maintaining cognitive function \\
\hline Beebe 2014 & Could not be contacted \\
\hline Bernstein 2012 & Data not yet available \\
\hline Boesen 2005 & Intervention not targeted at improving cognitive impairment or maintaining cognitive function \\
\hline Boesen 2011 & Intervention not targeted at improving cognitive impairment or maintaining cognitive function \\
\hline Bollman 2008 & Unable to establish contact with author \\
\hline
\end{tabular}

Cherrier $2013 \quad$ Proportion of participants have not received systemic treatment 
(Continued)

\begin{tabular}{|c|c|}
\hline Cherrier 2015 & Not enough information available to decide if trial should be included \\
\hline Cimprich 1993 & Participants unlikely to have received systemic treatment as first assessment was 3 days following surgery \\
\hline Cimprich 2003 & Participants unlikely to have received systemic treatment as first assessment was prior to surgery \\
\hline Culos-Reed 2006 & Intervention not targeted at improving cognitive impairment or maintaining cognitive function \\
\hline Derry 2015 & Proportion of participants have not received systemic treatment \\
\hline Dolbeault 2009 & Intervention not targeted at improving cognitive impairment or maintaining cognitive function \\
\hline Doorenbos 2006 & Intervention not targeted at improving cognitive impairment or maintaining cognitive function \\
\hline Duong 1997 & Unable to establish contact \\
\hline Ercoli 2013 & Not a randomised controlled trial: pre-post design \\
\hline Ercoli 2015 & Proportion of participants have not received systemic treatment \\
\hline Ferguson 2007 & Not a randomised controlled trial: single-arm pilot study \\
\hline Ferguson 2014 & No data available yet \\
\hline Freeman 2015 & Intervention not targeted at improving cognitive impairment or maintaining cognitive function \\
\hline Galiano-Castillo 2013 & Intervention not targeted at improving cognitive impairment or maintaining cognitive function \\
\hline Goedendorp 2014 & Intervention not targeted at improving cognitive impairment or maintaining cognitive function \\
\hline Gopinath 2011 & Unable to establish contact with author \\
\hline Hartmann 2007 & Intervention not targeted at improving cognitive impairment or maintaining cognitive function \\
\hline Hartmann 2014 & Proportion of participants have not received systemic treatment \\
\hline Haynes 2013 & No response from study authors \\
\hline Hunter 2014 & Not a randomised controlled trial: correspondence \\
\hline Janelsins $2012 b$ & No response from study authors \\
\hline Johns 2015 & Intervention not targeted at improving cognitive impairment or maintaining cognitive function \\
\hline Johnston 2011 & aintaining cognitive function \\
\hline
\end{tabular}

Non-pharmacological interventions for cognitive impairment due to systemic cancer treatment (Review) 
(Continued)

\begin{tabular}{|c|c|}
\hline Kervick 2005 & Unable to establish contact with author \\
\hline Kim 2008 & Proportion of patients currently receiving chemotherapy \\
\hline King 2015 & Proportion of participants have not received systemic treatment \\
\hline Kolidas 2012 & No response from study authors \\
\hline Korstjens 2006 & Intervention not targeted at improving cognitive impairment or maintaining cognitive function \\
\hline Korstjens 2011 & Intervention not targeted at improving cognitive impairment or maintaining cognitive function \\
\hline Larkey 2015 & Intervention not targeted at improving cognitive impairment or maintaining cognitive function \\
\hline Lee $2012 \mathrm{a}$ & Protocol only available at present \\
\hline Lee $2012 b$ & Protocol only available at present \\
\hline Lengacher 2012 & Intervention not targeted at improving cognitive impairment or maintaining cognitive function \\
\hline Lengacher 2015 & Not a randomised trial \\
\hline Lesiuk 2015 & Proportion of patients currently receiving chemotherapy \\
\hline Luctkar-Flude 2015 & Systematic review, not cancer-specific \\
\hline McDougall 2001 & $\begin{array}{l}\text { Not a randomised controlled trial (RCT): secondary analysis of RCT with sub-group analysis of patients } \\
\text { with a self-reported diagnosis of cancer }\end{array}$ \\
\hline McDougall 2011 & $\begin{array}{l}\text { Not a randomised controlled trial (RCT): secondary analysis of RCT with sub-group analysis of patients } \\
\text { with a self-reported diagnosis of cancer }\end{array}$ \\
\hline Mehnert 2011 & Intervention not targeted at improving cognitive impairment or maintaining cognitive function \\
\hline Mendoza 2015 & No response when contacted \\
\hline Miki 2014 & Proportion of patients currently receiving chemotherapy \\
\hline Oh 2012 & Proportion of patients currently receiving chemotherapy \\
\hline Penedo 2003 & Intervention not targeted at improving cognitive impairment or maintaining cognitive function \\
\hline Peterson 2015 & Proportion of patients undergoing active treatment \\
\hline Poppelreuter 2008 & Not a randomised controlled trial: two treatment groups were randomised; control group was not \\
\hline Poppelreuter 2009 & Not a randomised controlled trial: two treatment groups were randomised; control group was not \\
\hline
\end{tabular}

Non-pharmacological interventions for cognitive impairment due to systemic cancer treatment (Review)

Copyright @ 2016 The Cochrane Collaboration. Published by John Wiley \& Sons, Ltd. 
(Continued)

\begin{tabular}{|c|c|}
\hline Rea 2011 & Unable to establish contact \\
\hline Rottmann 2012 & Intervention not targeted at improving cognitive impairment or maintaining cognitive function \\
\hline Rummans 2006 & Intervention not targeted at improving cognitive impairment or maintaining cognitive function \\
\hline Schuurs 2013 & $\begin{array}{l}\text { Not a randomised controlled trial: participants were not randomly allocated to intervention and control } \\
\text { group }\end{array}$ \\
\hline Singh 2014 & No response from study authors \\
\hline Srivastava 2015 & Systematic review- no further new studies identified \\
\hline Steindorf 2014 & Intervention not targeted at improving cognitive impairment or maintaining cognitive function \\
\hline Vadiraja 2009 & Intervention not targeted at improving cognitive impairment or maintaining cognitive function \\
\hline Weis 2009 & Not an randomised trial: secondary analysis of randomised trial data \\
\hline Weis 2011 & Duplicate of Poppelreuter 2009 \\
\hline Winters-Stone 2011 & Intervention not targeted at improving cognitive impairment or maintaining cognitive function \\
\hline Winters-Stone 2013 & Intervention not targeted at improving cognitive impairment or maintaining cognitive function \\
\hline Winters-Stone 2014a & Intervention not targeted at improving cognitive impairment or maintaining cognitive function \\
\hline Winters-Stone $2014 \mathrm{~b}$ & Intervention not targeted at improving cognitive impairment or maintaining cognitive function \\
\hline Wu 2014 & Data not yet available \\
\hline
\end{tabular}

\section{Characteristics of ongoing studies [ordered by study ID]}

\section{Cohen 2014}

Trial name or title Effects of meditation on cognitive function and quality of life

\begin{tabular}{ll}
\hline Methods & RCT \\
\hline Participants & $\begin{array}{l}\text { Inclusion Criteria } \\
\text { Female breast cancer patients aged } 35 \text { to } 60 \text { years old, stage I-III who have undergone chemotherapy (either } \\
\text { neoadjuvant or adjuvant) } 6 \text { to } 60 \text { months prior to recruitment; who are currently undergoing hormone } \\
\text { therapy; who report cognitive impairment since starting chemotherapy as assessed by four questions of the } \\
\text { FACT-Cog; able to read and speak English, Spanish or Portuguese; who are all right-handed (for EEG analysis) } \\
\text { and willing to travel to one of two centres for meditation and assessment. } \\
\text { Exclusion Criteria }\end{array}$
\end{tabular}


Cohen 2014 (Continued)

Diagnosis of a formal thought disorder (e.g. schizophrenia) or neurological disorder known to affect cognitive function; MMSE score of 23 or less; recurrent cancer; neurological/psychological disorder that may interfere with ability to co-operate with study procedures; factors affecting fMRI and extreme mobility issues and regular meditation practice (at least once a week for the last year)

\section{Comparators}

Wait-list controls

Non-cancer controls: Women with no history of cancer or prior chemotherapy. Exclusions; taking oestrogen blockers or stimulators, extreme mobility issues or primary caretaker of a cancer patient

Country: USA

\begin{tabular}{ll} 
Interventions & $\begin{array}{l}\text { Definition: Tibetan Sound Meditation } \\
\text { Materials: CD and instructions for home practice } \\
\text { Duration: Twice weekly one-hour sessions over a 8-week period } \\
\text { Setting: Group-based setting } \\
\text { Personnel: Meditation instructor }\end{array}$ \\
\hline Outcomes & $\begin{array}{l}\text { Assessments at baseline and } 8 \text { weeks later at end of the intervention period } \\
\text { Primary outcome } \\
\text { Cognitive function } \\
\text { Secondary outcomes } \\
\text { Mood, fatigue, QoL, memory and concentration } \\
\text { EEG and fMRI }\end{array}$ \\
\hline Starting date & October 2013 \\
\hline Contact information & Lorenzo Cohen: lcohen@mdanderson.org \\
\hline Notes & Specific measures not reported \\
\hline
\end{tabular}

Damholdt 2013

Trial name or title Internet-delivered cognitive training for breast cancer survivors with cognitive complaints

\begin{tabular}{ll}
\hline Methods & RCT \\
\hline Participants & $\begin{array}{l}\text { Inclusion criteria } \\
\text { Forty years of age, disease-free breast cancer patients who have completed treatment with self-reported cog- } \\
\text { nitive impairment and access to the Internet } \\
\text { Exclusion criteria } \\
\text { Head trauma with loss of consciousness, neurological disease, severe physical or psychological disease, history } \\
\text { of drug or alcohol abuse, recurrence of breast cancer or a second cancer and where Danish is not their primary } \\
\text { language } \\
\text { Country: Denmark }\end{array}$ \\
\end{tabular}

Interventions Definition: Computerised cognitive training (Scientific Brain Training Pro)

Materials: Computer, Internet access

Duration: 40-60 minutes, 5 days a week for 6 weeks with weekly email reminders and motivational phone calls

Setting: Home 
Damholdt 2013 (Continued)

Comparator: Wait-list controls

\begin{tabular}{l|l}
\hline Outcomes & $\begin{array}{l}\text { Assessments at baseline, 6 weeks (post-intervention) and 27 weeks later } \\
\text { Primary outcome } \\
\text { Paced Auditory Serial Addition Test } \\
\text { Measures of working memory and concentration } \\
\text { Secondary outcome } \\
\text { Cognitive Failures Questionnaire }\end{array}$ \\
\hline Starting date & Recruitment completed: data not yet available \\
\hline Contact information & Malene Flensborg: damholdmalenefd@psy.au.dk \\
\hline Notes & \\
\hline
\end{tabular}

Dhillon 2012

Trial name or title Cognitive rehabilitation for breast cancer survivors with perceived cognitive impairment

\begin{tabular}{|c|c|}
\hline Methods & RCT \\
\hline Participants & $\begin{array}{l}\text { Inclusion criteria } \\
\text { At least } 18 \text { years of age with an invasive breast cancer diagnosis, surgery completed within } 5 \text { years and } \\
\text { completion of at least } 3 \text { cycles of chemotherapy } 6 \text { months previously (also radiotherapy completed } 6 \text { months } \\
\text { previously), self-reported cognitive function using the EORTC-CF subscale, current use of hormonal therapies } \\
\text { is permitted and English-language fluency } \\
\text { Exclusion criteria } \\
\text { ECOG status of more than } 2 \text {, metastatic disease, major pre-existing neurological, psychiatric condition, co- } \\
\text { morbidity that would interfere with cognitive testing, previous cancer (with the exception of non-melanoma } \\
\text { skin cancer) and prior chemotherapy receipt } \\
\text { Country: Australia }\end{array}$ \\
\hline
\end{tabular}

Interventions
Definition: Computerised cognitive training (Attention Process Training)
Materials: Computer programme, computer
Duration: 2-hour weekly sessions for 6 weeks
Setting: Group
Intervention two
Definition: Compensatory strategy training
Materials: None reported
Duration: 2 -hour weekly sessions for 6 weeks
Setting: Group
Comparator: Wait-list control

Outcomes $\quad$ Measured at baseline, 4 weeks-, 6 months, and 12 months later

Primary outcome

Self-reported cognitive function (FACT-Cog cognitive impairment subscale)

Secondary outcomes

Non-pharmacological interventions for cognitive impairment due to systemic cancer treatment (Review)

Copyright @ 2016 The Cochrane Collaboration. Published by John Wiley \& Sons, Ltd. 
Dhillon 2012 (Continued)

Neuropsychological test battery (WRAT reading tests, COWAT, Thurstone WFT, Category animal fluency, Trail Making Test A and B, WCST, Stroop test, WAIS digit symbol and digit span tests, Letter Number Sequence, Spatial span, HVLT, BVMT, Grooved pegboard, Cogstate Neuropsychological Test, Functional Impact Assessment)

QoL: FACT-G

Anxiety/depression: HADS

Fatigue: FACT-F

Starting date Not yet recruiting

Contact information Haryana Dhillion: haryana.dhillon@sydney.edu.au

Notes

Gokal 2012

Trial name or title Can physical activity enhance emotion, memory, attention and concentration in breast cancer patients receiving chemotherapy?

\begin{tabular}{|c|c|}
\hline Methods & RCT \\
\hline Participants & $\begin{array}{l}\text { Inclusion criteria } \\
\text { Aged 18-75 years old, diagnosis of breast cancer (stages I-III) receiving chemotherapy and are able to speak } \\
\text { and read English } \\
\text { Exclusion criteria } \\
\text { Previously diagnosed with cancer, currently meeting } 30 \text { minutes of moderate intensity exercise } 5 \text { times a week, } \\
\text { breast cancer is a secondary diagnosis and a current psychiatric disorder } \\
\text { Country: United Kingdom }\end{array}$ \\
\hline
\end{tabular}

Interventions Definition: Physical activity (moderate intensity walking)

Materials: Booklet, pedometer, accelerometer

Duration: 12 weeks of 30 minutes, 5 times a week

Setting: Home-based

Comparator: Wait-list control

Outcomes

Assessed at pre-intervention (mid-chemotherapy) and post-intervention (12 weeks later)

Primary outcomes

Neuropsychological test battery: Stroop test, WAIS digit span (forward and backward), Sustained Attention to Response Task and WAIS block design. Self-reported cognitive function using the Cognitive Failures Questionnaire

Secondary outcomes

HADS, Self-esteem questionnaire, Fatigue using the FACT-F, Emotional distress using the POMS

Starting date

Trial completed: data not yet available

Contact information Kajal Gokal: k.gokal@lboro.ac.uk

Notes

Non-pharmacological interventions for cognitive impairment due to systemic cancer treatment (Review)

Copyright @ 2016 The Cochrane Collaboration. Published by John Wiley \& Sons, Ltd. 


\begin{tabular}{|c|c|}
\hline Trial name or title & $\begin{array}{l}\text { Memory and thinking skills workshop in improving cognitive rehabilitation in gynaecologic and breast cancer } \\
\text { survivors }\end{array}$ \\
\hline Methods & RCT \\
\hline Participants & $\begin{array}{l}\text { Inclusion criteria } \\
\text { Prior curative treatment (including chemo-, radio- therapy and surgery) for gynaecological or breast cancer } \\
\text { at least } 6 \text { months previously, subjective concerns related to cancer and/or treatment, able to comprehend and } \\
\text { read English, able to provide consent and able to undergo consent, assessment and intervention sessions. For } \\
\text { a subset of participants able to undergo fMRI safety screening and fMRI assessments during study visits } \\
\text { Exclusion criteria } \\
\text { Currently ongoing curative treatment for cancer (including chemo-, radio- therapy and surgery); cancer onset } \\
\text { prior to age } 21 \text {; unstable medical problems (e.g. heart disease); history of, or current symptoms of psychiatric } \\
\text { illnesses; current over-use or binging of alcohol within the past week; history of, or current neurological illness; } \\
\text { history of brain injury that significantly impacted cognition; history of CNS tumour; a score of } 25 \text { or more } \\
\text { on PHQ; a MMSE score of less than 26; a core of } 45 \text { or more on the Wender Utah Rating Scale for ADD } \\
\text { and for those undergoing MRI no medical or device issues that preventing imaging } \\
\text { Country: USA }\end{array}$ \\
\hline
\end{tabular}

$\begin{array}{ll}\text { Interventions } & \text { Definition: Memory and skills workshop } \\ & \text { Materials: None reported } \\ & \text { Duration: Once weekly one-hour sessions for } 8 \text { weeks } \\ & \text { Setting: Group } \\ \text { Comparator: Wait-list control }\end{array}$

\begin{tabular}{l|l} 
Outcomes & $\begin{array}{l}\text { Assessments at baseline and 7 weeks later } \\
\text { Primary outcome(s) } \\
\text { Cognitive function and QoL } \\
\text { Secondary outcome(s) } \\
\text { fMRI }\end{array}$ \\
\hline Starting date & Trial ongoing \\
\hline Contact information & Heidi Gray: hgray@uw.edu \\
\hline
\end{tabular}

Notes

\section{Green}

Trial name or title Randomized controlled trial comparing a web-based version of the Responding to Cognitive Concerns ( $\mathrm{ReCog}$ ) cognitive-behavioural intervention to waitlist for subjective and objective cognitive functioning in cancer survivors

Methods RCT

Participants

\section{Inclusion criteria}

Adults aged 18 or more; experienced any adult-onset cancer (excluding cancer known to have affected the CNS); completed all major treatments for cancer (e.g. surgery, chemotherapy, and radiotherapy) at least 6 months prior to data collection (but ongoing hormone treatments are acceptable); subjective complaints of 


\begin{tabular}{|c|c|}
\hline & $\begin{array}{l}\text { cognitive impairment; access to a computer with a mouse and reliable Internet services } \\
\text { Exclusion criteria } \\
\text { Patients with cancer involving the CNS (primary or secondary tumours); previous treatment with cranial } \\
\text { radiotherapy or intrathecal chemotherapy; current cancer diagnosis } \\
\text { Country } \\
\text { Australia }\end{array}$ \\
\hline Interventions & $\begin{array}{l}\text { Definition } \\
\text { Cognitive rehabilitation } \\
\text { Materials } \\
\text { Computer, Internet access } \\
\text { Delivery } \\
\text { One module per week (one hour) for four weeks } \\
\text { Setting } \\
\text { Web-delivered } \\
\text { Personnel } \\
\text { None }\end{array}$ \\
\hline Outcomes & $\begin{array}{l}\text { Primary outcome } \\
\text { Objective cognitive function assessed by a series of } 13 \text { neuropsychological tests using the WebNeuro online } \\
\text { program } \\
\text { Subjective cognitive function assessed by the FACT-Cog, and the Brief Assessment of Prospective Memory } \\
\text { Secondary outcomes } \\
\text { Distress measured with the Kessler Psychological Distress scale, Illness perceptions assessed using the Brief } \\
\text { Illness Perceptions Questionnaire, Perceptions of Autonomy, assessed by the BPNS, Perceptions of Com- } \\
\text { petence, as measured by the Basic Psychological Needs Scale, Perceptions of Relatedness, as assessed by the } \\
\text { BPNS and QoL measured using the EORTC-QLQ-C30 }\end{array}$ \\
\hline Starting date & Not yet recruiting \\
\hline Contact information & Heather Green: h.green@griffith.edu.au \\
\hline Notes & \\
\hline
\end{tabular}

Joly-Lobbedez 2013

Trial name or title Cancer and disorders of cognitive functions and QoL: "Cognitive rehabilitation in patients suffering from cancer and treated with chemotherapy"

\begin{tabular}{ll}
\hline Methods & RCT \\
\hline Participants & $\begin{array}{l}\text { Inclusion criteria } \\
\text { Eighteen years and older with a solid or haematological tumour; between } 1 \text { month and } 5 \text { years since end of } \\
\text { chemotherapy and/or targeted therapy in the adjuvant or metastatic setting (ongoing Herceptin is permitted) } \\
\text {; absence of personality/psychiatric disorders; absence of brain metastases or primary brain tumour; absence } \\
\text { of analgesic treatment or opioid use; subjective cognitive complaints during or after treatment; provided } \\
\text { informed consent for the study and; fluency in the French language } \\
\text { Exclusion criteria } \\
\text { Primary CNS tumour or brain metastases, haematological malignancy, documented disorder of higher func- }\end{array}$
\end{tabular}


Joly-Lobbedez 2013 (Continued)

tions; psychiatric pathology; documented drug use; childhood-onset cancer; use of analgesic treatment and opioids; alcohol consumption; participants unable to complete cognitive tests and refusal to participate

Country: France

Interventions Defintion: Computerised cognitive training using RehaCom @ software

Setting: Computer

Duration: Nine standardised cognitive rehabilitation sessions over a three-month period

Comparator group one: homework group completing 9 sessions of standardised exercise over the 3-month period

Comparator group two: telephone follow-up ( 9 calls over the 3-month period)

\begin{tabular}{ll} 
Outcomes & $\begin{array}{l}\text { Assessments conducted at baseline and 3 months later (post-intervention) } \\
\text { Primary outcome } \\
\text { FACT-Cog } \\
\text { Secondary outcomes } \\
\text { QoL and objective cognitive neuropsychological tests }\end{array}$ \\
\hline Starting date & Recruitment ongoing \\
\hline Contact information & Florence Joly-Lobbedez: f.joly@baclesse.unicancer.fr \\
\hline
\end{tabular}

Notes

Kesler

Trial name or title Cognitive enhancement program in improving cognitive function in breast cancer survivors

\begin{tabular}{ll}
\hline Methods & RCT \\
\hline Participants & $\begin{array}{l}\text { Inclusion criteria } \\
\text { Diagnosed with breast cancer, completion of chemotherapy at least } 1 \text { year previously aged over } 21 \text { years old } \\
\text { Exclusion criteria } \\
\text { History of learning disability, head trauma, neurological disorder or significant psychiatric condition or } \\
\text { significant medical condition unrelated to cancer (e.g. diabetes), contraindications for MRI or pregnancy } \\
\text { Country: USA }\end{array}$ \\
\hline
\end{tabular}

Interventions Intervention one

Definition: Computer-based cognitive training (Lumiosity), compensatory strategy training and relaxation Materials: Computer, Internet access

Duration: 20 minutes a day, 5 days a week for 6 weeks (cognitive training) and, 10 minutes a day for 6 week (relaxation)

Setting: Home

Intervention two

Definition: Active journal writing, compensatory strategy training and relaxation

Materials: Diary or journal

Duration: 20 minutes a day, 5 days a week for 6 weeks (active journal writing) and, 10 minutes a day for 6 week (relaxation)

Setting: Home

Non-pharmacological interventions for cognitive impairment due to systemic cancer treatment (Review) 


\begin{tabular}{|c|c|}
\hline & $\begin{array}{l}\text { Intervention three } \\
\text { Definition: Computer-based cognitive training (Lumiosity) } \\
\text { Materials: Computer, Internet access } \\
\text { Duration: } 20 \text { minutes per day, } 5 \text { days a week for } 6 \text { weeks } \\
\text { Setting: Home }\end{array}$ \\
\hline Outcomes & $\begin{array}{l}\text { Baseline and possibly } 3 \text { months post-intervention } \\
\text { Primary outcome } \\
\text { Standardised Executive Function Composite Score } \\
\text { Secondary outcome(s) } \\
\text { None reported }\end{array}$ \\
\hline Starting date & Study withdrawn as PI left institution \\
\hline Contact information & Shelli Kesler: skesler@standford.edu \\
\hline Notes & \\
\hline
\end{tabular}

Matthews 2007

\begin{tabular}{|c|c|}
\hline Trial name or title & The Activity Intervention for Chemobrain (TACTIC) \\
\hline Methods & RCT \\
\hline Participants & $\begin{array}{l}\text { Inclusion criteria } \\
\text { Aged } 18 \text { years or older with non-metastatic cancer who has received at least } 4 \text { cycles of chemotherapy and } \\
\text { report persistent cognitive difficulties following treatment } \\
\text { Exclusion criteria } \\
\text { Have no prior diagnosis of CNS cancer, not have engaged in regular exercise (more than } 20 \text { minutes a day, } \\
\text { more than } 5 \text { days a week for at least } 3 \text { months), no cardiovascular disease or orthopaedic problems and no } \\
\text { major systemic diseases (e.g. liver) } \\
\text { Country: USA }\end{array}$ \\
\hline Interventions & $\begin{array}{l}\text { Definition: Aerobic exercise } \\
\text { Materials: none reported } \\
\text { Duration: } 6 \text { months } \\
\text { Setting: none reported } \\
\text { Comparator: } 6 \text { compensatory strategies to aid memory and cognition }\end{array}$ \\
\hline Outcomes & $\begin{array}{l}\text { Reported details indicate that trial is a cross-sectional study with follow-up } 6 \text { months later at end of intervention } \\
\text { Primary outcome } \\
\text { Objective cognitive function using a neuropsychological test battery } \\
\text { Secondary outcome(s) } \\
\text { Psychological status, cardiorespiratory fitness and inflammatory biomarkers }\end{array}$ \\
\hline Starting date & Trial finished: will not share data \\
\hline Contact information & Charles Matthews: matthewsce@mail.nih.gov \\
\hline
\end{tabular}


Matthews 2007 (Continued)

Notes

Myers

Trial name or title Emerging From the Haze ${ }^{\mathrm{TM}}$ - Measuring the impact of a psycho-education program on perceived cognition after breast cancer Treatment

\begin{tabular}{ll} 
Methods & RCT \\
\hline Participants & $\begin{array}{l}\text { Inclusion Criteria } \\
\text { Females (aged } 18 \text { years or older) who have completed treatment (chemotherapy with or without radiotherapy) } \\
\text { for stage } 1 \text { to } 3 \text { breast cancer between } 2 \text { and } 24 \text { months previously, FACT-Cog score less than } 59 \text { on the } \\
\text { Perceived Cognitive Impairment subscale and subjective complaint of cognitive concerns at time of enrolment, } \\
\text { must be able to understand and communicate proficiently in English and ability to provide written informed }\end{array}$ \\
\hline
\end{tabular}

\section{Exclusion Criteria}

Patients with: a significant personality disorder or unstable psychiatric disorder (including active major depression, substance abuse, psychosis or bipolar disorder); a known brain metastases, history of brain metastases or radiation to the brain and; a history of stroke or other pre-existing neurological condition that may contribute to cognitive dysfunction. Patients who are non-English speaker, receiving treatment for another malignancy other than breast cancer and uncontrolled intercurrent illness including, but not limited to, ongoing or active infection, chronic anaemia, uncontrolled hypothyroidism, symptomatic congestive heart failure, unstable angina pectoris, uncontrolled cardiac arrhythmia, or psychiatric illness/social situations that would limit compliance with study requirements

\section{Country}

USA

\begin{tabular}{|c|c|}
\hline Interventions & $\begin{array}{l}\text { Definition } \\
\text { Psycho-education program } \\
\text { Materials } \\
\text { None reported } \\
\text { Duration } \\
\text { Weekly for two hours for } 6 \text { weeks in total } \\
\text { Setting } \\
\text { Clinic or via satellite } \\
\text { Comparator } \\
\text { Wait-list control } \\
\text { Personnel } \\
\text { Neuropsychologist }\end{array}$ \\
\hline
\end{tabular}

Outcomes Assessed at baseline and 6 weeks later following completion of the intervention

Primary

Self-reported cognitive function measured using the FACT-Cog

Starting date Currently recruiting

Contact information Charlotte Bailey: charlotte.bailey@cshs.org 
Myers (Continued)

Notes

Niedeggen 2009

\begin{tabular}{|c|c|}
\hline Trial name or title & Cognitive training to improve cognitive function following chemotherapy \\
\hline Methods & RCT \\
\hline Participants & $\begin{array}{l}\text { Inclusion criteria } \\
\text { Patients who have completed chemotherapy } 6 \text { weeks ago } \\
\text { Exclusion criteria } \\
\text { Patients with neurological and psychiatric disorders or have not provided consent } \\
\text { Country: Germany }\end{array}$ \\
\hline Interventions & $\begin{array}{l}\text { Definition: Cognitive training targeting concentration and memory problems } \\
\text { Materials: none reported } \\
\text { Duration: Weekly } 45 \text {-minute sessions for } 6 \text { weeks ( } 3 \text { sessions on concentration and } 3 \text { sessions on memory) } \\
\text { Setting: not reported } \\
\text { Comparator: Wait-list control }\end{array}$ \\
\hline Outcomes & $\begin{array}{l}\text { Assessments made at baseline and } 7 \text { weeks later (one week post-intervention) } \\
\text { Primary outcome } \\
\text { Objective cognitive function (Neuropsychological test battery) } \\
\text { Secondary outcomes } \\
\text { Subjective cognitive function and QoL }\end{array}$ \\
\hline Starting date & No response from author regarding trial status \\
\hline Contact information & Michael Niedeggen: niedegg@zedat.fu-berlin.de \\
\hline Totes & \\
\hline
\end{tabular}

Ryan 2010

\begin{tabular}{ll}
\hline Trial name or title & Rehabilitation of cognitive changes in breast cancer survivors \\
\hline Methods & RCT \\
\hline Participants & $\begin{array}{l}\text { Inclusion criteria } \\
\text { Female breast cancer patients (stages I-III), aged } 18 \text { to } 70 \text { years old who have completed chemotherapy } 1 \text { to } \\
10 \text { years previously, disease-free, English language fluency, demonstrable cognitive deficiency (1.0 SD below } \\
\text { normative values on at least one NP test during telephone screening or } 1.0 \text { SD below estimated pre-morbid } \\
\text { cognitive function and one of the pre-screen phone assessment measures) and computer skills sufficient to } \\
\text { use and upload data from the programme } \\
\text { Comparator: Family member or friend identified by the participant and has at least weekly contact with } \\
\text { participant } \\
\text { Exclusion criteria }\end{array}$
\end{tabular}

Non-pharmacological interventions for cognitive impairment due to systemic cancer treatment (Review)

Copyright @ 2016 The Cochrane Collaboration. Published by John Wiley \& Sons, Ltd. 
History of neurological disorder, traumatic brain injury or psychiatric disorder which may interfere with cognitive testing, prior history or secondary diagnosis of cancer (with the exception of basal cell carcinoma or melanoma treated with surgery only), prior chemotherapy receipt, evidence of recurrence, hearing or visual deficit which impairs ability to use programme, unable to provide informed consent and male breast cancer survivors

\section{Country: USA}

Intervention

Definition: Computerised cognitive training (Cogmed)

Materials: Computer, computer programme

Duration: 30 minutes a day, 5 days a week for 5 weeks with weekly 'coach' telephone calls

Setting: Home

Comparator: Attentional control: less difficult version of above software

Outcomes Assessments measured at baseline, 1 to 4 weeks post-intervention and 3 to 4 months post-intervention

Primary outcome

Objective working memory using neuropsychological test battery

Secondary outcome(s)

Self-reported functional status

Starting date No response from author regarding trial status

Contact information Elizabeth Ryan: ryane1@mskcc.org

Notes

Vardy 2009

Trial name or title Evaluation of a web-based cognitive rehabilitation programme in cancer survivors with self reported cognitive impairment

Methods RCT

\section{Participants Inclusion criteria}

Diagnosis of a primary breast, colorectal or ovarian cancer with completion of a minimum of 3 cycles of potentially curative chemotherapy within the last 6 to 60 months (completion of radio- or immuno- therapy 12 weeks prior to study enrolment), hormonal therapy is permitted if commenced at least 4 weeks prior to randomisation, aged 18 years or older, male or female, self-reporting changes in memory and concentration, English language fluency, able to give informed consent, access to computer and Internet and available for intervention and follow-up

\section{Exclusion criteria}

ECOG Performance Status of > 2, evidence of recurrent or metastatic disease, history of, or active psychiatric, cognitive or neurological or other disorder which may impact on cognitive testing, psychotropic medication use is permitted if a stable routine has been established, any previous chemotherapy or cancer (with the exception of non-melanoma skin cancer, cervical cancer in situ)

Interventions

Definition: Computerised cognitive training and 30-minute telephone consultation teaching compensatory strategies

Materials: Computer, Internet access 
Duration: Four-weekly 45-minute sessions per week for a total of 15 weeks

Setting: Home

Comparator: Treatment as usual (30-minute telephone consultation teaching compensatory strategies)

Assessments taken at baseline, post-intervention and 6 months post-intervention
Primary outcome
Self-reported cognitive function as assessed by the Functional Assessment of Cancer Therapy - Cognitive
Function (FACT-COG)
Secondary outcomes
Objective cognitive function as assessed by the CogState battery of tests (memory, attention and decision
making). Depression/Anxiety as assessed by the General Health Questionnaire (GHQ); Fatigue as assessed
by FACT-F; QoL as assessed by the FACT-G and; Stress as assessed by the PSS

Starting date Trial closed- data not yet available

Contact information Victoria Bray: victoria.bray2@sswhas.nsw.gov.au

Notes

Abbreviations: ADD = Attention Deficit Disorder; BPNS = basic Psychological Needs Survey; BVMT = Brief Visuospatial Memory Test $\mathbf{C D}$ = Compact Disc; CNS = Central Nervous System; COWAT = Controlled Oral Word Association Test $\mathbf{E C O G}=$ Eastern Cooperative Oncology Group; EEG = electroencephalogram; EORTC-CF = European Organisation for Research and Treatment for Cancer- Cognitive Function subscale; EORTC-QLQ-C30 = European Organisation for Research and Treatment for CancerQuality of Life Questionnaire; FACT-Cog = Functional Assessment of Cancer Therapy- Cognition subscale; FACT-F = Functional Assessment of Cancer Therapy-Fatigue subscale; FACT-G = Functional Assessment of Cancer Therapy-General scale; $\mathbf{f M R I}=$ functional Magnetic Resonance Imaging; HADS = Hospital Anxiety Depression Scale; HVLT-R = Hopkin's Verbal Learning TestRevised; MMSE = Mini-Mental Status Examination; PSS = Perceived Stress Scale; PHQ = Patient Health Questionnaire; POMS = Profile of Mood State; $\mathbf{Q o L}=$ quality of life; RCT = Randomised Controlled Trial; SD = Standard Deviation; WAIS = Wechsler Adult Intelligence; WCST = Wisconsin Card Sorting Test; WFT = Word Fluency Test; WRAT = Wide Range Achievement Test 
DATA AND ANALYSES

Comparison 1. Compensatory strategy training versus wait-list control immediately post-intervention

\begin{tabular}{lcclc} 
Outcome or subgroup title & $\begin{array}{c}\text { No. of } \\
\text { studies }\end{array}$ & $\begin{array}{c}\text { No. of } \\
\text { participants }\end{array}$ & Statistical method & Effect size \\
\hline 1 Physical well-being & 2 & 95 & Std. Mean Difference (IV, Random, 95\% CI) & $0.12[-0.59,0.83]$ \\
2 Psychological well-being & 2 & 95 & Std. Mean Difference (IV, Random, 95\% CI) & $-0.57[-0.98,-0.16]$ \\
\hline
\end{tabular}

Comparison 2. Compensatory strategy training versus wait-list control 2-months post-intervention

\begin{tabular}{lccccc} 
Outcome or subgroup title & $\begin{array}{c}\text { No. of } \\
\text { studies }\end{array}$ & $\begin{array}{c}\text { No. of } \\
\text { participants }\end{array}$ & Statistical method & Effect size \\
\hline 1 Physical well-being & 2 & 95 & Std. Mean Difference (IV, Random, 95\% CI) & $-0.21[-0.89,0.47]$ \\
2 Psychological well-being & 2 & 95 & Std. Mean Difference (IV, Random, 95\% CI) & $-0.38[-1.10,0.34]$ \\
\hline
\end{tabular}

\section{Analysis I.I. Comparison I Compensatory strategy training versus wait-list control immediately post- intervention, Outcome I Physical well-being.}

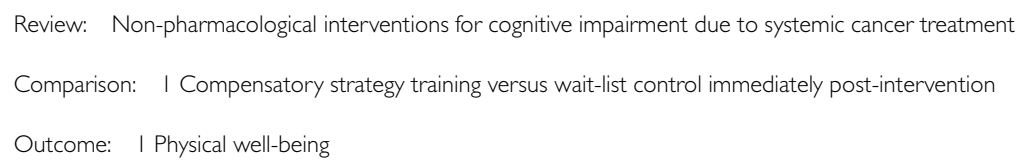

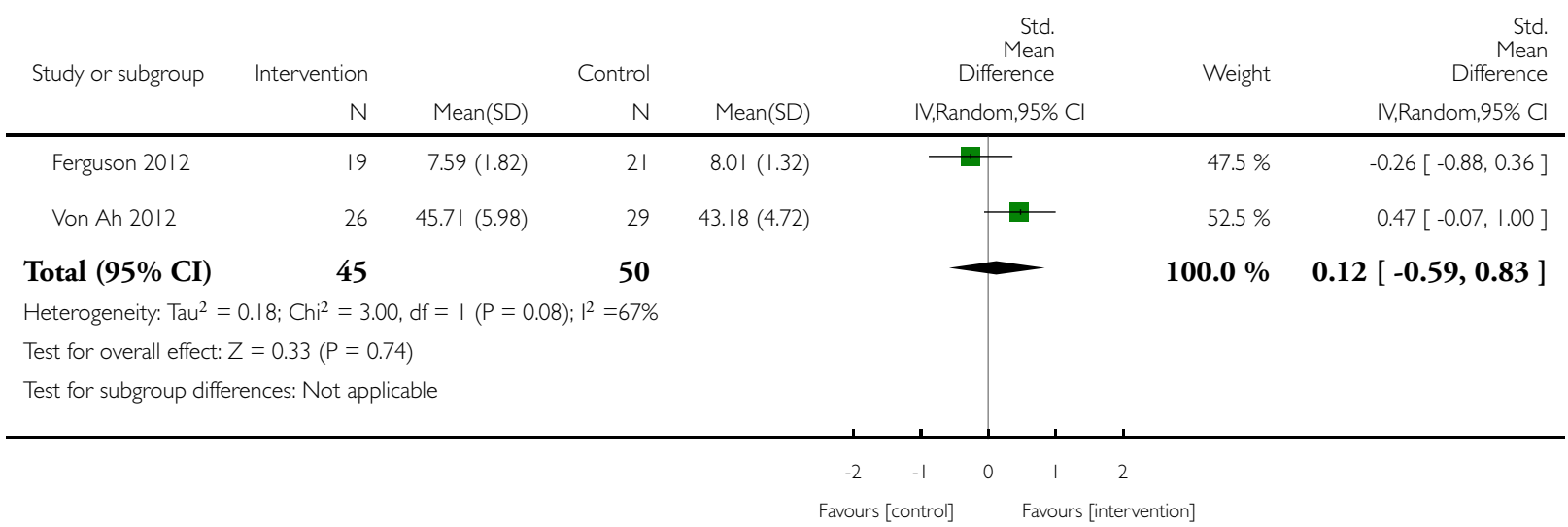


Analysis I.2. Comparison I Compensatory strategy training versus wait-list control immediately postintervention, Outcome 2 Psychological well-being.

Review: Non-pharmacological interventions for cognitive impairment due to systemic cancer treatment

Comparison: I Compensatory strategy training versus wait-list control immediately post-intervention

Outcome: 2 Psychological well-being

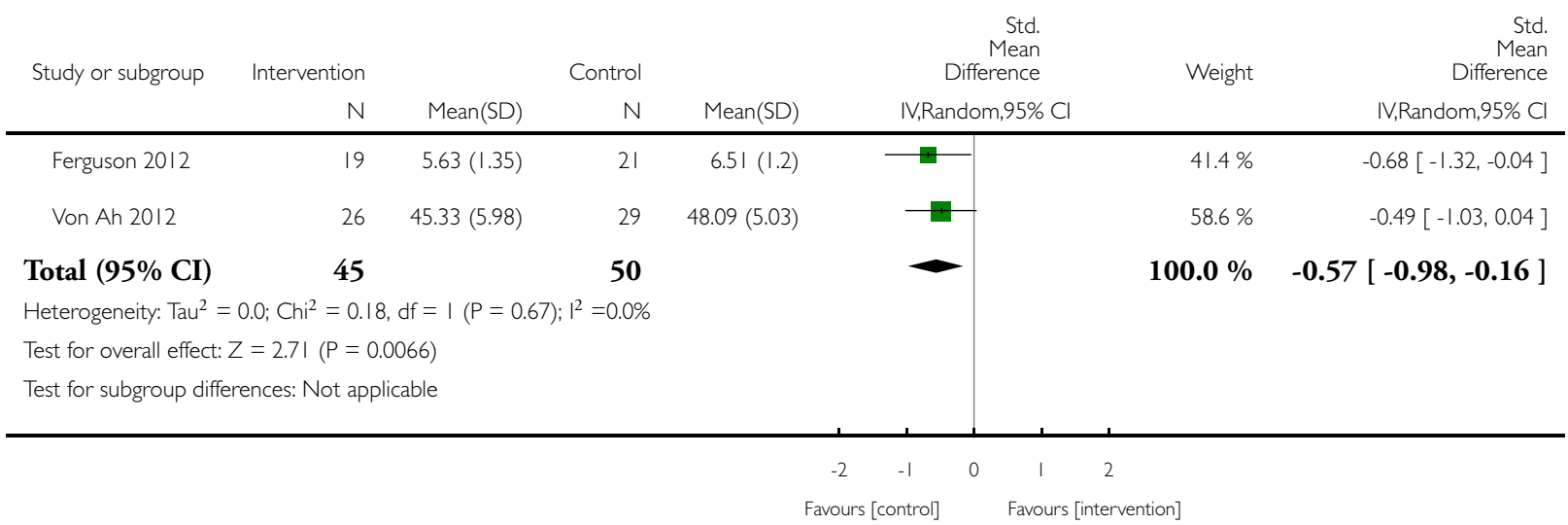

\section{Analysis 2.1. Comparison 2 Compensatory strategy training versus wait-list control 2-months post-} intervention, Outcome I Physical well-being.

Review: Non-pharmacological interventions for cognitive impairment due to systemic cancer treatment

Comparison: 2 Compensatory strategy training versus wait-list control 2-months post-intervention

Outcome: I Physical well-being

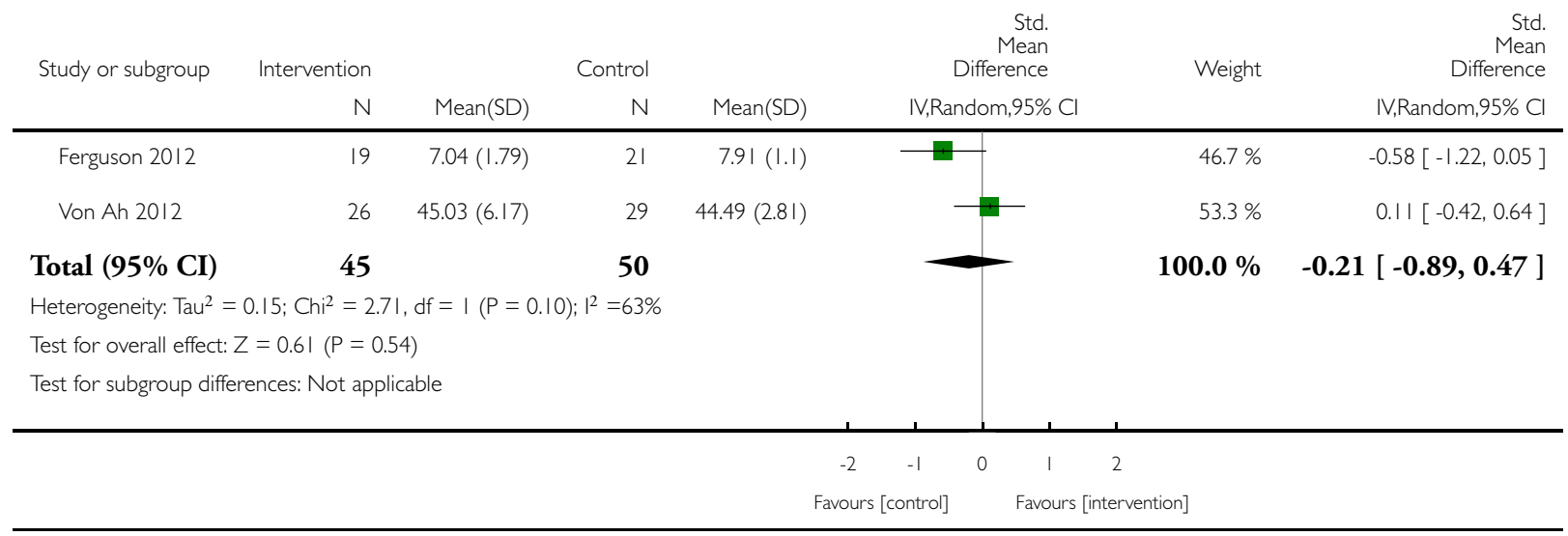

Non-pharmacological interventions for cognitive impairment due to systemic cancer treatment (Review) 


\section{Analysis 2.2. Comparison 2 Compensatory strategy training versus wait-list control 2-months post- intervention, Outcome 2 Psychological well-being.}

Review: Non-pharmacological interventions for cognitive impairment due to systemic cancer treatment

Comparison: 2 Compensatory strategy training versus wait-list control 2-months post-intervention

Outcome: 2 Psychological well-being

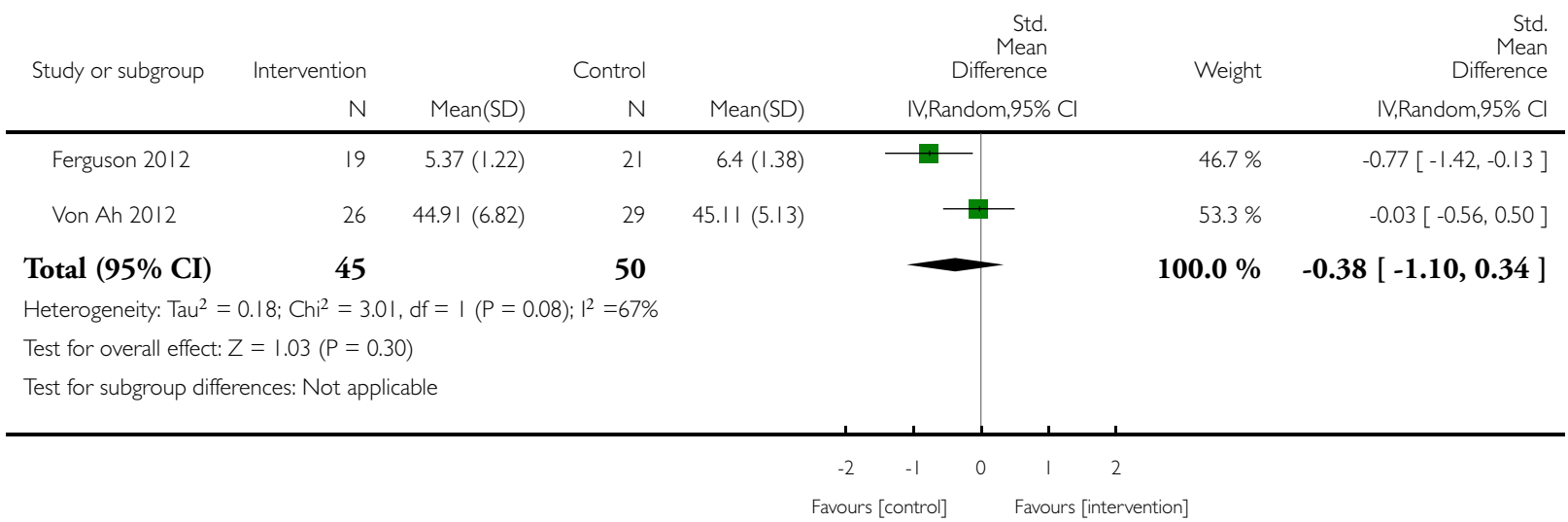

\section{A P P E N D I CES}

\section{Appendix I. CENTRAL search strategy}

\#1 MeSH descriptor: [Neoplasms] explode all trees

\#2 (cancer* or neoplas* or tumor* or tumour* or carcinoma* or adenocarcinoma* or malignan* or leukemia* or leukaemia*) .mp

\#3 \#1 or \#2

\#4 MeSH descriptor: [Cognition Disorders] explode all trees

\#5 MeSH descriptor: [Neurobehavioral Manifestations] explode all trees

\#6 MeSH descriptor: [Mental Processes] explode all trees

\#7 MeSH descriptor: [Neuropsychological Tests] explode all trees

\#8 MeSH descriptor: [Attention] explode all trees

\#9 (chemo* near/5 (fog or brain))

Non-pharmacological interventions for cognitive impairment due to systemic cancer treatment (Review)

Copyright $\Subset 2016$ The Cochrane Collaboration. Published by John Wiley \& Sons, Ltd. 
\#10 ((cognit* or neurocognit* or neuropsycholog* or memory or neurobehavior* or neurobehaviour* or problem solving or attention or concentrat*) adj5 (deficit* or declin* or disorder* or function* or dysfunction* or impair* or decrement* or disturb* or problem* or sequelae*))

$\# 11 \# 4$ or $\# 5$ or $\# 6$ or \#7 or \#8 or \#9 or \#10

$\# 12 \# 3$ and \#11

\section{Appendix 2. MEDLINE search strategy}

1 exp Neoplasms/

2 (cancer* or neoplas* or tumor* or tumour* or carcinoma* or adenocarcinoma* or malignan* or leukemia* or leukaemia*).mp

31 or 2

4 exp Cognition Disorders/

5 exp Neurobehavioral Manifestations/

6 exp Mental Processes/

7 exp Neuropsychological Tests/

8 Attention/

$9 \quad$ (chemo* adj5 (fog or brain)).mp.

10 ((cognit* or neurocognit* or neuropsycholog* or memory or neurobehavior* or neurobehaviour* or problem solving or attention or concentrat*) adj5 (deficit* or declin* or disorder* or function* ${ }^{*}$ or dysfunction* or impair* or decrement* or disturb* ${ }^{*}{ }^{*}$ problem* or sequelae*)).mp

114 or 5 or 6 or 7 or 8 or 9 or 10

123 and 11

13 randomized controlled trial.pt.

14 controlled clinical trial.pt.

15 randomized.ab.

16 placebo.ab.

17 clinical trials as topic.sh.

18 randomly.ab.

19 trial.ti. 
22 exp animals/ not humans.sh.

$23 \quad 21 \operatorname{not} 22$

$\mathrm{mp}=$ title, abstract, original title, name of substance word, subject heading word, keyword heading word, protocol supplementary concept word, rare disease supplementary concept word, unique identifier

$\mathrm{pt}=$ publication type

$\mathrm{ab}=\mathrm{abstract}$

ti=title

\section{Appendix 3. Embase search strategy}

1 exp neoplasm/

2 (cancer* or neoplas* $^{*}$ or tumor* ${ }^{*}$ or tumour* or carcinoma* $^{*}$ or adenocarcinoma* or malignan* ${ }^{*}$ or leukemia* or leukaemia* $^{*}$.mp.

31 or 2

4 exp cognitive defect/

5 cognition/

6 neuropsychological test/

7 attention/

8 (chemo* adj5 (fog or brain)).mp.

9 ((cognit* or neurocognit* or neuropsycholog* or memory or neurobehavior* or neurobehaviour* or problem solving or attention or concentrat*) adj5 (deficit* or declin* or disorder* or function* or dysfunction* or impair* or decrement* or disturb* or problem* or sequelae $\left.{ }^{*}\right)$ ).mp.

104 or 5 or 6 or 7 or 8 or 9

113 and 10

12 crossover procedure/

13 double-blind procedure/

14 randomized controlled trial/

15 single-blind procedure/

16 random*.mp.

17 factorial $^{*} . \mathrm{mp}$.

18 (crossover* or cross over* or cross-over*).mp.

19 placebo*.mp.

20 (double* adj blind*).mp.

21 (singl* $^{*}$ adj blind*).mp.

22 assign*.mp.

23 allocat*.mp.

24 volunteer*.mp.

2512 or 13 or 14 or 15 or 16 or 17 or 18 or 19 or 20 or 21 or 22 or 23 or 24

2611 and 25

key: [mp=title, abstract, subject headings, heading word, drug trade name, original title, device manufacturer, drug manufacturer, device trade name, keyword] 


\section{Appendix 4. PsycINFO search strategy}

1 exp neoplasms/

(cancer* or neoplas* or tumor* or tumour* or carcinoma* or adenocarcinoma* or malignan* or leukemia* or leukaemia*).mp.

31 or 2

4 cognitive impairment/

5 exp cognitive processes/

6 exp neuropsychological assessment/

7 attention/

8 (chemo* adj5 (fog or brain)).mp.

9 ((cognit* or neurocognit* or neuropsycholog* or memory or neurobehavior* or neurobehaviour* or problem solving or attention or concentrat*) adj5 (deficit* or declin* or disorder* or function* or dysfunction* or impair* or decrement* or disturb* or problem* or sequelae*)).mp.

104 or 5 or 6 or 7 or 8 or 9

113 and 10

12 clinical trials/

13 (random* or trial* or crossover* or cross over* or double blind or single blind or placebo* or assign* or allocat*).mp.

1412 or 13

1511 and 14

\section{Appendix 5. CINAHL search strategy}

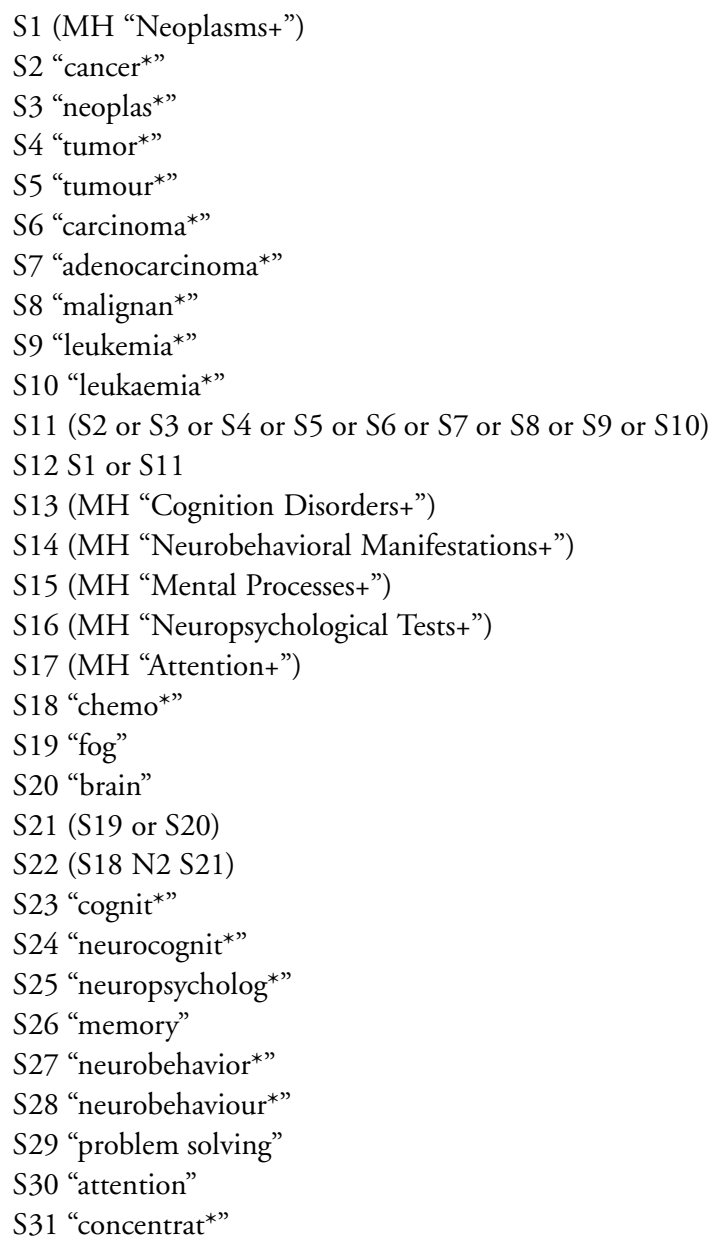

Non-pharmacological interventions for cognitive impairment due to systemic cancer treatment (Review) 
S32 (S23 or S24 or S25 or S26 or S27 or S28 or S29 or S30)

S33 "deficit*"

S34 "declin*"

S35 "disorder*"

S36 "function*"

S37 "dysfunction*"

S38 “impair*”

S39 "decrement*"

S40 "disturb"

S41 "problem*"

S42 "sequelae*"

$\mathrm{S} 43$ (S33 or S34 or S35 or S36 or S37 or S38 or S39 or S40 or S41 or S42)

S44 (S32 N2 S43)

$\mathrm{S} 45$ (S13 or $\mathrm{S} 14$ or $\mathrm{S} 15$ or $\mathrm{S} 16$ or $\mathrm{S} 17$ or $\mathrm{S} 22$ or $\mathrm{S} 44)$

S46 (S12 and S45)

S47 MH "Randomized controlled trials"

S48MH "Clinical trials"

S49 MH "Placebos"

S50 (S47 or S48 or S49)

S51 (S44 and S50)

\section{Appendix 6. PubMed search strategy}

\#1 neoplasm*[MeSH Terms]

\#2 (cancer* or neoplas* or tumor* or tumour* or carcinoma* or adenocarcinoma* or malignan* or leukemia* or leukaemia*)

$\# 3 \# 1$ or \#2

\#4 cognition disorders[MeSH Terms]

\#5 neurobehavioral manifestations[MeSH Terms]

\#6 mental processes[MeSH Terms]

\#7 neuropsychological tests[MeSH Terms]

\#8 attention[MeSH Terms]

\#9 "chemo* fog"

\#10 "chemo* brain"

\#11 (((((((“cognit* deficit*”) OR “cognit* declin*”) OR “cognit* disorder*”) OR “cognit* function*”) OR “cognit* dysfunction*”) OR “cognit* impair*”) OR “cognit* decrement*”) OR “cognit* problem*”) OR "cognit* sequelae*”

\#12 (((()((“memory deficit*”) OR “memory declin*”) OR “ memory disorder*”) OR “ memory function*”) OR “ memory dysfunction*”) OR "memory impair*”) OR “memory decrement*”) OR “ memory problem*”) OR “memory sequelae*”

\#13 (((((((“neurobehavior* deficit*”) OR “neurobehavior* declin*”) OR “neurobehavior* disorder*”) OR "neurobehavior * function*”)

OR "neurobehavior* dysfunction*”) OR “neurobehavior* impair") OR "neurobehavior* decrement*”) OR "neurobehavior* problem*”) OR "neurobehavior* sequelae*”

\#14 ((()(((“neurobehaviour* deficit*”) OR “neurobehaviour* declin*”) OR “neurobehaviour* disorder*”) OR “ neurobehaviour * function*”) OR “neurobehaviour* dysfunction*”) OR “neurobehaviour* impair*“) OR "neurobehaviour* decrement*”) OR "neurobehaviour* problem*”) OR "neurobehaviour* sequelae*”

\#15 ((((()(("problem solving deficit””) OR “problem solving declin*“) OR ”problem solving disorder*“) OR ”problem solving function*“) OR "problem solving dysfunction*“) OR "problem solving impair*“) OR "problem solving decrement*“) OR ”problem solving problem*“) OR ”problem solving sequelae*“

\#16 ((()((("attention deficit*“) OR ”attention declin*“) OR "attention disorder*") OR "attention function*") OR "attention dysfunction $^{* “)}$ OR "attention impair*") OR "attention decrement*") OR "attention problem*") OR "attention sequelae*"

\#17 ( (( (((("concentrat* deficit*“) OR "concentrate*“) OR "concentrat disorder*“) OR "concentrat function*“) OR "concentrat dysfunction*“) OR "concentrat impair*“) OR "concentrat decrement*“) OR "concentrat problem*") OR "concentrat sequelae*“

$\# 18$ \#4 or \#5 or \#6 or \#7 or \#8 or \#9 or \#10 or \#11 or \#12 or \#13 or \#14 or \#15 or \#16 or \#17 $\# 19 \# 3$ and \#17

Non-pharmacological interventions for cognitive impairment due to systemic cancer treatment (Review)

Copyright @ 2016 The Cochrane Collaboration. Published by John Wiley \& Sons, Ltd. 
\#20randomized controlled trial[pt]

\#21 controlled clinical trial[pt]

\#22 randomized[tiab]

\#23 placebo[tiab]

\#24 clinical trials as topic[mesh:noexp]

\#25 randomly[tiab]

\#26 \#20 or \#21 or \#22 or \#23 or \#24

\#27 animals [mh] NOT humans [mh]

\#28 \#26 NOT \#27

\#29 \#19 AND \#28

\section{CONTRIBUTIONSOFAUTHORS}

CT is the recipient of a Cochrane Review Training Fellowship from the Northern Ireland Public Health Agency, Health and Social Care Research and Development Division. MD is the lead supervisor of the review. MC is senior cancer epidemiologist and an experienced systematic reviewer. CC is our lead statistician in cancer care. RON and ÚMM are post-doctoral research fellows in cancer epidemiology. MJC is our methodological expert on Cochrane Reviews and trials. All review authors have seen a draft version of the review and amendments have been made based on their comments.

\section{DECLARATIONSOF INTEREST}

We have no declarations of interest to report.

\section{SOURCES OF SUPPORT}

\section{Internal sources}

- No sources of support supplied

\section{External sources}

- Northern Ireland Health and Social Care Research and Development Division of the Public Health Agency, UK. Cochrane Training Fellowship funding for CT to undertake the review

\section{DIFFERENCES BETWEEN PROTOCOLANDREVIEW}

We added satisfaction with treatment as a secondary outcome of interest in the study. 